SANDIA REPORT

SAND98-0811 • UC-900

Unlimited Release

Printed April 1998

\title{
User's Guide for the Augmented Computer Exercise for Inspection Training (ACE-IT) Version 2.0 Software
}

\author{
RECEIVED \\ APR 291998
}

OSTI MASTER

Pauline R. Dobranich, Karl E. Horak, Deborah A. Evanko, David S. Hagan, Jon D. Nelson

Prepared by

Sandia National Laboratories

Albuquerque, New Mexico 87185 and Livermore, California 94550

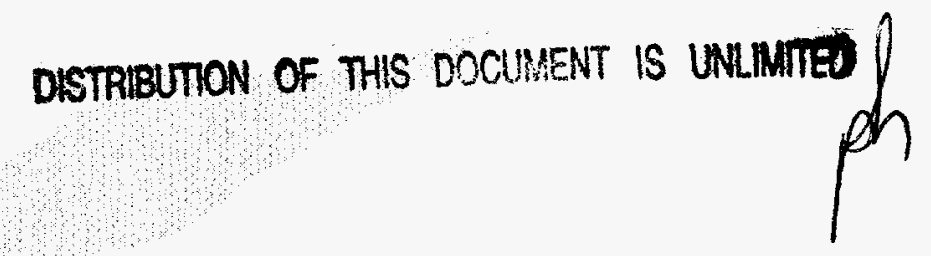

Sandia is a multiprogram laboratory operated by Sandia Corporation

a Lockheed Martin Company, for the United States Department of

Energy under Contract DE-AC04-94AL85000.

Approved for public release; further dissemination unlimited.

\section{T.7. Sandia National Laboratories}


Issued by Sandia National Laboratories, operated for the United States Department of Energy by Sandia Corporation.

NOTICE: This report was prepared as an account of work sponsored by an agency of the United States Government. Neither the United States Government nor any agency thereof, nor any of their employees, nor any of their contractors, subcontractors, or their employees, makes any warranty, express or implied, or assumes any legal liability or responsibility for the accuracy, completeness, or usefulness of any information, apparatus, product, or process disclosed, or represents that its use would not infringe privately owned rights. Reference herein to any specific commercial product, process, or service by trade name, trademark, manufacturer, or otherwise, does not necessarily constitute or imply its endorsement, recommendation, or favoring by the United States Government, any agency thereof, or any of their contractors or subcontractors. The views and opinions expressed herein do not necessarily state or reflect those of the United States Government, any agency thereof, or any of their contractors.

Printed in the United States of America. This report has been reproduced directly from the best available copy.

Available to DOE and DOE contractors from

Office of Scientific and Technical Information

P.O. Box 62

Oak Ridge, TN 37831

Prices available from (615) 576-8401, FTS 626-8401

Available to the public from

National Technical Information Service

U.S. Department of Commerce

5285 Port Royal Rd

Springfield, VA 22161

NTIS price codes

Printed copy: A05

Microfiche copy: A01

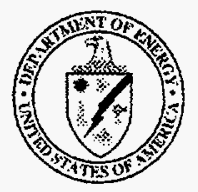




\section{DISCLAIMER}

Portions of this document may be illegible electronic image products. Images are produced from the best available original document. 


\title{
User's Guide for the Augmented Computer Exercise For Inspection Training (ACE-IT) Version 2.0 Software
}

\author{
Pauline R. Dobranich \\ Cooperative Monitoring Center and Regional Security \\ Sandia National Laboratories \\ P.O. Box 5800 \\ Albuquerque, NM 87185-1373 \\ Karl E. Horak and Deborah A. Evanko \\ Excel Tactical Staffing \\ Albuquerque, NM 87110 \\ David S. Hagan and Jon D. Nelson \\ Ogden Environmental and Energy Services, Inc. \\ Albuquerque, NM 87110
}

\begin{abstract}
The on-site inspection provisions in many current and proposed arms control agreements require extensive preparation and training on the part of both the Inspection Teams (inspectors) and Inspected Parties (hosts). Traditional training techniques include lectures, table-top inspections, and practice inspections. The Augmented Computer Exercise for Inspection Training (ACE-IT), an interactive computer training tool, increases the utility of table-top inspections. ACE-IT is used for training both inspectors and hosts to conduct a hypothetical challenge inspection under the Chemical Weapons Convention (CWC). The training covers the entire sequence of events in the challenge inspection regime, from initial notification of an inspection through post-inspection activities. The primary emphasis of the training tool is on conducting the inspection itself, and in particular, implementing the concept of managed access. (Managed access is a technique used to assure the inspectors that the facility is in compliance with the CWC, while at the same time protecting sensitive information unrelated to the CWC.) Information for all of the activities is located in the electronic "Exercise Manual." In addition, interactive menus are used to negotiate access to each room and to alternate information during the simulated inspection. ACE-IT also demonstrates how various inspection provisions impact compliance determination and the protection of sensitive information.
\end{abstract}




\section{Acronyms}

ACE-IT

$\mathrm{CMC}$

CWC

HTML

IIS

IP

LAN

OPCW

QTVR

Augmented Computer Exercise for Inspection Training Cooperative Monitoring Center

Chemical Weapons Convention

hypertext markup language

Internet Information Services

Internet protocol

local area network

Organization for the Prohibition of Chemical Weapons

Quick Time Virtual Reality 


\section{Contents}

EXECUTIVE SUMMARY

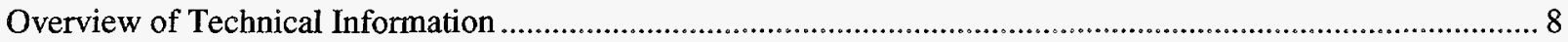

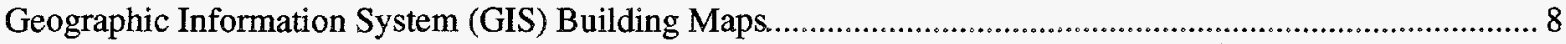

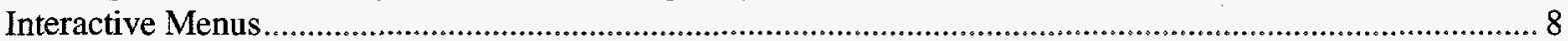

Digital Images and Quick Time Virtual Reality (QTVR) Movies.................................................................. 8

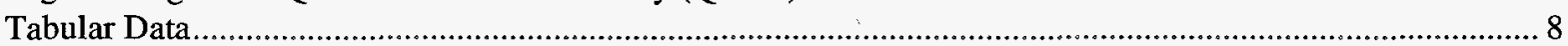

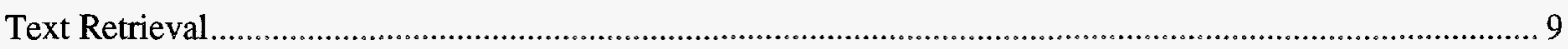

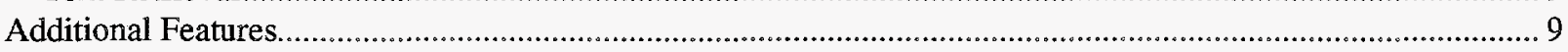

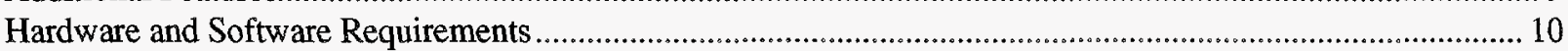

Availability of ACE-IT Version 2.0

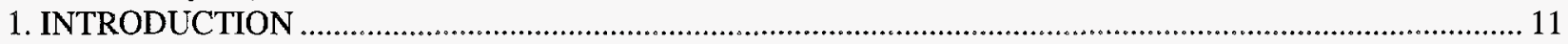

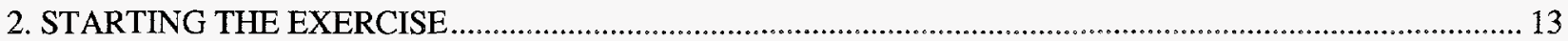

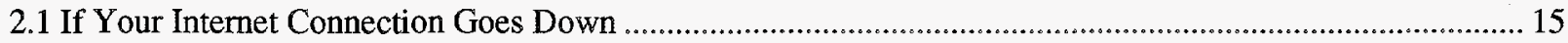

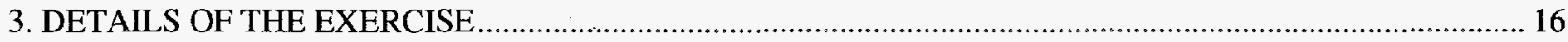

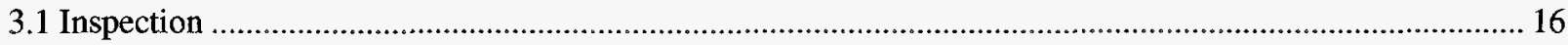

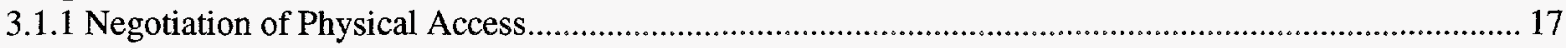

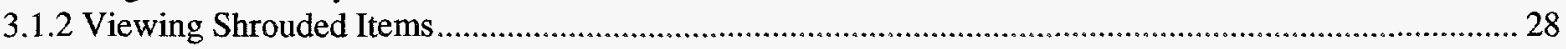

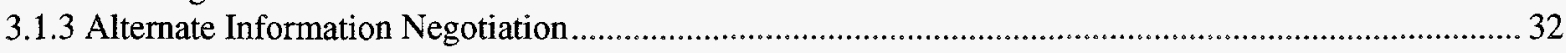

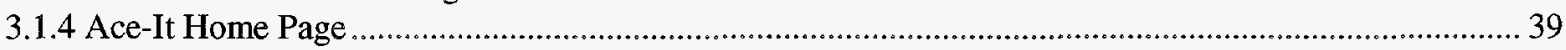

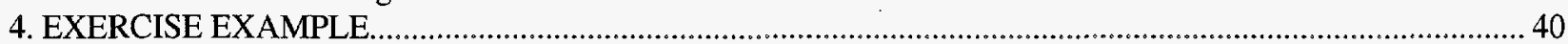

5. PREPARING THE EXERCISE REPORT AND ENDING THE EXERCISE ............................................... 53

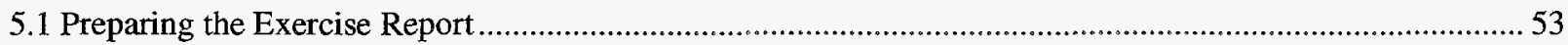

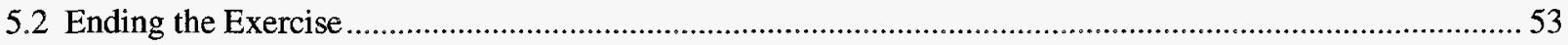

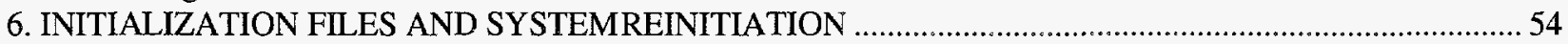

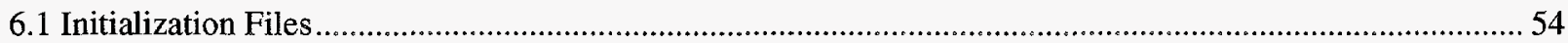

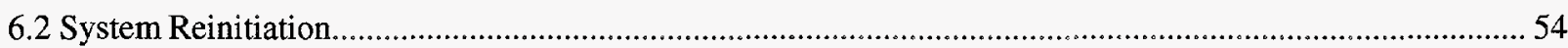

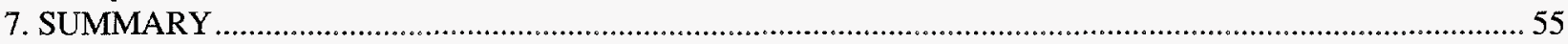

Appendix A Hardware/Software Requirements, Installation and Setup Instructions........................................... 57

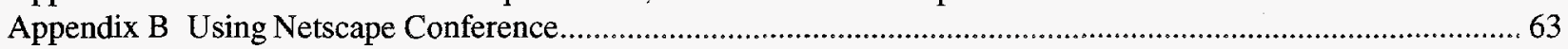

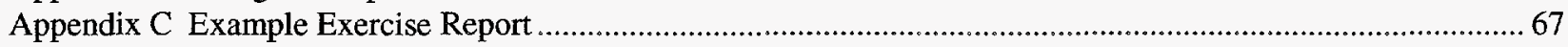

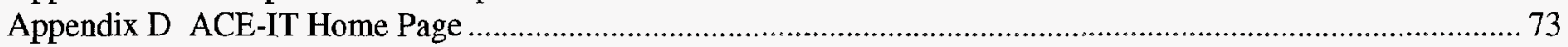

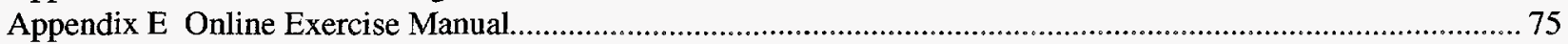

\section{Figures}

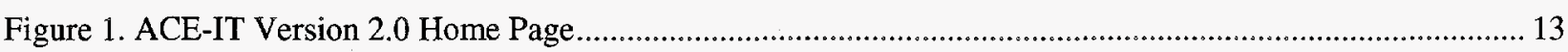

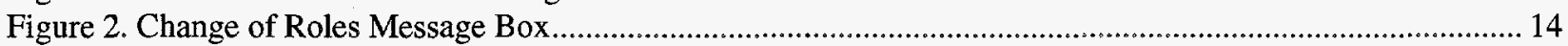

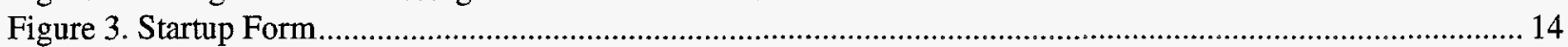

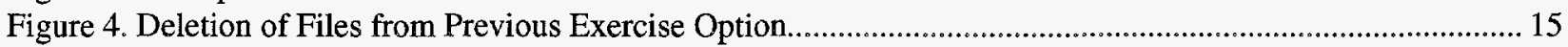

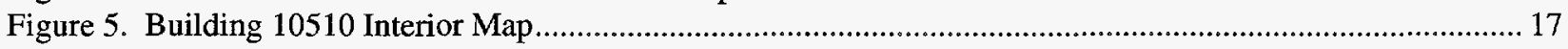

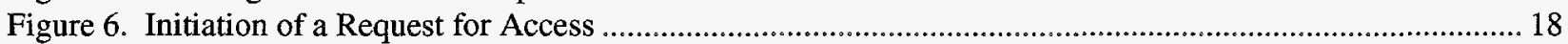

Figure 7. Receipt of Access Denied Notification...................................................................................... 19

Figure 8. Receipt of Partial Access Granted Notification............................................................................ 19

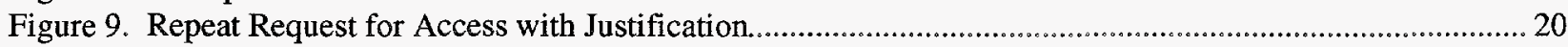

Figure 10. Inspection Team Views Partial Access Photo Tour ................................................................ 20

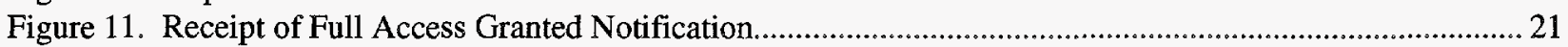

Figure 12. Inspection Team Views Full Access Photo Tour ............................................................................... 22

Figure 13. Zoom Window with On-Screen Meter Stick..................................................................................... 22

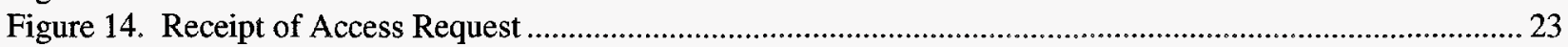

Figure 15. Inspected Party Accessing the Room Preview ......................................................................................... 24

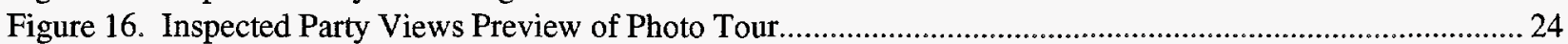

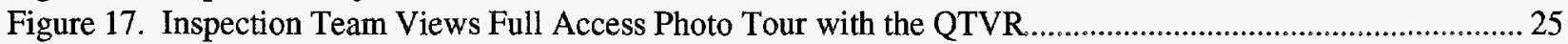

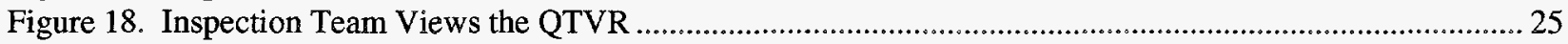

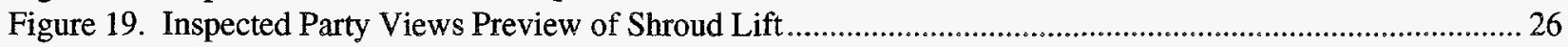




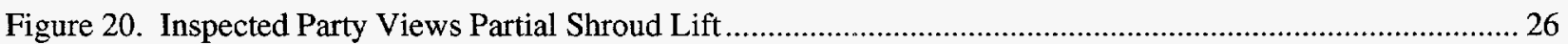

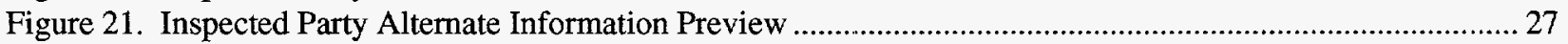

Figure 22. Inspected Party Hazardous Waste Information Preview .................................................................... 27

Figure 23. Inspection Team Views Full Access Photo Tour .......................................................................... 28

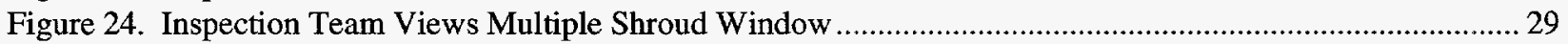

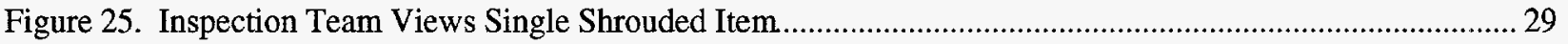

Figure 26. Inspection Team Views Complete Unshroud..................................................................................... 30

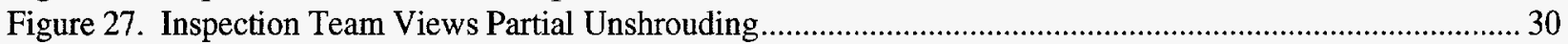

Figure 28. Inspection Team is Denied Permission to Lift Shroud............................................................................. 31

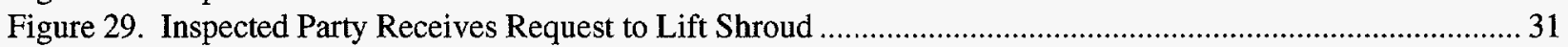

Figure 30. Inspected Party Previews Partial Lift of Shroud .......................................................................... 32

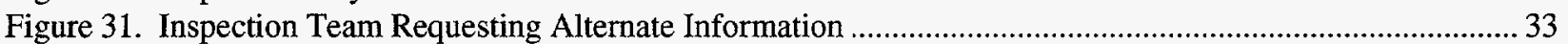

Figure 32. Inspection Team Requesting All Available Alternate Information.................................................. 33

Figure 33. Inspection Team Adding Detail to Request for Alternate Information .................................................. 34

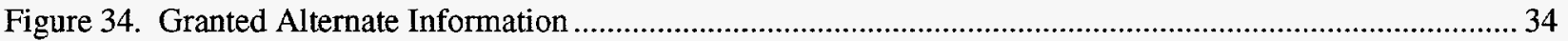

Figure 35. Viewing Alternate Information (Hazardous Waste Information) .................................................... 35

Figure 36. Inspection Team Receives Sample Analysis Time Delay Notification..................................................... 35

Figure 37. Inspection Team Records Sample Type and Analysis.................................................................... 36

Figure 38. Inspection Team Receives Sample Results .................................................................................... 36

Figure 39. Receipt of Alternate Information Request.................................................................................. 37

Figure 40. Inspected Party Views Proprietary Research Information ................................................................. 38

Figure 41. Inspected Party Views Hazardous Waste Information ................................................................... 38

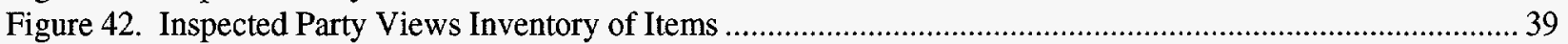

Figure 43. Inspection Team Initiates Request for Access ................................................................................. 40

Figure 44. Inspected Party Denies Request for Access .................................................................................... 41

Figure 45. Inspection Team Repeats Request with Justification ............................................................... 41

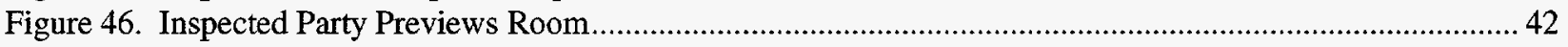

Figure 47. Inspected Party Previews Requested Location .................................................................................... 42

Figure 48. Inspected Party Previews 100\% Lift of Shroud from Item ....................................................... 43

Figure 49. Inspected Party Grants Partial Access ................................................................................ 43

Figure 50. Inspection Team Receives Partial Access ............................................................................... 44

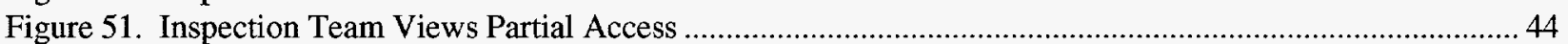

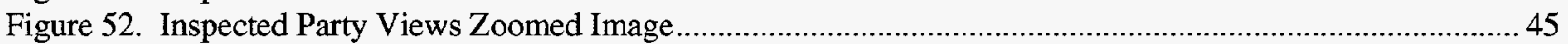

Figure 53. Inspection Team Requests Greater Access .................................................................................... 45

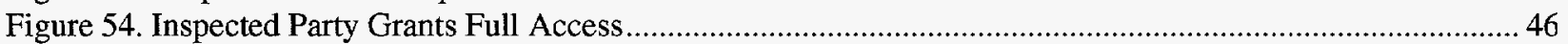

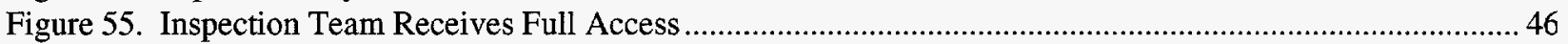

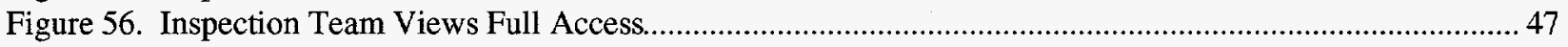

Figure 57. Inspection Team Views Hints Window from Photo Tour........................................................................ 47

Figure 58. Inspection Team Requests Alternate Information ............................................................................. 48

Figure 59. Inspected Party Receives Alternate Information Request.................................................................... 48

Figure 60. Inspection Team Requests Chemical Sample...................................................................................... 49

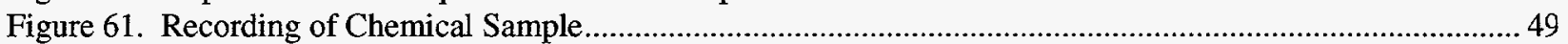

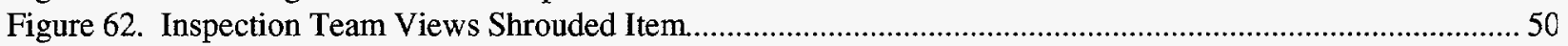

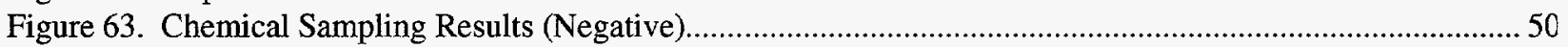

Figure 64. Inspected Party Previews Unshrouded Item........................................................................................... 51

Figure 65. Inspected Party Previews 50\% Lift of Shroud from Item ...................................................................51

Figure 66. Inspection Team Views 50\% Lift of Shroud from Item............................................................... 52

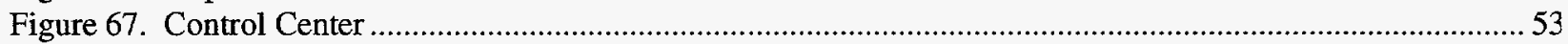

\section{Table}

Table 1. CWC Challenge Inspection Timeline. 


\section{EXECUTIVE SUMMARY}

The on-site inspection provisions in many current and proposed arms control agreements require extensive preparation and training on the part of both the Inspection Teams and the Inspected Parties. Traditional training techniques include lectures, table-top inspections, and practice inspections. The Augmented Computer Exercise for Inspection Training (ACE-IT Version 2.0), an interactive, computer-based inspection simulation, increases the utility of table-top inspections.

ACE-IT is used for training both the Inspection Team (inspector) and the Inspected Party (host) to conduct a hypothetical challenge inspection under the Chemical Weapons Convention (CWC). Challenge inspections are short-notice inspections that may occur at any time, anywhere, and with no right of refusal. (The challenge inspection must also be approved by the Organization for the Prohibition of Chemical Weapons.) The time interval between the notice of intent to inspect a facility and the arrival of inspectors at the facility may be as short as 72 hours. Both government facilities and private firms may be subject to these inspections. Therefore, advance training is important.

The primary emphasis of the training tool is on conducting the inspection itself, and in particular, implementing the concept of managed access. Managed access is a technique used to assure the inspectors that the facility is in compliance with the CWC, while protecting sensitive information unrelated to the CWC. Interactive menus are used to negotiate access to each room and to provide alternate information during the simulated inspection.

The mandate for the hypothetical challenge inspection is to inspect an undeclared site for possible noncompliance with the CWC, specifically the alleged production and/or storage of chemicals or chemical munitions prohibited by the CWC.

Three hypothetical buildings are available for inspection in ACE-IT: a chemical processing building, an office building, and a technology demonstration building. Under the CWC challenge inspection provisions, the Inspected Party can control the movement of the inspectors by using managed access. Access to rooms can be controlled by allowing the inspector to view the rooms only through the door or the window. Access to shrouded (or covered) items can be controlled by partially removing the shrouds or by providing alternate information, such as chemical sampling. ACE-IT allows the Inspection Team and the Inspected Party to practice managed access techniques.

Each team has access to an electronic "Exercise Manual" that includes the following information:

- CWC Treaty

- CWC inspection timeline

- description and requirements pertaining to each inspection step (from notification of an inspection through post-inspection procedures)

- requested perimeter and alternate perimeter maps

- pre-inspection briefing

- perimeter monitoring reports

- records (medical, material and safety data sheets, and shipping and receiving)

- general on-site inspection information

Information in the Exercise Manual is available for review from the ACE-IT home page at any time, even when you are not participating in an exercise. Treaty provisions associated with each inspection step, given in the inspection timeline, set the context for the inspection and are described in the on-line Exercise Manual. 
This user's guide is intended to provide a step-by-step view of the events that take place during the inspection exercise. The guide is written in sufficient detail to permit the trainees to "walk through" a training exercise and become familiar with situations that may arise during the inspection simulation. Online material is available via your Internet browser. At any time during the exercise, click on the Host's Exercise Manual or Inspector's Exercise Manual button to view this information.

ACE-IT can be operated between two computers connected by a local area network (LAN) or the Internet. It incorporates Quick Time Virtual Reality (QTVR) technology and digital images for viewing individual rooms. ACE-IT also includes Netscape browser technology by using hypertext markup language (HTML), mapped images and graphics, and hyperlinks to other web sites, and it invokes helper applications.

Therefore, ACE-IT teaches users (1) how to conduct an inspection and (2) how the provisions of an onsite inspection affect the ability to determine compliance and protect sensitive information.

\section{Overview of Technical Information}

\section{Geographic Information System (GIS) Building Maps}

In its initial configuration, ACE-IT has been programmed to include three buildings that are used to conduct a challenge inspection: a declared "single small-scale facility," an office building, and a technology demonstration building. At the "single small-scale facility," a country produces Schedule 1 chemicals for research, medical, pharmaceutical, and protective purposes.

\section{Interactive Menus}

Interactive menus allow the Inspection Team and the Inspection Party to "conduct" the inspection. These menus teach the important concept of managed access - - how the Inspected Party can protect sensitive information that is unrelated to the CWC. This includes controlling physical access to a room, negotiating permission to look behind shrouds, and controlling requests for alternate information. (See Figures E-1 and $\mathrm{E}-2$.

\section{Digital Images and Quick Time Virtual Reality (QTVR) Movies}

Digital images provide users with multiple views of each room. The images may be zoomed to full screen and, where available, QTVR images will be provided by the system. QTVR images are interactive $360^{\circ}$ photographs that provide the illusion of being inside an area and looking around at will. For large areas: multiple points of view are included and the user may jump from one point of view to another at any time.

\section{Tabular Data}

The user can access data associated with each room, if permission to access this information is granted by the Inspected Party. The data include an inventory of the items in each room, chemical inventory, chemical sampling results, proprietary research information, hazardous waste information, shipping and. receiving records, and employee medical records. 


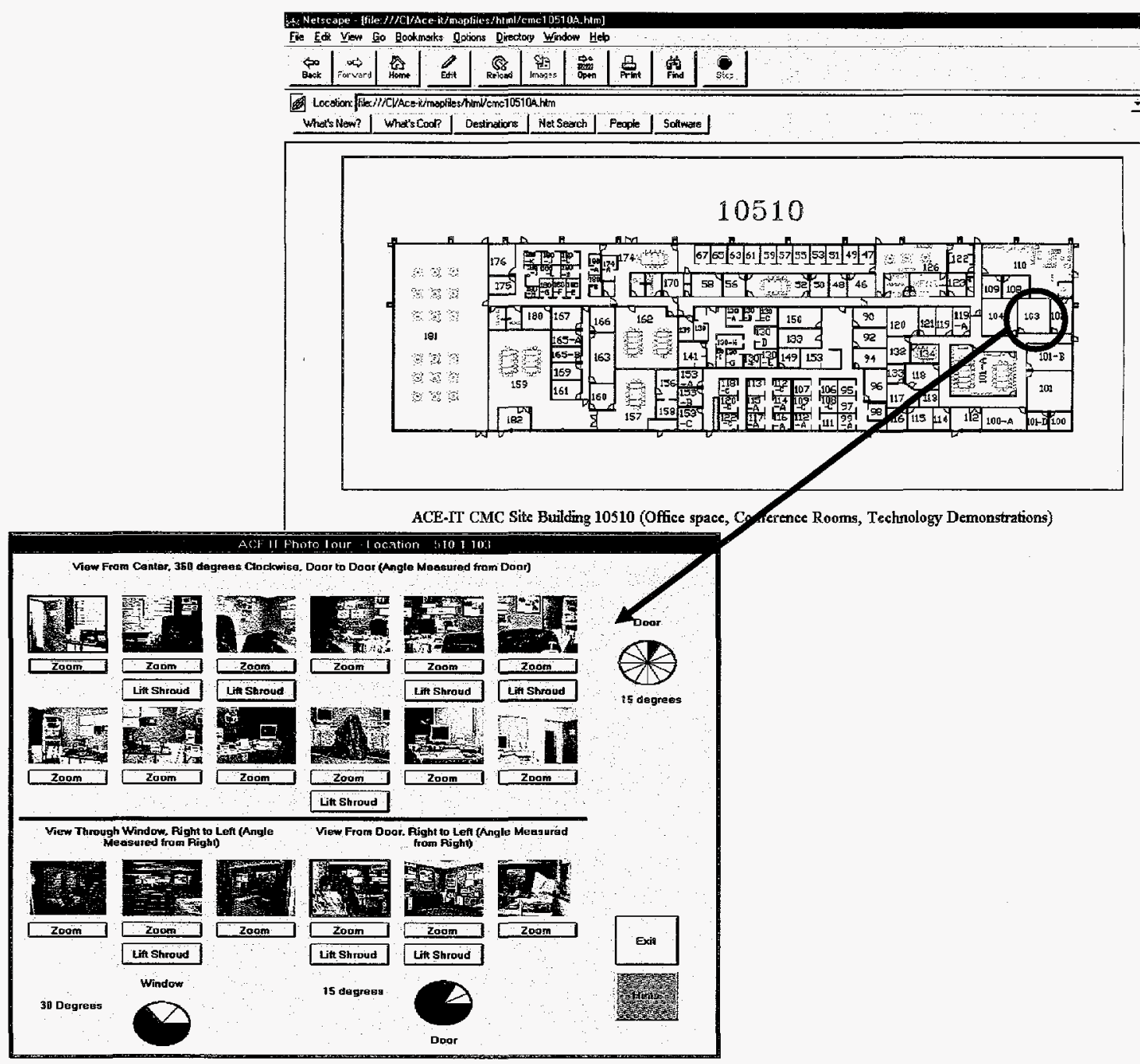

Figure E-1. Sample Building Map and Interactive Menu with Digital Images of a Room to be Inspected

\section{Text Retrieval}

The documents that are not associated with a particular room (e.g., CWC text, inspection mandate, site/building information, traffic logs and safety plans) are displayed as HTML documents.

\section{Additional Features}

ACE-IT Version 2.0 is compatible with Windows NT 4.0, e-mail, chat, conferencing, and messaging systems. It is also compatible with Netscape 4.0 Internet conferencing tools. 


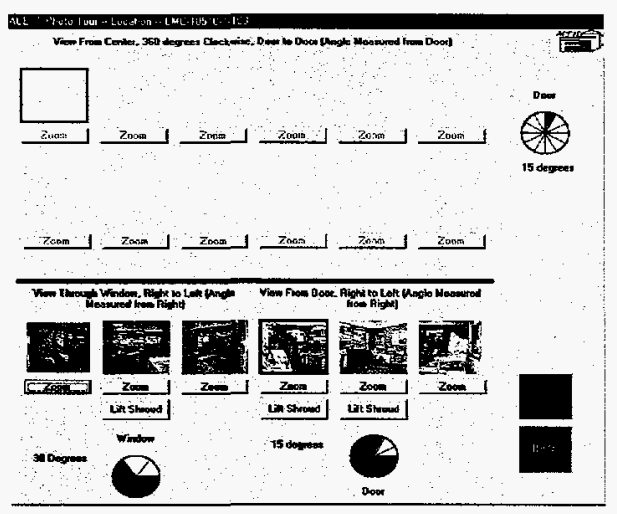

Partial Access View (through window and door only)

Shrouded Item (Shroud partially lifted)

Shrouded Item (Shroud completely lifted)

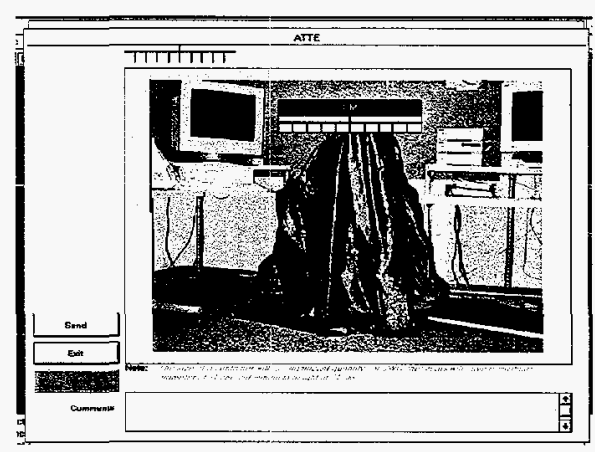

Shrouded Item (Shroud not lifted)
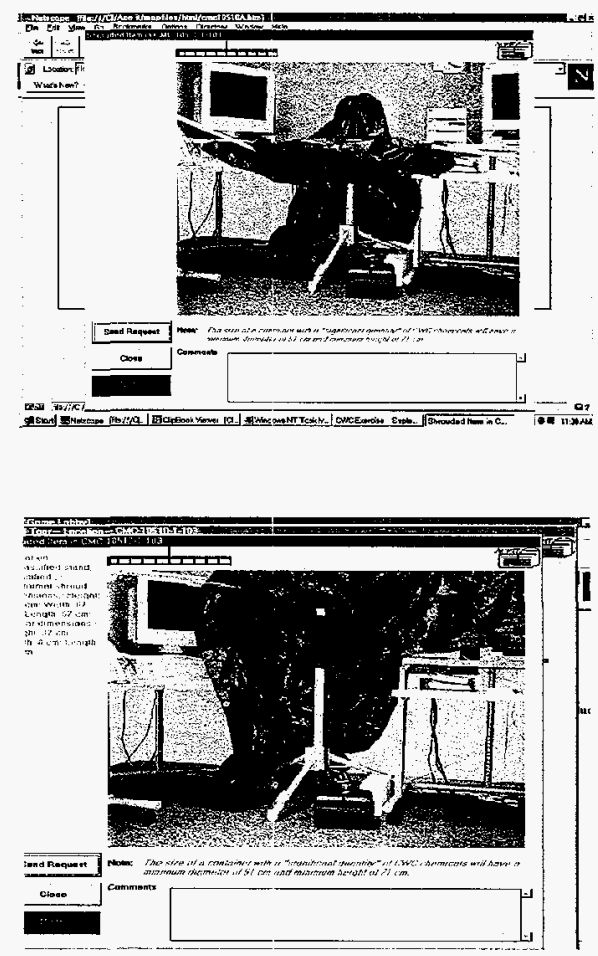

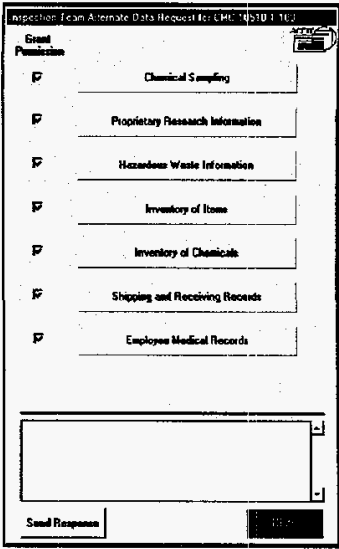

Alternate Information Available

Figure E-2. Views Available to the Inspection Team

\section{Hardware and Software Requirements}

ACE-IT Version 2.0 consists of a suite of software that runs on a LAN with two personal computers. Each computer must be at least Pentium/133-class, with $32 \mathrm{MB}$ RAM and $15 \mathrm{MB}$ of free hard drive space, capable of video display at a resolution of at least 1024 by 768 . The operating system must be Windows NT 4.0.

\section{Availability of ACE-IT Version 2.0}

The customized code is protected by copyright, and is available from Sandia National Laboratories or Ogden Environmental and Energy Services. 


\section{INTRODUCTION}

The on-site inspection provisions in many current and proposed arms control agreements require extensive preparation and training on the part of both the Inspection Teams and the Inspected Parties. Traditional training techniques include lectures, table-top inspections, and practice inspections. The Augmented Computer Exercise for Inspection Training (ACE-IT Version 2.0), an interactive, computer-based inspection simulation, increases the utility of table-top inspections. The inspection simulation is hereafter referred to as an inspection exercise.

ACE-IT is used for training both the Inspection Team (inspector) and Inspected Party (host) to conduct a hypothetical challenge inspection under the Chemical Weapons Convention (CWC). Challenge inspections are short-notice inspections that may occur at any time, anywhere, and with no right of refusal. (The challenge inspection must also be approved by the Organization for the Prohibition of Chemical Weapons.) The time interval between the notice of intent to inspect a facility and the arrival of inspectors at the facility may be as short as 72 hours. Therefore, advance training is important.

The primary emphasis of the training tool is on conducting the inspection itself, and in particular, implementing the concept of managed access. Managed access is a technique used to assure the inspectors that the facility is in compliance with the CWC, while at the same time protecting sensitive information unrelated to the CWC.

The mandate for this hypothetical inspection is to inspect an undeclared site for possible noncompliance with the CWC, specifically the alleged production and/or storage of chemicals or chemical munitions prohibited by the CWC.

Three hypothetical buildings are available for inspection in ACE-IT: a chemical processing building, an office building, and a technology demonstration building. Under the CWC challenge inspection provisions, the Inspected Party can control the movement of the inspectors by using managed access. Access to rooms can be controlled by allowing the inspector to view the rooms only through the door or the window. Access to shrouded (or covered) items can be controlled by partially removing the shrouds or by providing alternate information, such as chemical sampling. ACE-IT allows the Inspection Team and the Inspected Party to practice managed access techniques.

Each team has access to an electronic "Exercise Manual" that includes the following information:

- CWC Treaty

- CWC inspection timeline

- description and requirements pertaining to each inspection step (from notification of an inspection through post-inspection procedures)

- requested perimeter and alternate perimeter maps

- pre-inspection briefing

- perimeter monitoring reports

- records (medical, material and safety data sheets, and shipping and receiving)

- general on-site inspection information

Information in the Exercise Manual is available for review from the ACE-IT home page (C:LAce-it it 2.htm) at any time. Treaty provisions associated with each inspection step (listed in the inspection timeline and described in the CWC exercise package) set the context for the inspection. 
The context for the exercise can be described briefly as follows:

- The inspectors and the host have agreed to a perimeter that meets the CWC requirements.

- The inspectors have received a pre-inspection briefing at the site and have been provided the results of: the perimeter monitoring conducted by the host.

- The inspectors have begun to monitor the final perimeter.

- The inspectors need to develop their plan to inspect the three buildings at the site for production and storage of chemicals and chemical munitions prohibited by the CWC.

- For this exercise, a significant quantity of chemical weapons agent could be stored in a container $51 \mathrm{~cm}$ in diameter and $71 \mathrm{~cm}$ high.

After reviewing the list above, the inspectors and host are ready to start the exercise. 


\section{STARTING THE EXERCISE}

To begin the training, two computers must be either (1) logged onto the LAN and the proper network connections established or (2) connected to the Internet via a TCP/IP connection (usually a "socket" connection). (For a detailed description of these settings and the contents of the initialization file, see Section 6.1. For hardware and software requirements, see Appendix A.)

To begin the exercise, double-click the Netscape icon. Navigate to the ACE-IT Version 2.0 home page (C:LAce-itLAce-it2.htm). (See Figure 1.) Detailed "how-to-start" instructions are available on-line by clicking the How to Start button. Participants in the exercise should communicate ahead of time to synchronize startup and to avoid long waiting periods. Netscape Communicator (version 4.0 ) has a "Conference" function that may be useful for real-time electronic messaging during the exercise. (For details, see Appendix B.)

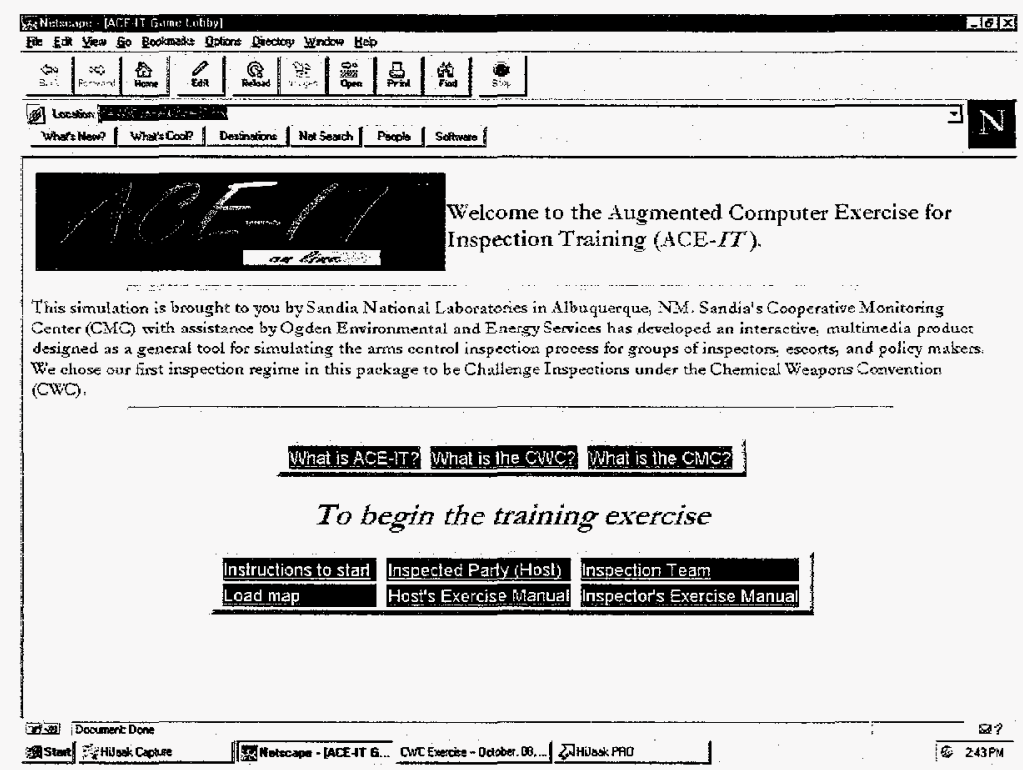

Figure 1. ACE-IT Version 2.0 Home Page

The Inspection Team should click the Inspection Team button and the Inspected Party should click the Inspected Party (Host) button. If the roles have changed from the previous exercise, a message box appears, verifying your intention to switch roles. Select "Yes" if this is correct. (See Figure 2.) Fill out the on-line startup questionnaire, starting with selecting either the LAN or Internet version of the exercise. Next, select your Scenario and Inspection Regime from the pull-down menus at the bottom of the form. (See Figure 3.) 


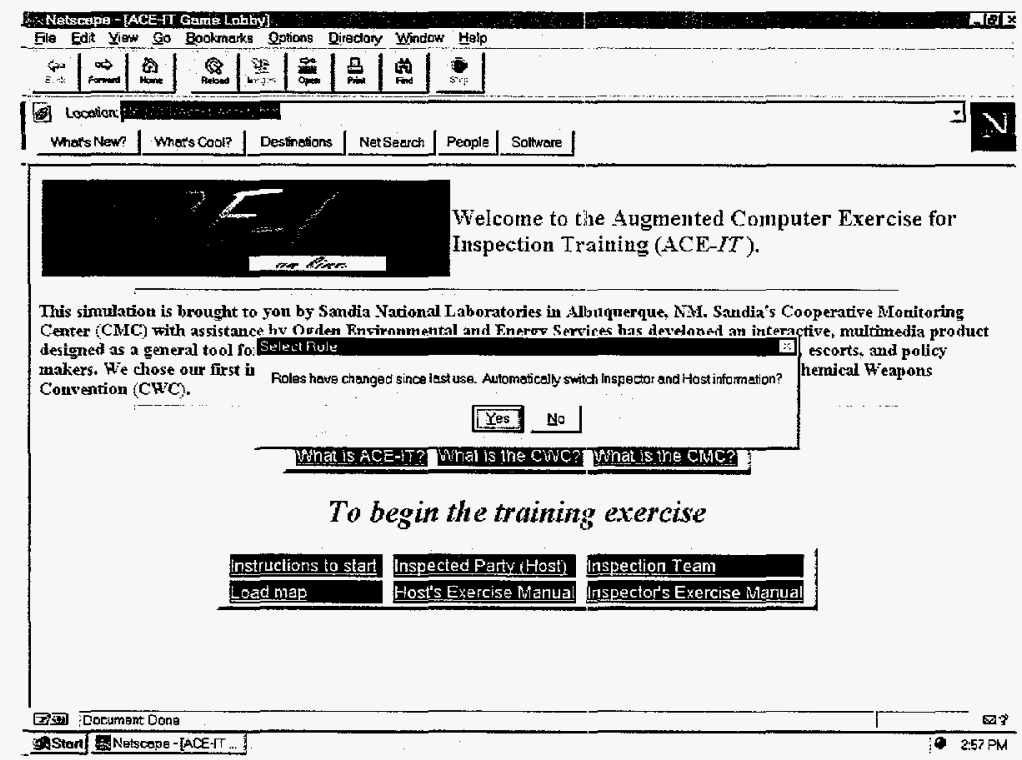

Figure 2. Change of Roles Message Box

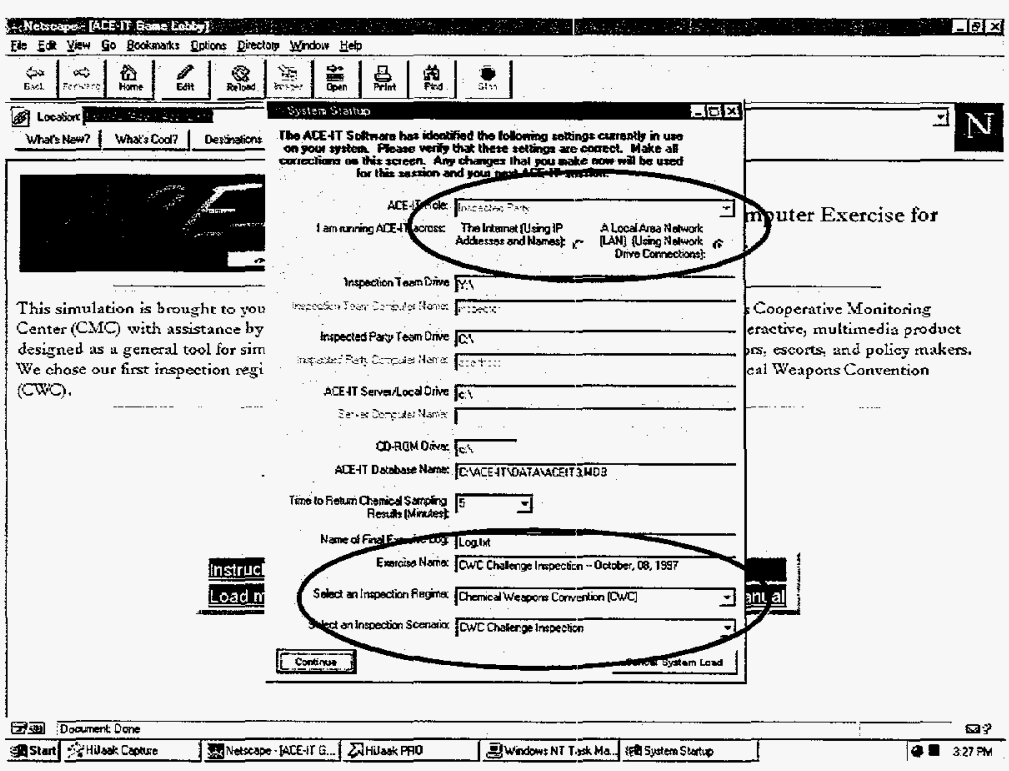

Figure 3. Startup Form

After making your selections, click on the Continue button. A message box will appear that asks if you want to delete old $\log$ and transfer files. Select "OK" to remove information files from a previous exercise. (See Figure 4.) 


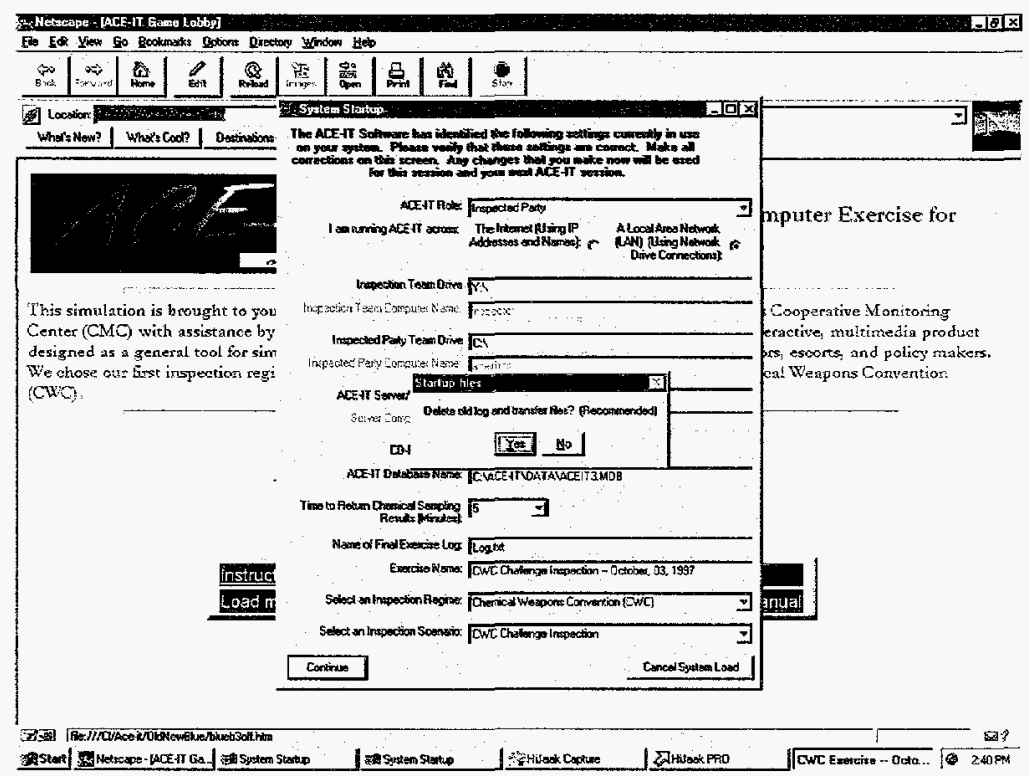

Figure 4. Deletion of Files from Previous Exercise Option

For both participants, the ACE-IT Control Center will be visible as a Taskbar entity (usually at the bottom of the screen). Click the Control Center item in the Taskbar to view a simple set of buttons. These buttons allow either party to end the exercise, print the exercise report (see Appendix C) or hide (minimize) the Control Center. The Control Center can be maximized at any time.

The Hosts will receive a "Waiting for Request" message. Hosts can take advantage of any lapses in the action to study the "Host's Exercise Manual." (See Appendix D.)

The Inspectors must click the Load Maps button after completing the startup questionnaire. Next, the Inspectors click on a building and, from the building map that then appears, select a room to inspect. They must then wait for a Host response. Inspectors, too, can take advantage of any lapses in the action to study the "Inspector's Exercise Manual." (See Appendix D.)

Each version of the on-line exercise notebook differs; participants should not look into their counterpart's material to obtain an unfair advantage during the exercise. The Hosts may load and examine the site and building maps from the "Load Maps" function; these materials are also available in the exercise manual.

\subsection{If Your Internet Connection Goes Down}

For some types of Internet connections, especially long-distance independent Internet Service Providers, a connection failure is possible during the several hours that an exercise may last. To restart, go into Netscape and navigate to the ACE-IT Version 2.0 home page. Do not delete the startup and log files when asked. Click on your role, either "Inspection Team" or "Inspected Party (Host)." Fill out the startup questionnaire (it should still have the previous values in place) and resume the exercise. It may be necessary for the Host to notify the Inspectors to click on the room they wanted to inspect to restart the access request process. 


\section{DETAILS OF THE EXERCISE}

This section provides a detailed outline of a training exercise. Table 1 presents a sample CWC challenge inspection timeline, showing the maximum time allotted for each event. Although the information is available on all Treaty events, the exercise focuses on the 84-hour "Inspection" step.

Table 1. CWC Challenge Inspection Timeline

\begin{tabular}{|l|c|}
\hline Treaty Events & $\begin{array}{c}\text { CWC Challenge Inspection } \\
\text { (hours) }\end{array}$ \\
\hline Notification of Challenge Inspection & - \\
\hline Arrival at Point of Entry/Specify Site & 12 \\
\hline Inspected Party Monitors Requested Perimeter & 72 \\
\hline Negotiate Alternative Perimeter & 60 \\
\hline Travel to Site & 12 \\
\hline Inspection Team Monitors Final Perimeter & 180 \\
\hline Negotiate Final Perimeter & 96 \\
\hline Pre-Inspection Briefing & 3 \\
\hline Inspection Planning & 2 \\
\hline Inspection & 84 \\
\hline Post-Inspection Procedures & 24 \\
\hline
\end{tabular}

Before or during an exercise, either party may examine their on-line "Exercise Manual" by clicking on the Host's Exercise Manual button or Inspector's Exercise Manual button from the ACE-IT Version 2.0 home page. Information is provided on each step of the challenge inspection process in the "CWC Exercise Package for Inspection Team (Inspectors) and Inspected Party (Host)" section in the manual.

\subsection{Inspection}

The inspection team views site and building maps by clicking on the Load Maps button on the ACE-IT Version 2.0 home page. A "virtual" inspection is conducted by accessing the building interior maps. Inspectors may request access to any room by clicking on that room when viewing the building map. Figure 5 shows the interior of an example building, Building 10510. 


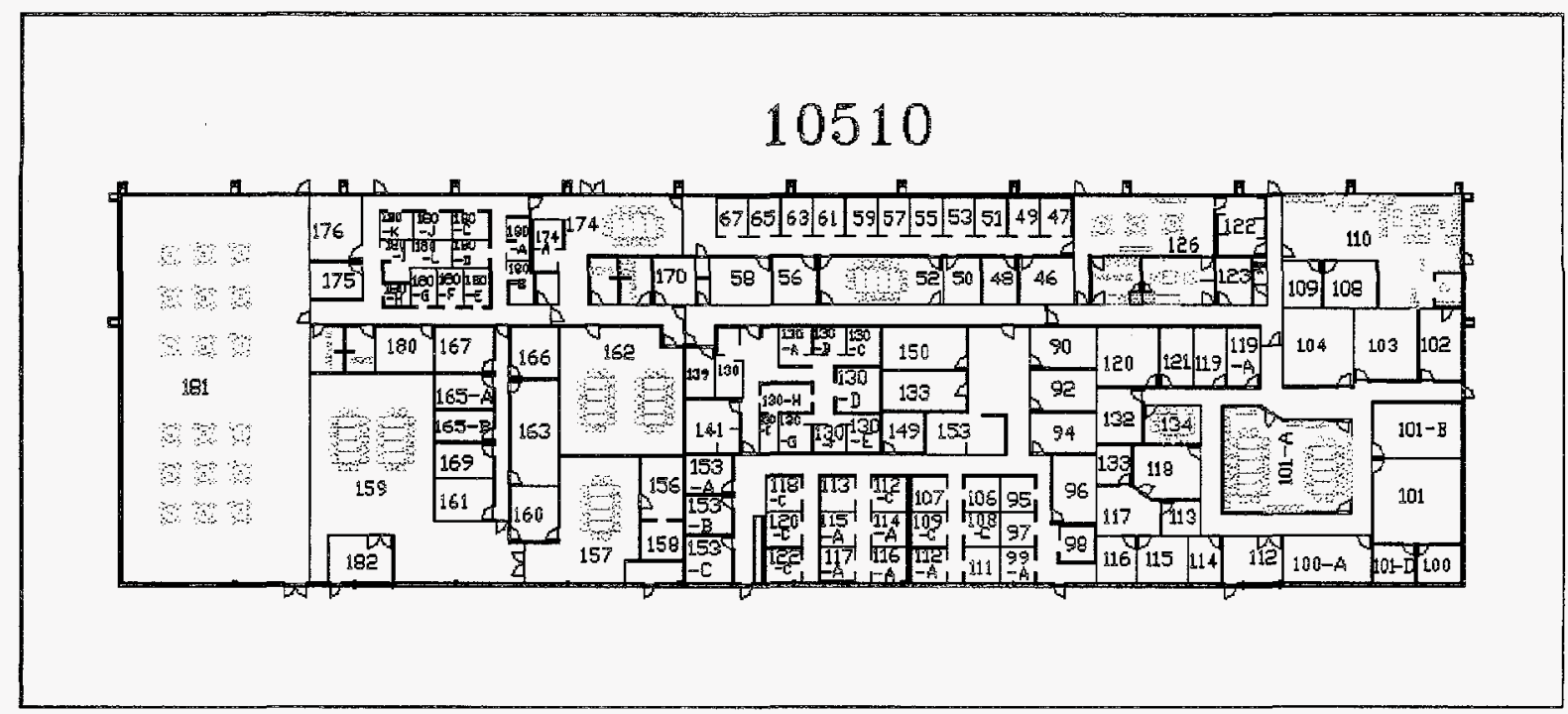

ACE-IT CMC Site Building 10510 (Office space, Conference Rooms, Technology Demonstrations)

Figure 5. Building 10510 Interior Map

The primary training focus of the Inspection event is to demonstrate the concept of managed access to participants. ACE-IT provides trainees with three types of negotiations:

- negotiation of physical access,

- negotiation of visual access, and

- negotiation of access to alternate information.

One example of controlling visual access is the covering (or "shrouding") of a sensitive item that is not related to the treaty.

Each type of negotiation is very different. All negotiations consist of a request from the Inspection Team and an accompanying response from the Inspected Party. At many points, a Hints button will allow the user to reach a screen containing additional information. An example of where to find a Hints button can be found in Section 3.1.2.2. The following sections discuss each type of negotiation in detail from Inspection Team and Inspected Party perspectives.

\subsubsection{Negotiation of Physical Access}

This section addresses the operation of ACE-IT beginning with an Inspection Team request for physical access to a facility. It is assumed that all physical access requests are for full access to a specified location. 


\subsubsection{Inspection Team}

To initiate negotiation for physical access, the Inspection Team clicks on the Inspection Team button from the ACE-IT Version 2.0 home page and fills in the startup form. (See Appendix D.) Then the Inspectors click on the Load Maps button and select a building from the building map. They may click on any room to generate the request. The Inspection Team receives an on-screen notification that the request is being processed while this request is passed to the Inspected Party. (See Figure 6.) There are three possible responses to the request: "Access Denied," "Partial Access," or "Full Access."

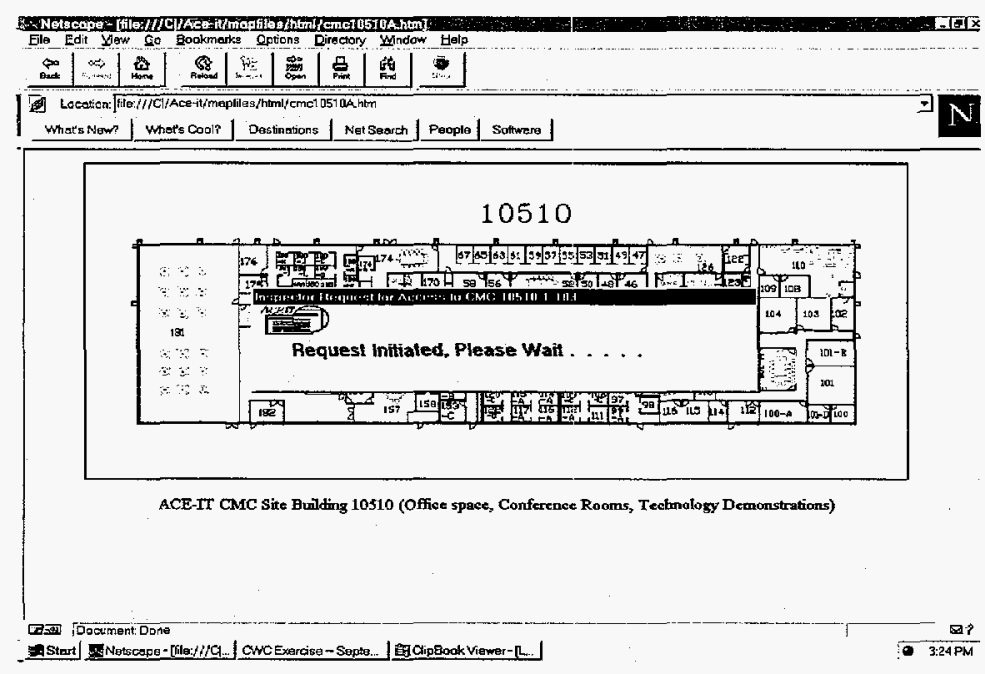

Figure 6. Initiation of a Request for Access

\section{Response: Access Denied}

"Access Denied" gives the Inspection Team a color-coded (red) message stating that access will not be granted. (See Figure 7.) When this response is received, the Inspection Team can repeat the request for access into the room, request Alternate Information, or continue on to a different room, all of which can be initiated from the notification window. Click the Repeat Access Request button to enter a justification for entering the room. Click the Continue button to return to the map and select another room. Requests for Alternate Information are initiated from the Hints button on the response window. For more information on requesting alternate information, see Section 3.1.3. 


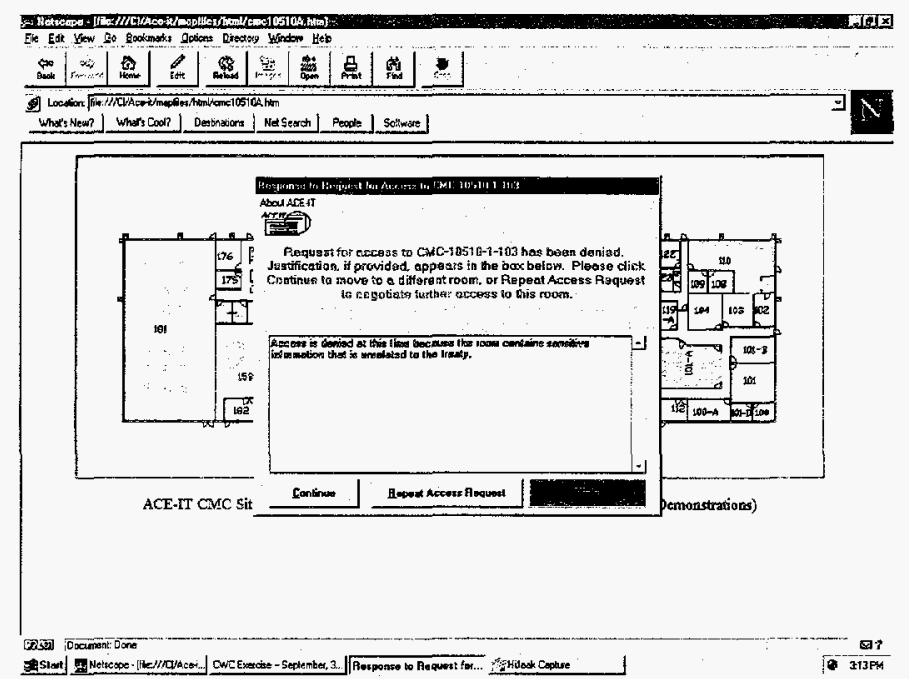

Figure 7. Receipt of Access Denied Notification

\section{Response: Partial Access}

"Partial Access" gives the Inspection Team a color-coded (yellow) message as well as access to a limited photo tour of the room, which consists of views from the door, the window, or both. (See Figure 8.) From the response window, the Inspection Team can repeat the access request, request alternate information, or access the photo tour. Click the Repeat Access Request button to type a justification for entering the room. (See Figure 9.) Click the Continue button to view the photo tour of the room. (See Figure 10.) From the photo tour windows, the photos can be zoomed and requests for shroud lifts and alternate information are made. Click the Zoom button to enlarge the photos. The "pie-chart" indicates the orientation of the photo to the room.

Lifting shrouds and requesting alternate information are negotiated separately. For more information on lifting shrouds and requests for alternate information, see Sections 3.1.2 and 3.1.3, respectively.

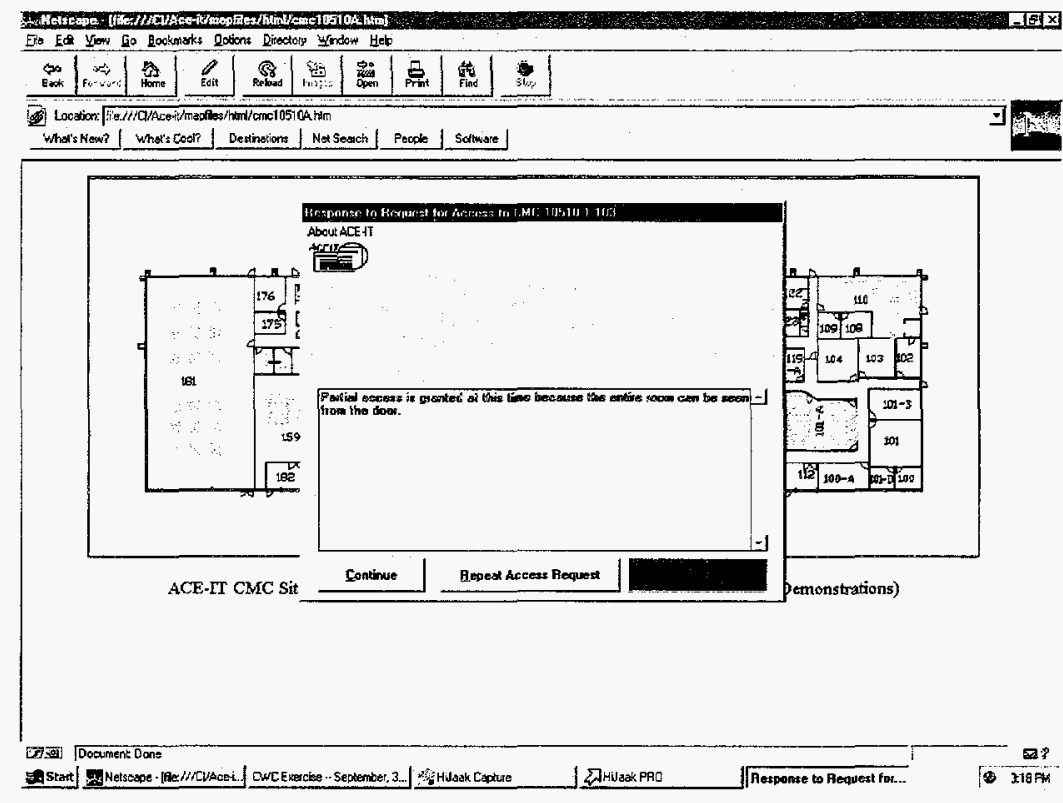

Figure 8. Receipt of Partial Access Granted Notification 


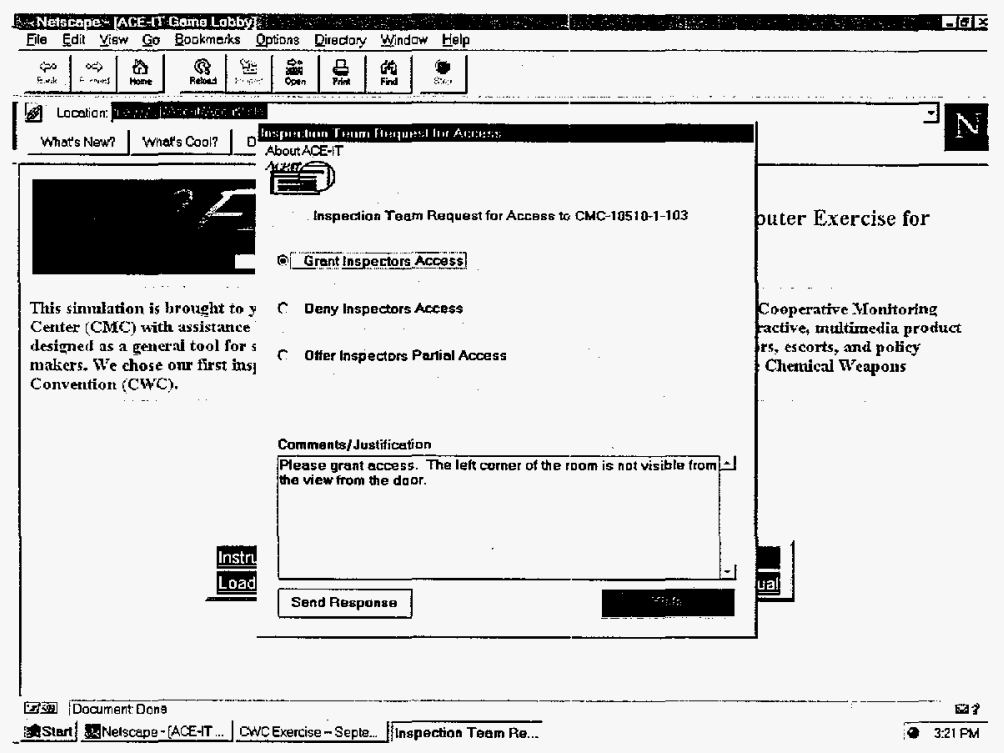

Figure 9. Repeat Request for Access with Justification ACE II Phato Tour - L Location - - [MC-101510-1-103

View From Center. 360 degrees Clackwise, Door to Doot [Angle Measured from Door]<smiles>C1CCC1</smiles>

Zoom Zoom Zoom Z Zoom Z Zoom I Zom J

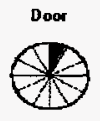

15 degrees

Zoom I Zoom Zoom J Zoom Zoom Zoom J

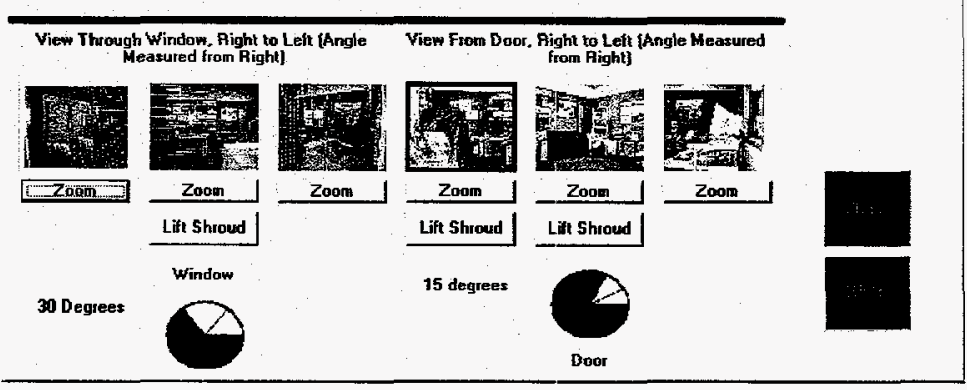

Figure 10. Inspection Team Views Partial Access Photo Tour 


\section{Response: Full Access}

"Full Access" gives the Inspection Team a color-coded (green) message as well as access to a photo tour of the entire room. (See Figure 11.) From the response window, the Inspection Team can either request alternate information or access the photo tour. Click the Continue button to access the photo tour of the entire room, which consists of a view from the door, a view from the window if available, and a $360^{\circ}$ view from the center of the room. (See Figure 12.)

From the Photo Tour window, the participants can enlarge photos, lift shrouds and request alternate information. Click the Zoom button to enlarge the photos. To assist the user in determining the approximate scale of the objects in the zoom window, an on-screen 1-meter-scale measuring stick has been provided. Double-click on the yellow measuring stick to activate this feature. The meter stick can then be dragged to any location on the screen. Clicking the right mouse button will switch the meter stick from the vertical orientation to the horizontal and back again. Double-click on the yellow part of the stick to remove the meter stick from the screen. Figure 13 shows the meter stick on a zoomed window.

Lifting shrouds and requesting alternate information must be negotiated separately. For more information on these actions, see Sections 3.1.2 and 3.1.3, respectively.

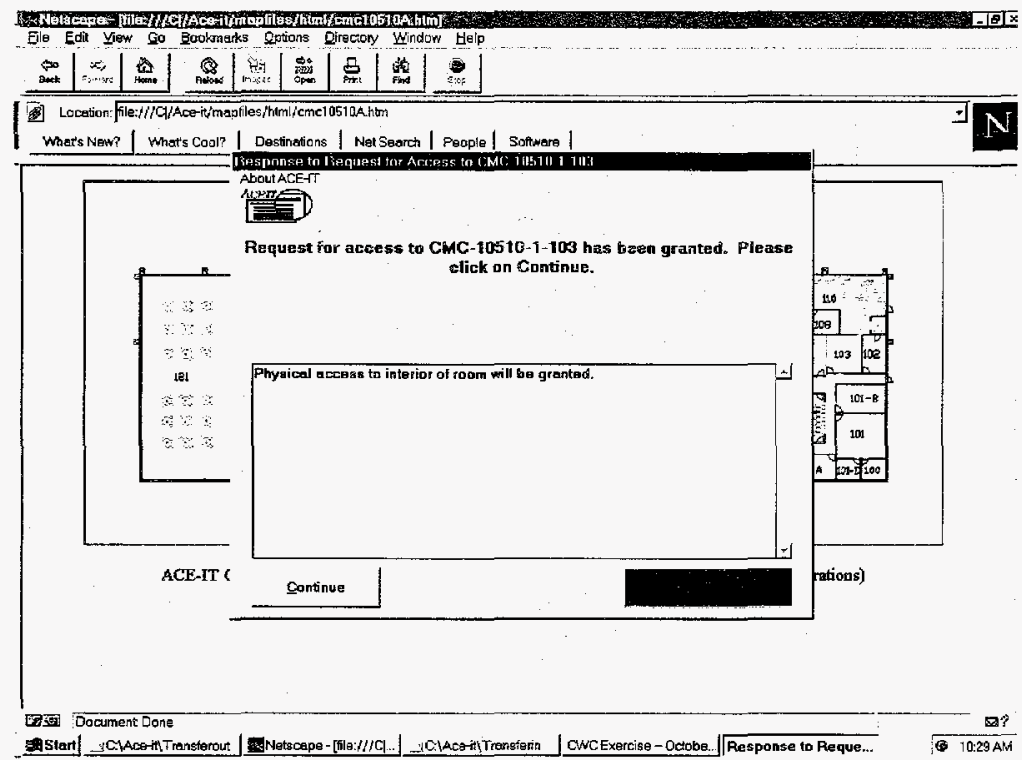

Figure 11. Receipt of Full Access Granted Notification 


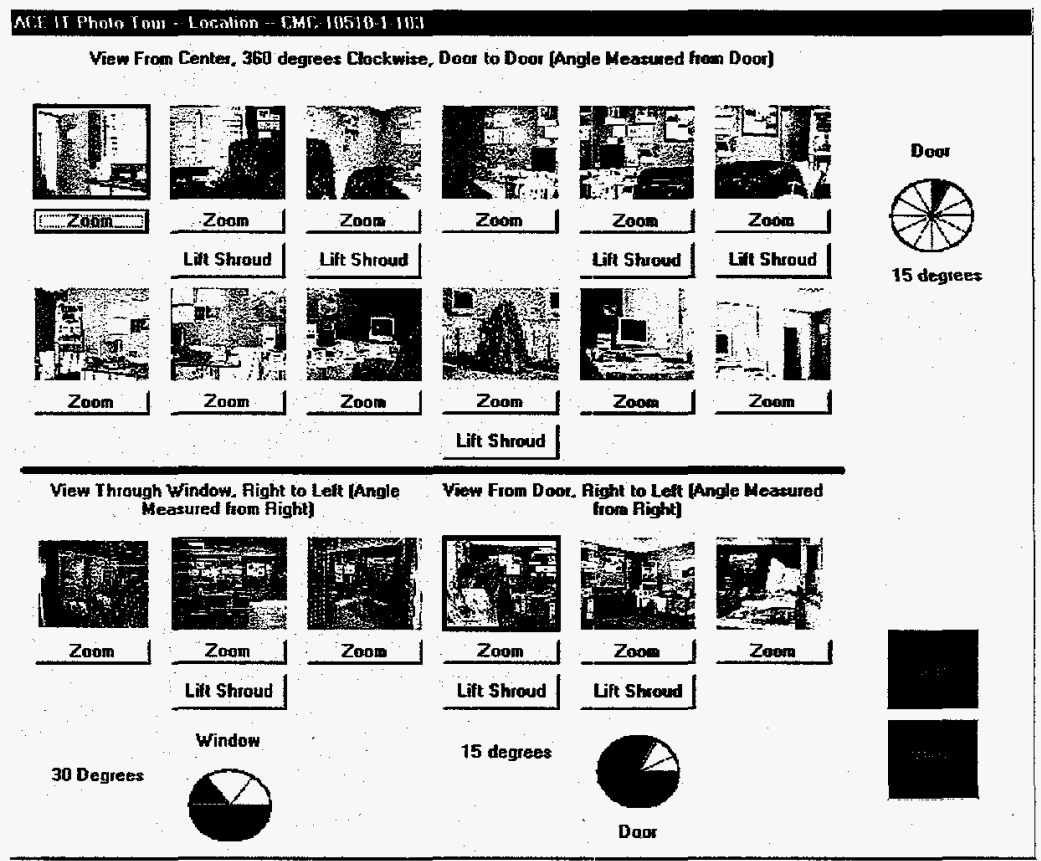

Figure 12. Inspection Team Views Full Access Photo Tour

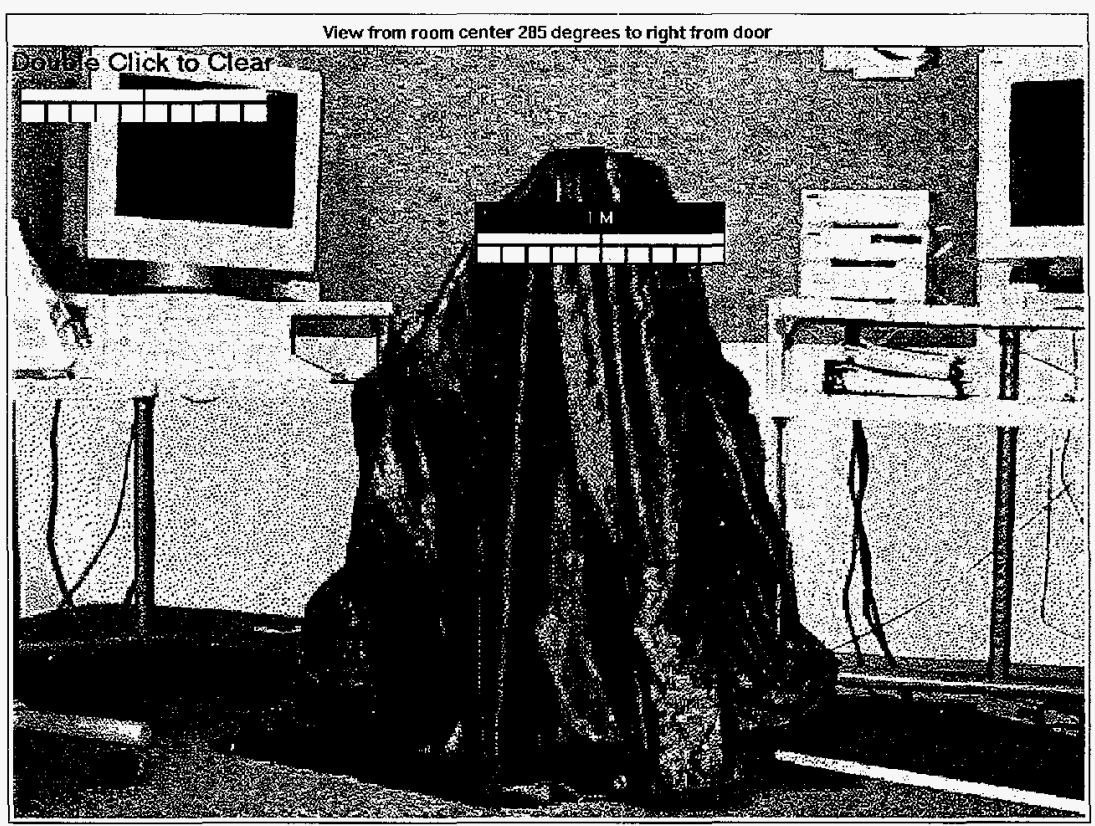

Figure 13. Zoom Window with On-Screen Meter Stick 


\subsubsection{Inspected Party}

The Inspected Party receives a request from the Inspection Team for full access to a selected room. The Inspected Party has several response options: Grant Full Access, Deny Access, or Offer Partial Access. (See Figure 14.) "Full Access" provides the Inspection Team with a photo tour of the entire room, consisting of views from the door, the window, and a $360^{\circ}$ view from the center of the room. "Access Denied" does not provide the Inspection Team with any view of the room. "Partial Access" provides the Inspection Team with a photo tour of the room, consisting of views from the door, the window, or both.

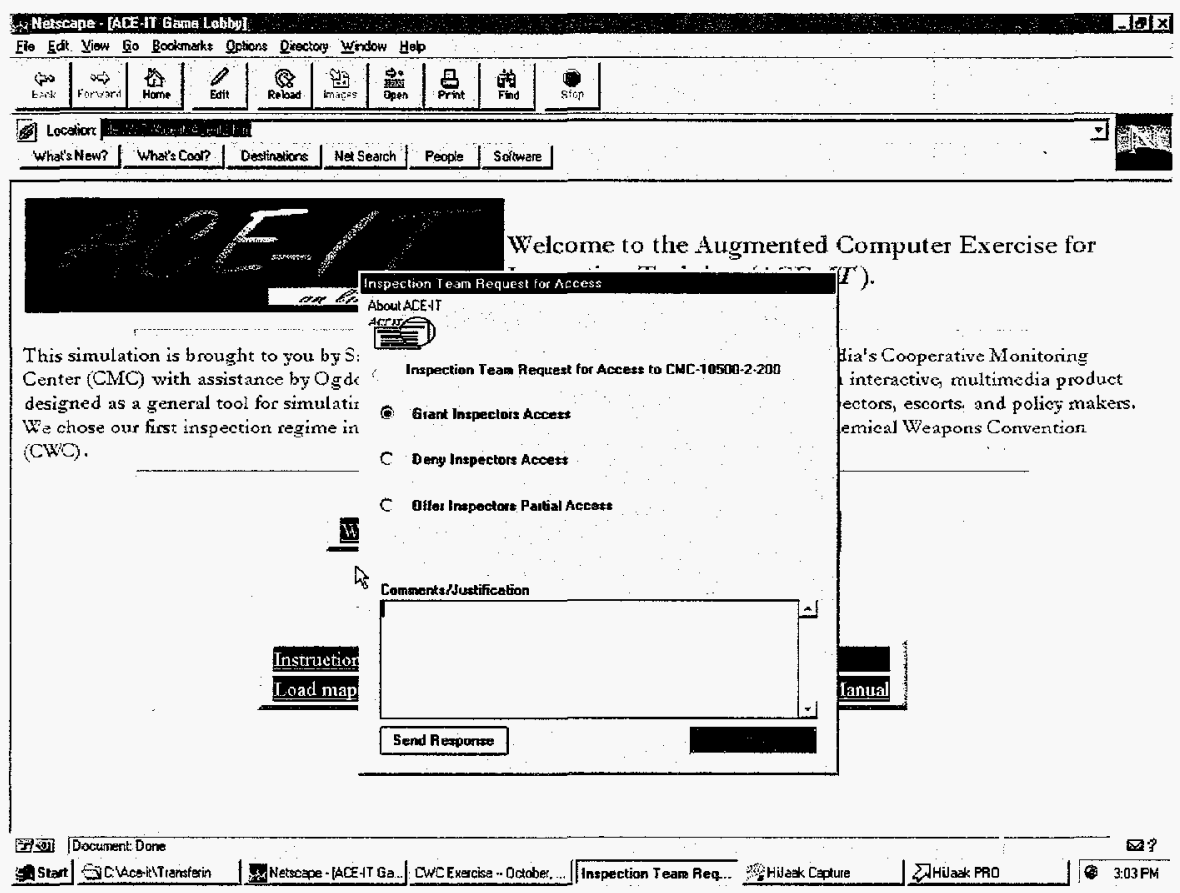

Figure 14. Receipt of Access Request

NOTE: The Inspected Party does not have to be familiar with the facility layout. The computer will display the information associated with the requested room.

Several options can help the Inspected Party decide what level of access to grant to the Inspection Team. Click the Hints button in the lower right-hand corner of the Access Negotiation box and then click the Preview Room button in the resulting Hints box to view the photo tour of the entire room. (See Figures 15 and 16.) From the photo tour the photos can be enlarged, shrouds can be lifted, and alternate information can be previewed. Click the Zoom button to enlarge the photos. The on-screen meter stick is the same as that provided for the Inspection Team. If the location selected has no photographs associated with it (such as conference rooms, rest rooms, and other nonsensitive areas), the user will be provided with a message box stating that there is no photographic data for the requested location. 


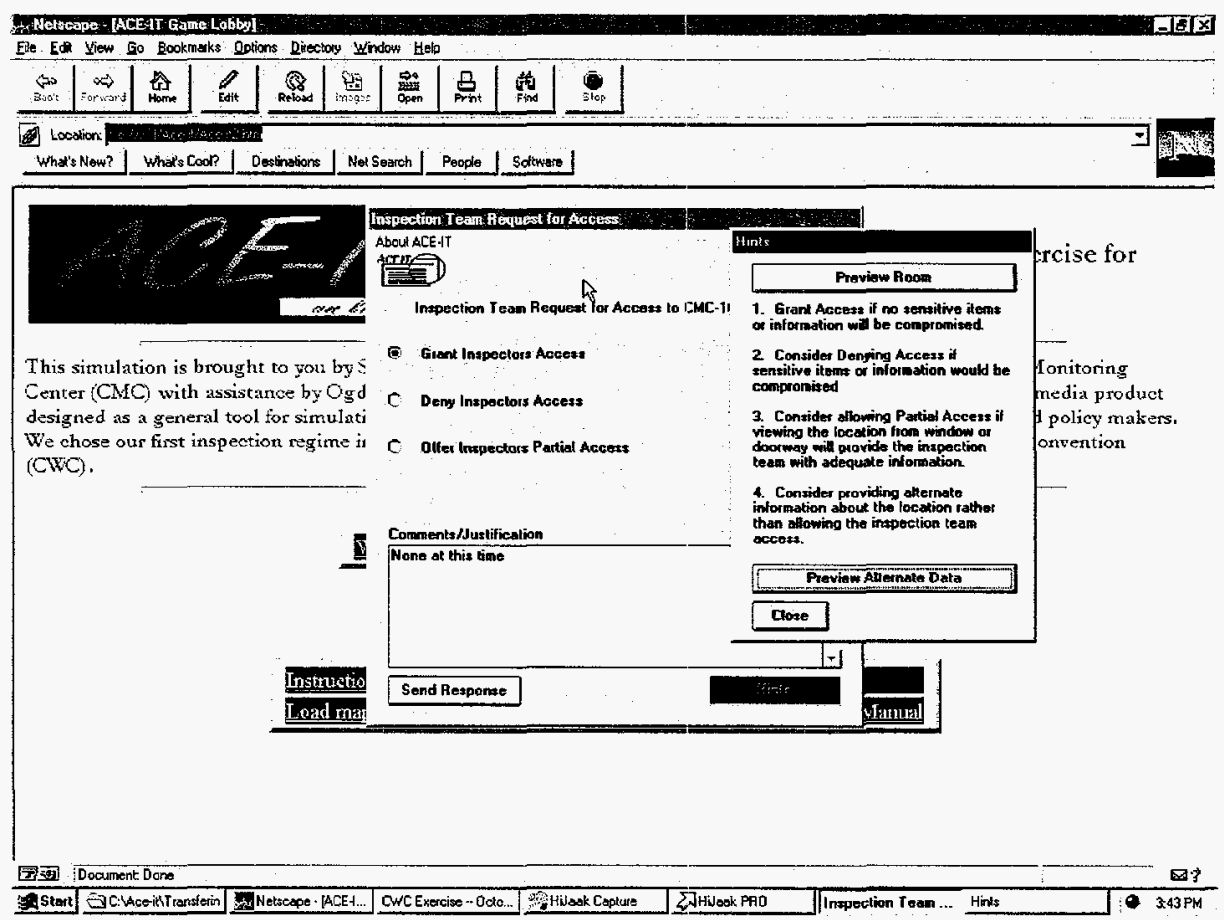

Figure 15. Inspected Party Accessing the Room Preview

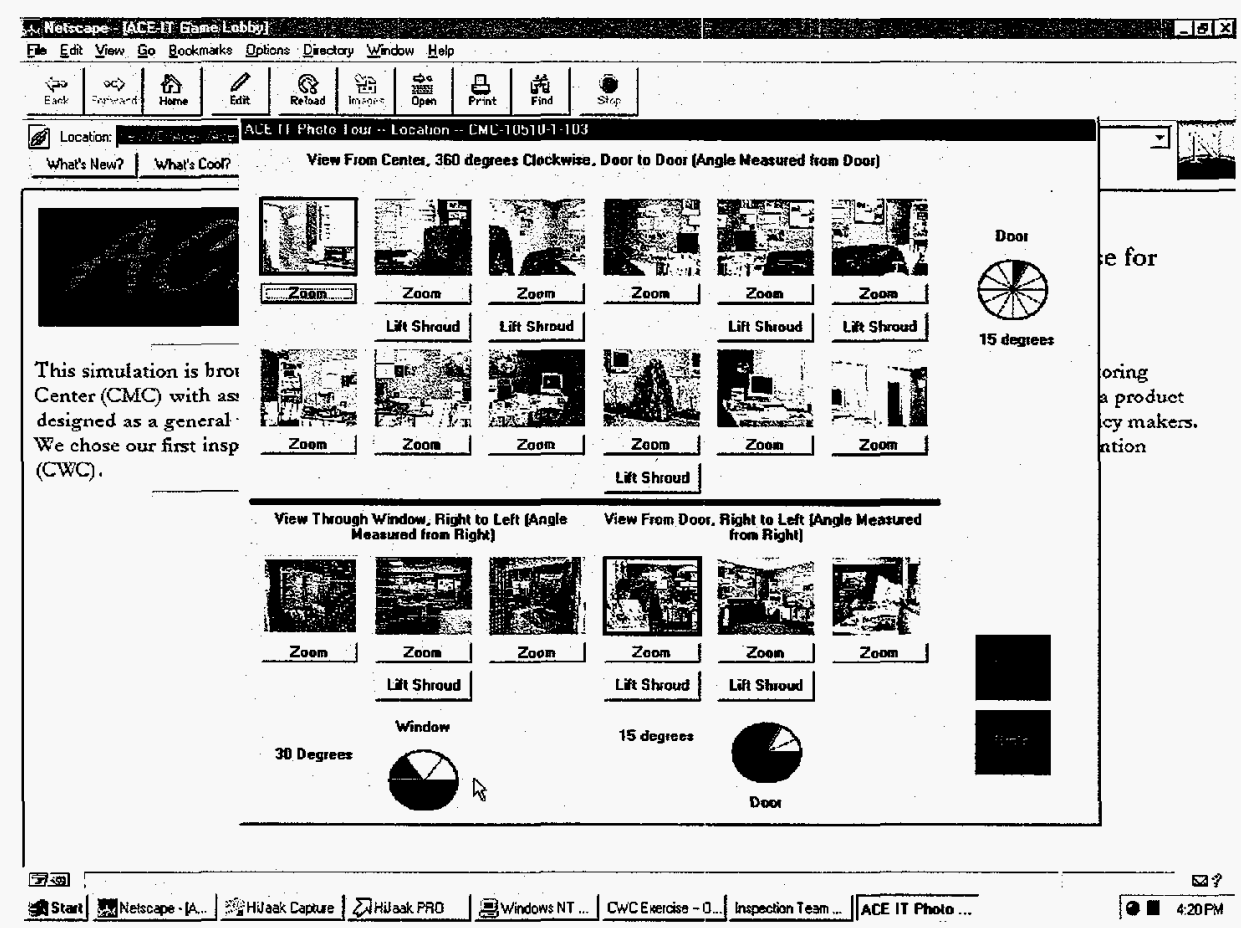

Figure 16. Inspected Party Views Preview of Photo Tour

For certain areas, Quick Time Virtual Reality (QTVR) images have been produced. If a QTVR image is available, a QTVR button will appear on the right above the Close button. (See Figure 17.) Clicking on the QTVR button will cause a window to appear running the QTVR viewer. The viewer allows the user to pan and zoom using mouse controls. (See Figure 18.) 


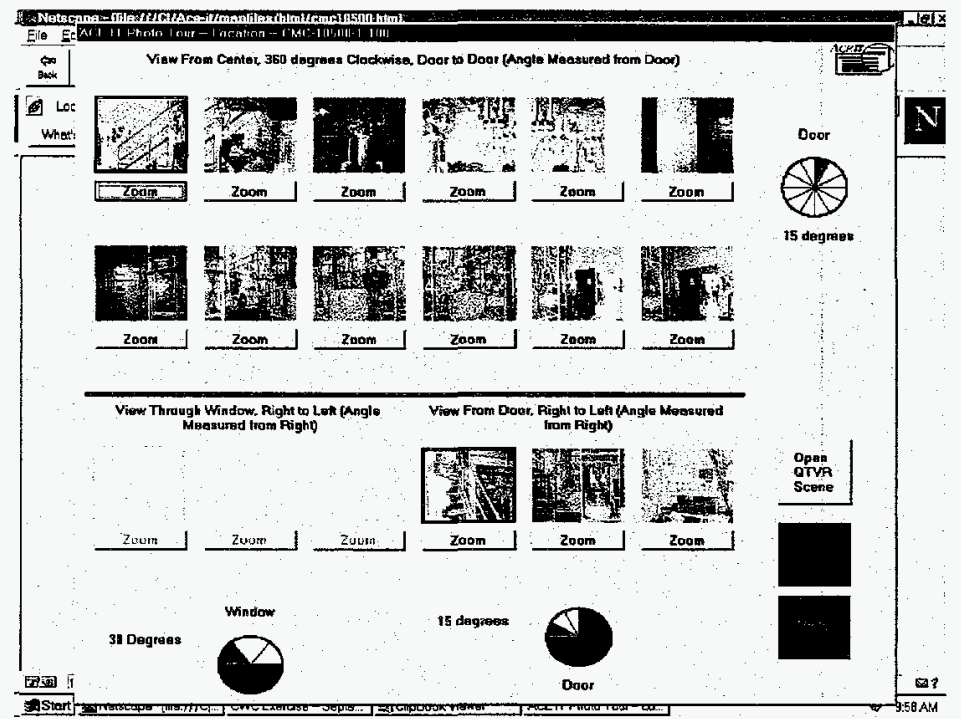

Figure 17. Inspection Team Views Full Access Photo Tour with the QTVR

Pan: Click and hold down the left mouse button. Drag the mouse in the direction you want to view (up, down, left, right, diagonally). The farther you drag, the faster you turn in that direction. Dragging in a new direction turns you in that direction. Releasing the mouse button stops panning.

Zoom: While holding down the left mouse button, use the control key to zoom in and the shift key to zoom out.

Moving to a linked image: When viewing an image (but not while panning), the cursor will change to an arrow pointing at a circle (a) if a link exists to another QTVR image representing another point of view. For example, the single small scale facility QTVR has one outside, five downstairs, and two upstairs images.

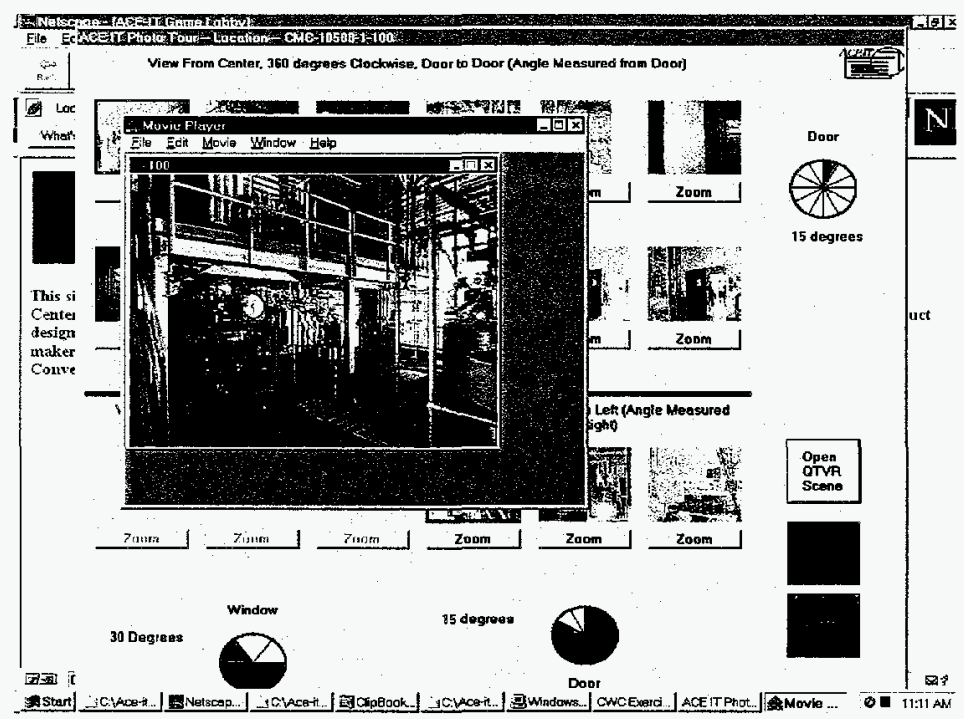

Figure 18. Inspection Team Views the QTVR 
To preview the item beneath the shroud, click the Lift Shroud button under the picture of the shrouded item of interest. The Lift Shroud window displays the shrouded item and provides a brief description and the approximate dimensions of the object. (See Figure 19.) The on-screen meter stick is also provided in this window. The scroll bar running from right to left beneath the image determines how much of the: shroud will be lifted. Slide this scroll bar to $50 \%$ and click the Play button. (See Figure 20.) The item will be partially unshrouded. To determine the level of unshrouding that would be acceptable withou: revealing any sensitive information, slide the scroll bar to different percentages and click the Play button. Repeat this action until the desired level of unshrouding is achieved. Click the Close button to close the window.

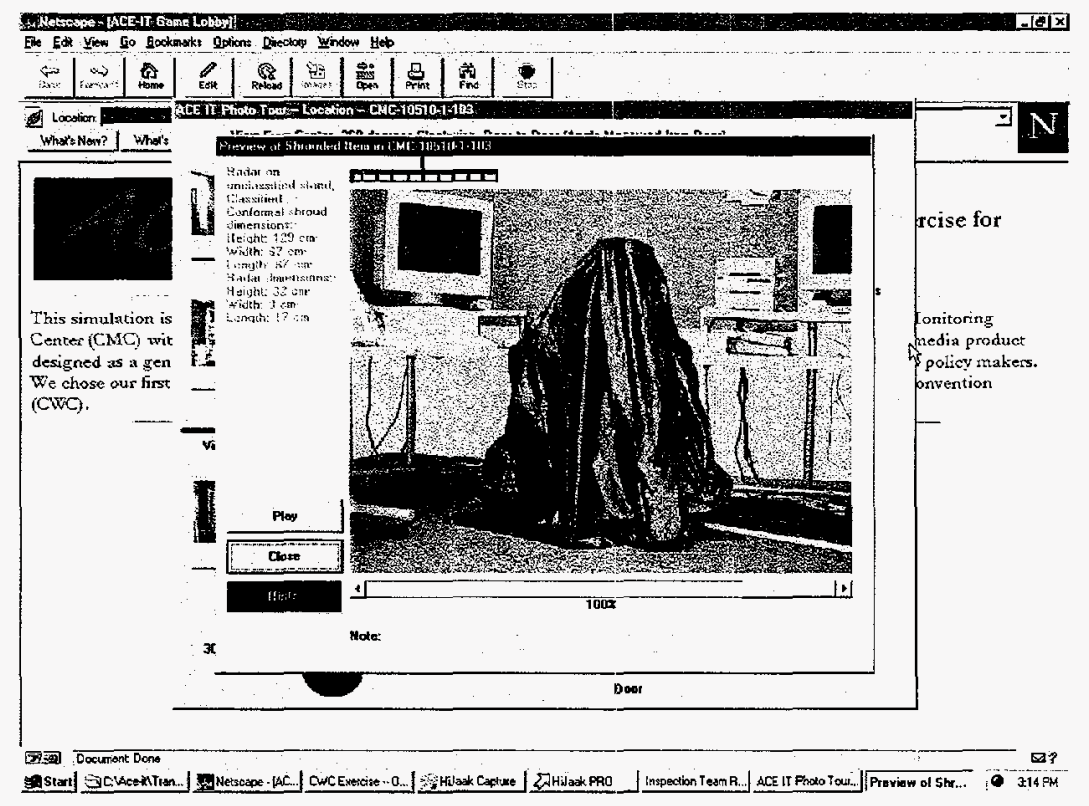

Figure 19. Inspected Party Views Preview of Shroud Lift

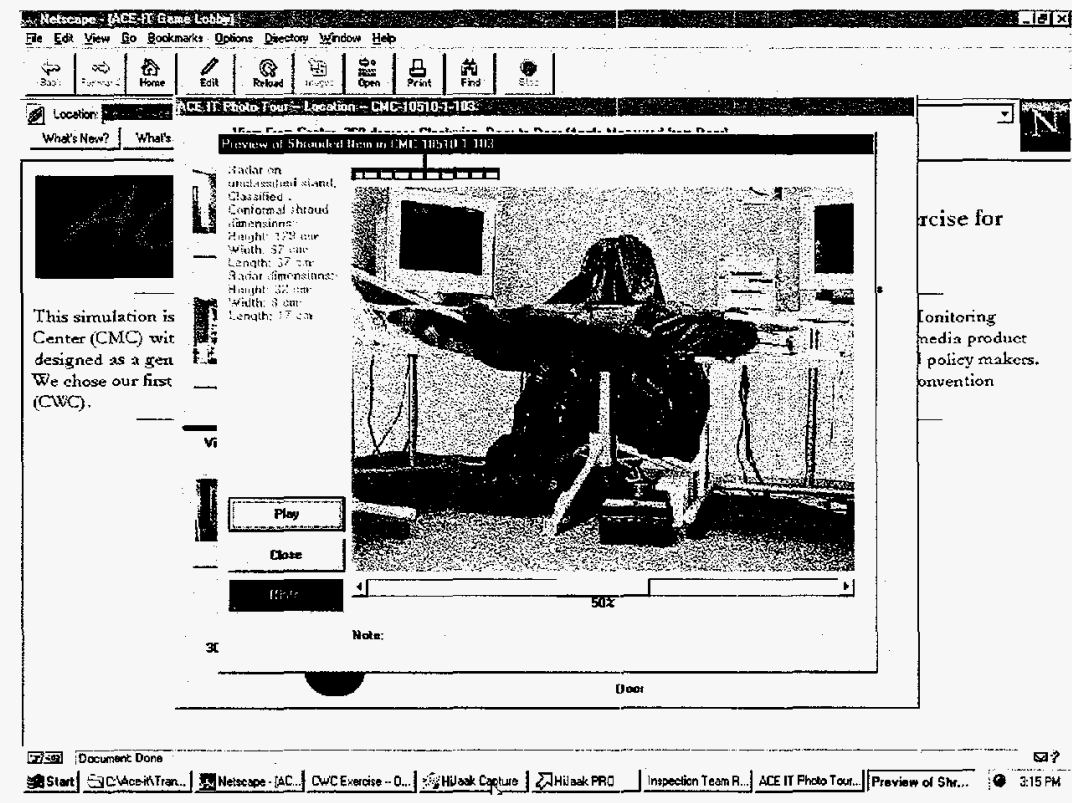

Figure 20. Inspected Party Views Partial Shroud Lift 
To access Alternate Information, click the Hints button on the photo tour window, and then click the Alternate Information button. "Alternate Information" consists of seven topics, each of which is represented by a button: Chemical Sampling, Proprietary Research Information, Hazardous Waste Information, Inventory of Items, Inventory of Chemicals, Shipping and Receiving Records and Employee Medical Records. (See Figure 21.) Click the appropriate button to preview the desired alternate information. For example, click the Hazardous Waste Information button to display information about any hazardous wastes associated with the requested room. (See Figure 22.) The other buttons work similarly, with the exception of Chemical Sampling. Chemical Sampling is an interactive window, and is meant to be used to record the taking of a sample, not to display sampling results.

For details on negotiating access to alternate information, see Section 3.1.3. If the selected topic has no data for the requested location, the screen will display a message box stating that no information is available.

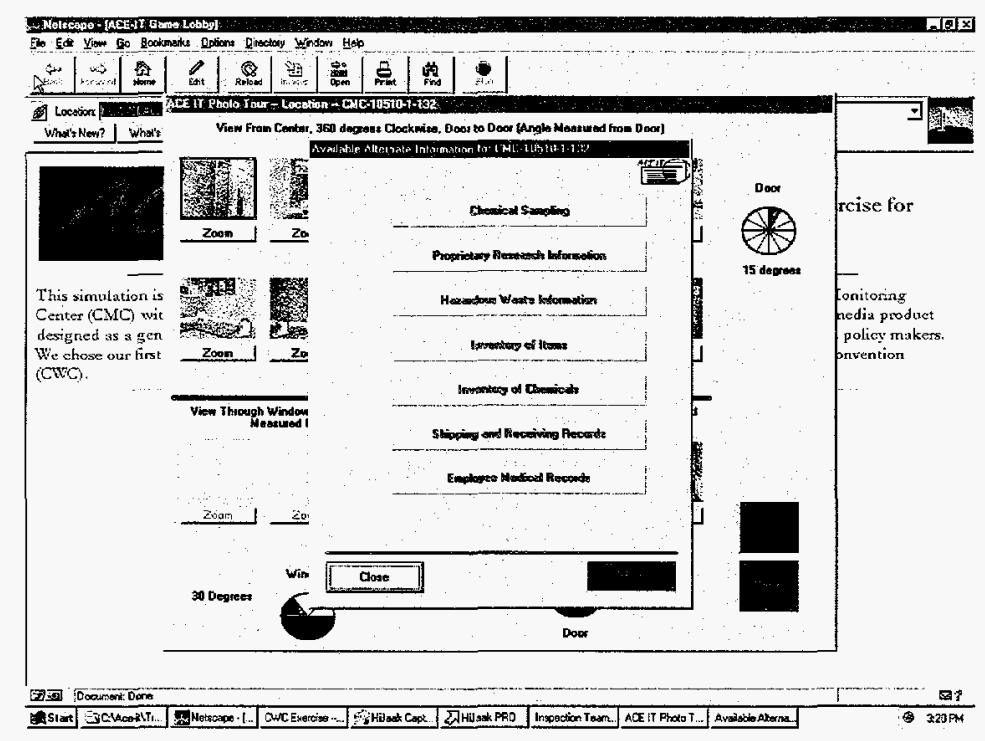

Figure 21. Inspected Party Alternate Information Preview

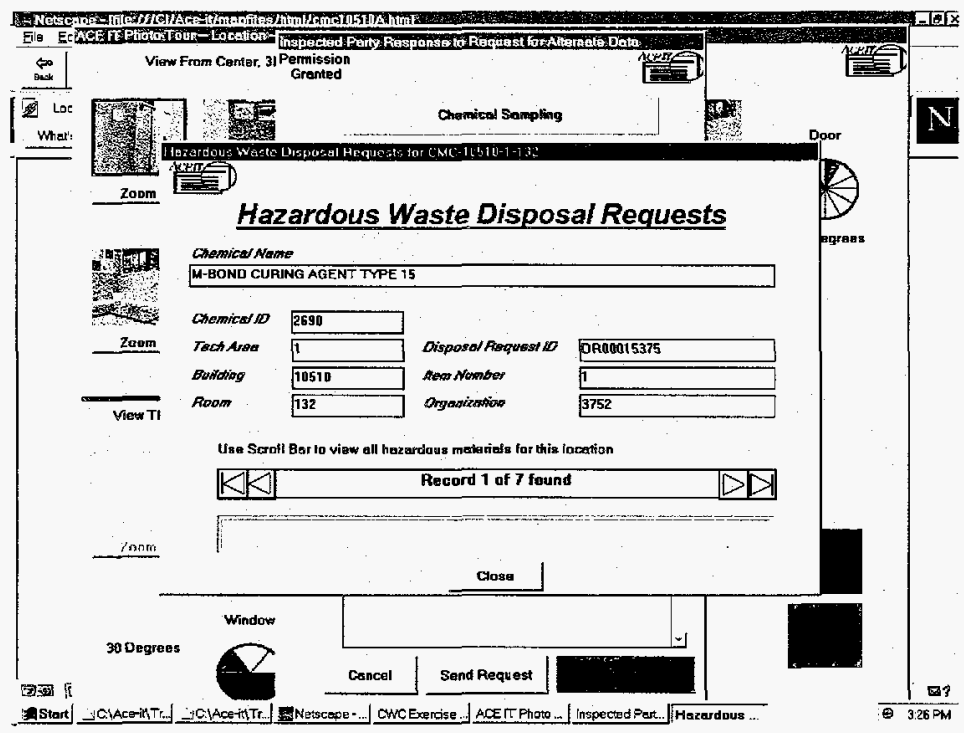

Figure 22. Inspected Party Hazardous Waste Information Preview 


\subsubsection{Viewing Shrouded Items}

Once the Inspection Team reaches a point where they see a shrouded item, negotiations to lift the shroud begin. Requests to view shrouded items will be negotiated on an individual basis.

\subsubsection{Inspection Team}

To initiate a negotiation to view a shrouded item, click the Lift Shroud button located beneath the photo that contains the item of interest in the photo tour window. (See Figure 23.) If there are multiple shrouds in a photo, the next window will contain photos of each of the shrouded items in the original photo. (See Figure 24.) If only one item is visible, only that item is displayed. From the lift-shroud window, a justification for the request can be entered. (See Figure 25.) To send a request to the Inspected Party to view a shrouded item, click the Send Request button.

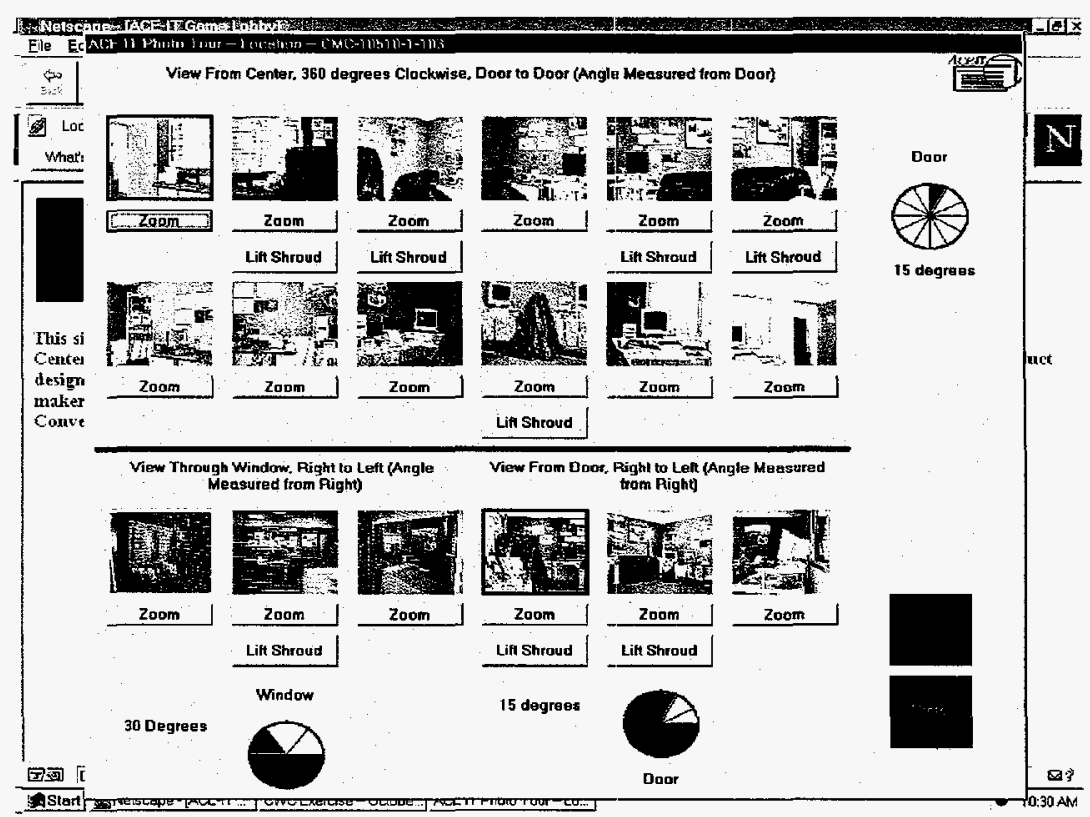

Figure 23. Inspection Team Views Full Access Photo Tour 


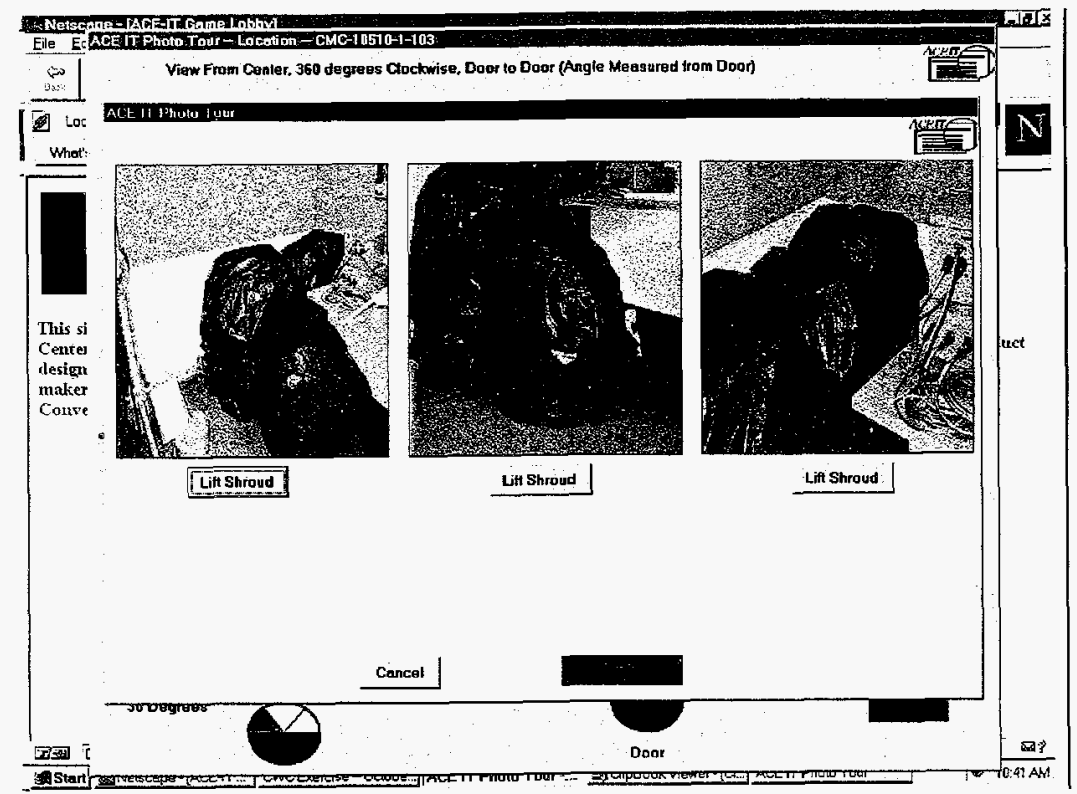

Figure 24. Inspection Team Views Multiple Shroud Window

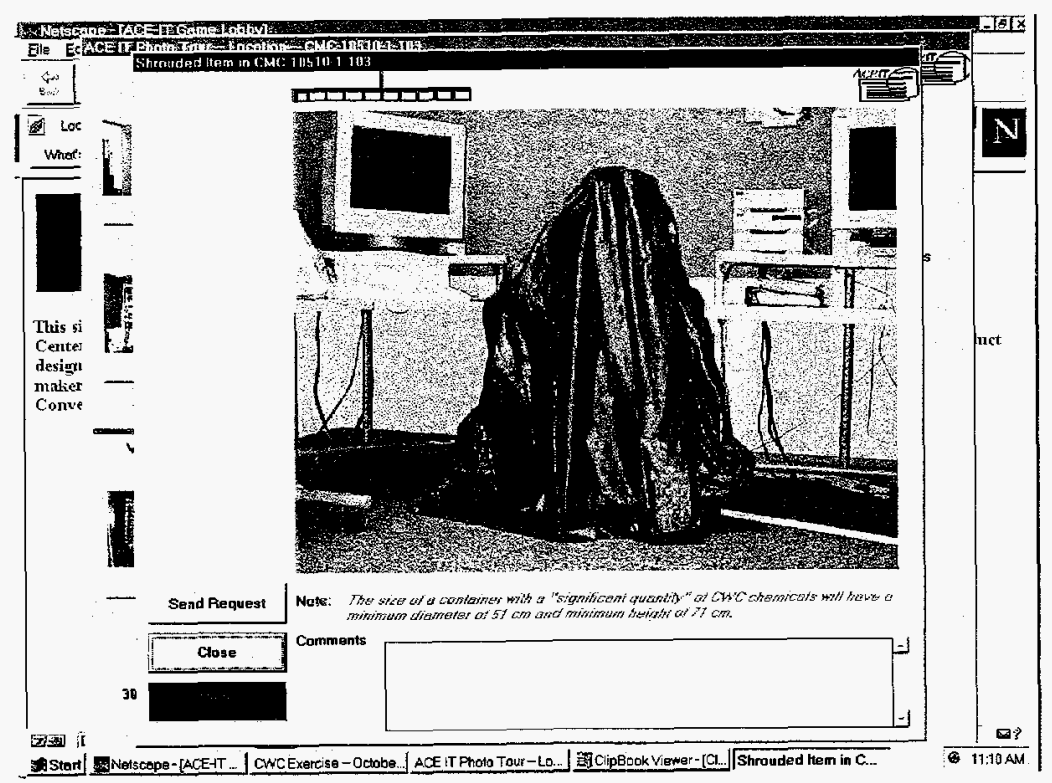

Figure 25. Inspection Team Views Single Shrouded Item

The response to the request can either be "Full Unshroud," "Partial Unshroud," or "Request Denied." If the response from the Inspected Party is "Full Unshroud," the Inspection Team's computer will chime and the unshrouding will begin a few seconds after the chime. The item will be automatically and completely unshrouded, and the description and dimensions of the object will be displayed. (See Figure 26.) If the response is "Partial Unshrouding," the Inspection Team's computer will chime and the unshrouding will begin a few seconds after the chime. The item will be automatically unshrouded between $0 \%$ and $100 \%$, depending on the selection the Inspected Party has made. (See Figure 27.) No description/dimensions are displayed unless the shroud is lifted $100 \%$. If the request is denied, the computer will chime and a notification that the request was denied will be displayed. Any comments from the Inspected Party will appear after the message box is cleared. (See Figure 28.) 


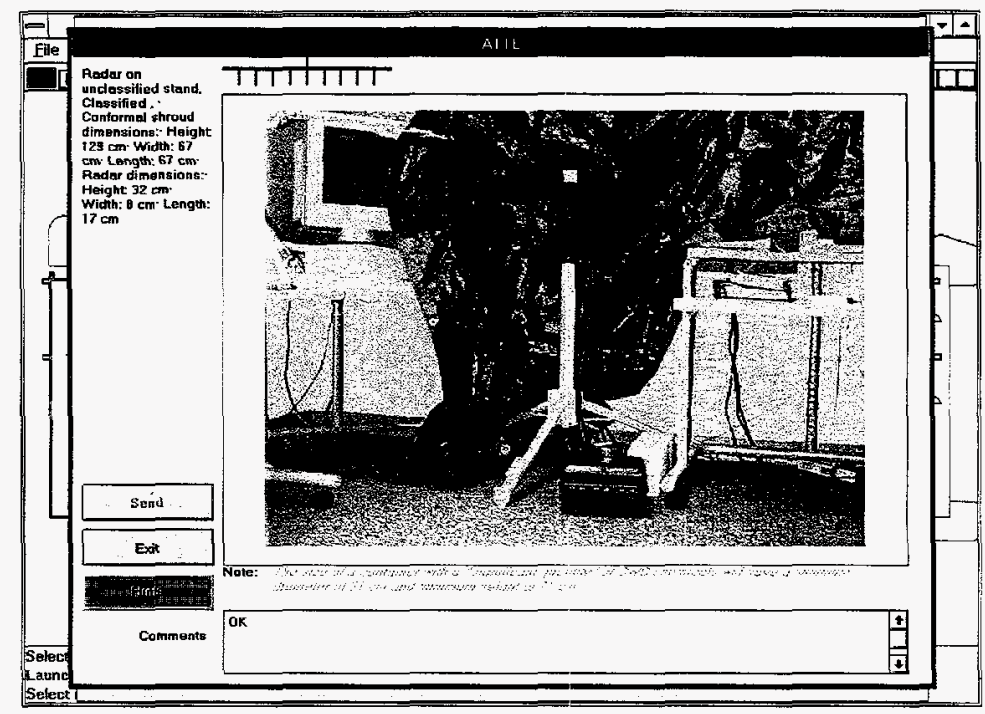

Figure 26. Inspection Team Views Complete Unshrouding

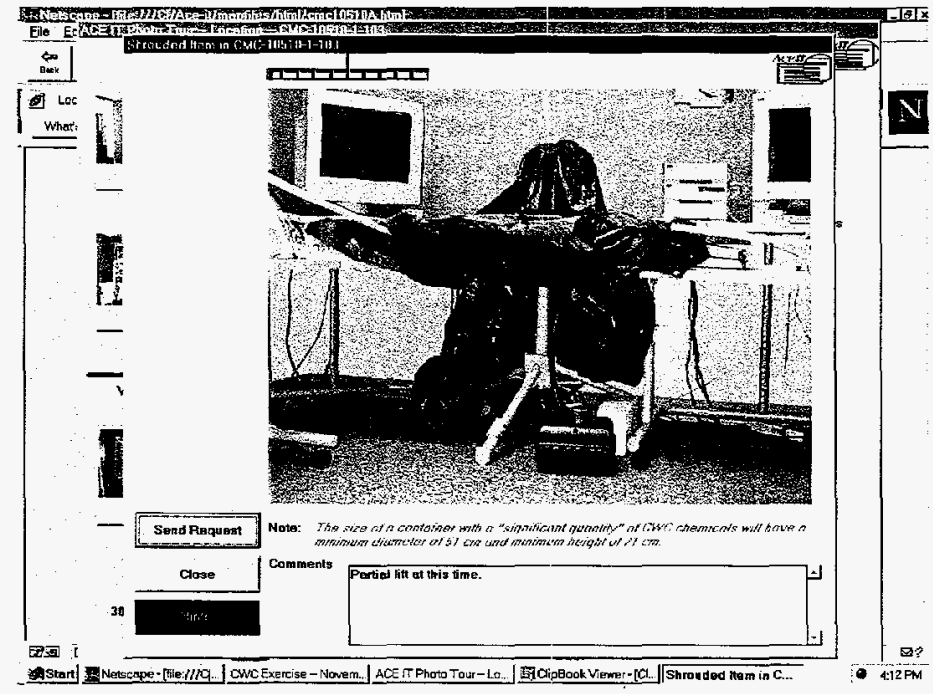

Figure 27. Inspection Team Views Partial Unshrouding 


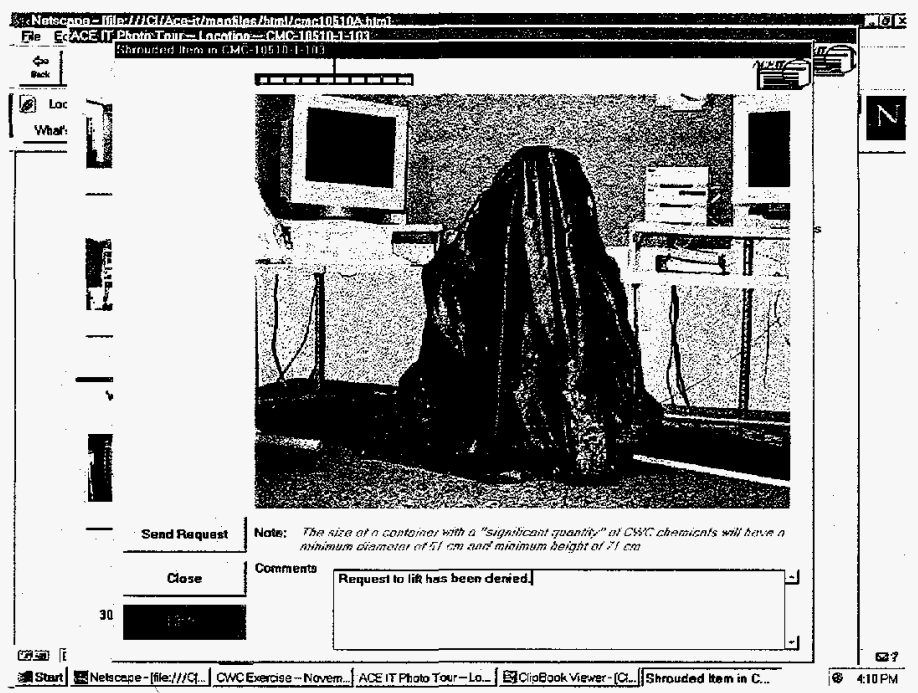

Figure 28. Inspection Team is Denied Permission to Lift Shroud

\subsubsection{Inspected Party}

The Inspected Party receives a request to lift a shroud. (See Figure 29.) The Lift Shroud window is displayed with the scroll bar set at $100 \%$, and the description and dimensions of the object are displayed. Slide the scroll bar and click Play to preview any percentage of the shroud lift. (See Figure 30.) If partial or complete unshrouding will reveal a sensitive object, click the Request Denied button. To send a more detailed response to the Inspection Team, enter any desired comments in the box labeled "Comments." If a partial or complete unshrouding of the item is granted, slide the scroll bar to the desired percentage of shroud lift, and click the Send Response button.

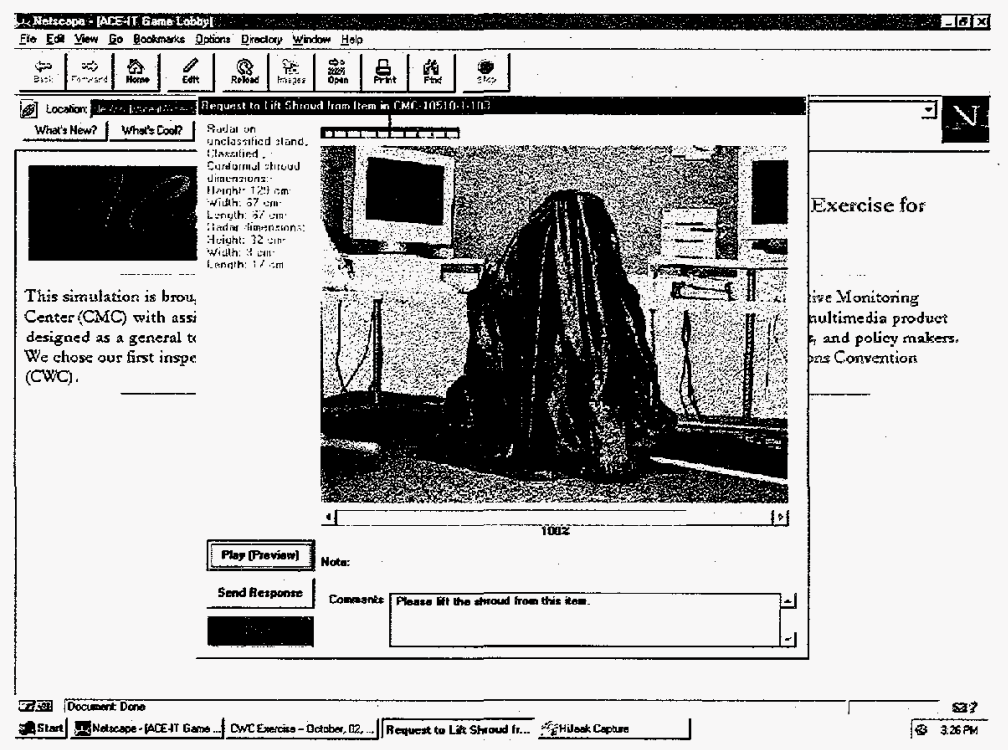

Figure 29. Inspected Party Receives Request to Lift Shroud 


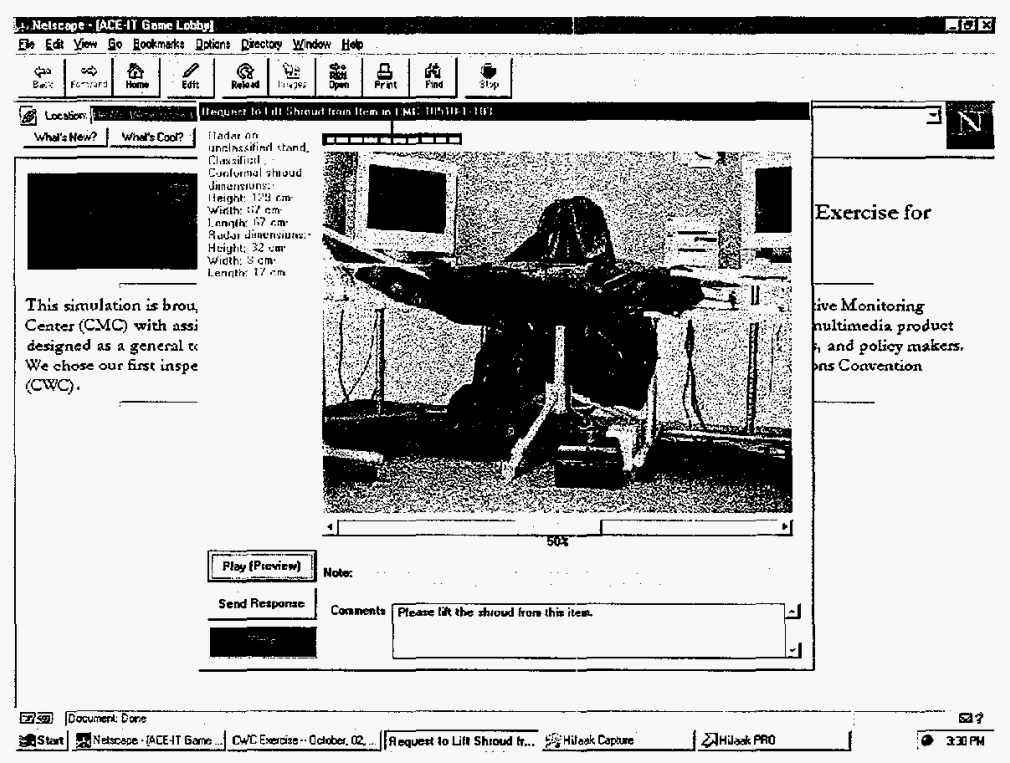

Figure 30. Inspected Party Previews Partial Lift of Shroud

\subsubsection{Alternate Information Negotiation}

Access to alternate information can only be requested once a request for physical access to a specific location has been made - requests for Alternate Information can only be processed for specific locations. Alternate information can be requested regardless of the response to a request for physical access. The Host may use external conferencing software, such as Netscape Communicator, to pass information to the Inspectors from the "Host's Exercise Manual".

\subsubsection{Inspection Team}

Alternate information can be requested from most of the Hints windows in the system. To request alternate information click the Hints button, then click the Alternate Information button. (See Figure 31.) Alternate information consists of seven topics: Chemical Sampling, Proprietary Research Information, Hazardous Waste Information, Inventory of Items, Inventory of Chemicals, Shipping and Receiving Records, and Employee Medical Records. (See Figure 32.) Click the Request All Alternate Data button to request all seven areas, or click any combination of buttons to request specific areas. Then click Send Request. The system will ask if the user would like to add specific comments to this request. If the answer is yes, a text box will appear in the bottom of the Alternate Data window. Type comments in this box, and click the Send Request button again to send the request to the Inspected Party. (See Figure 33.) 


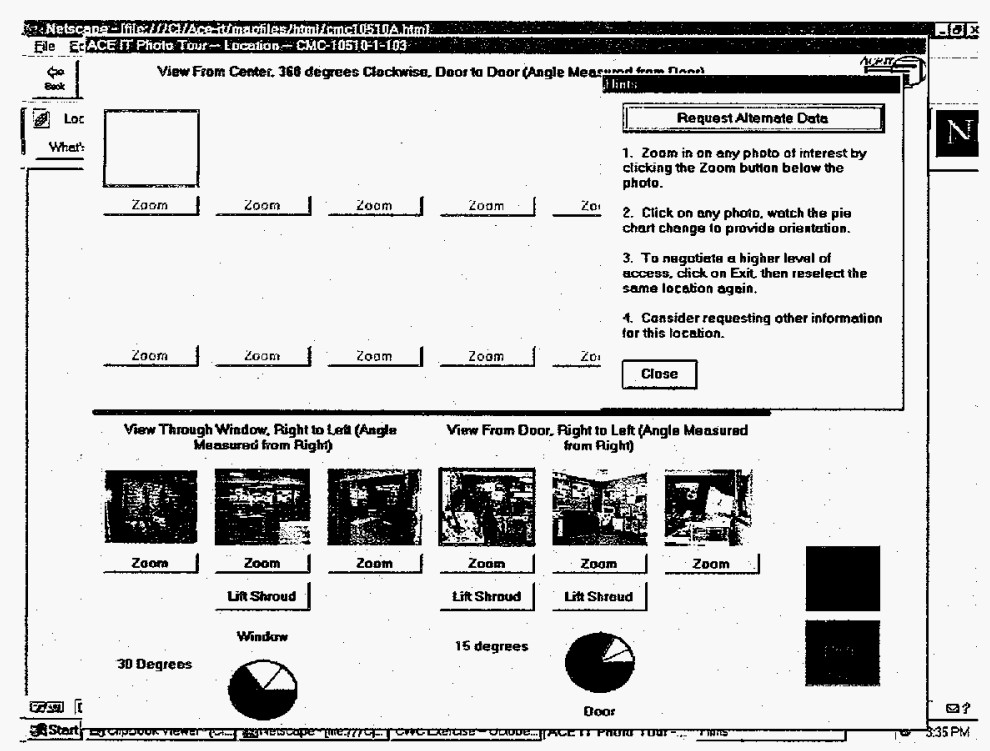

Figure 31. Inspection Team Requesting Alternate Information

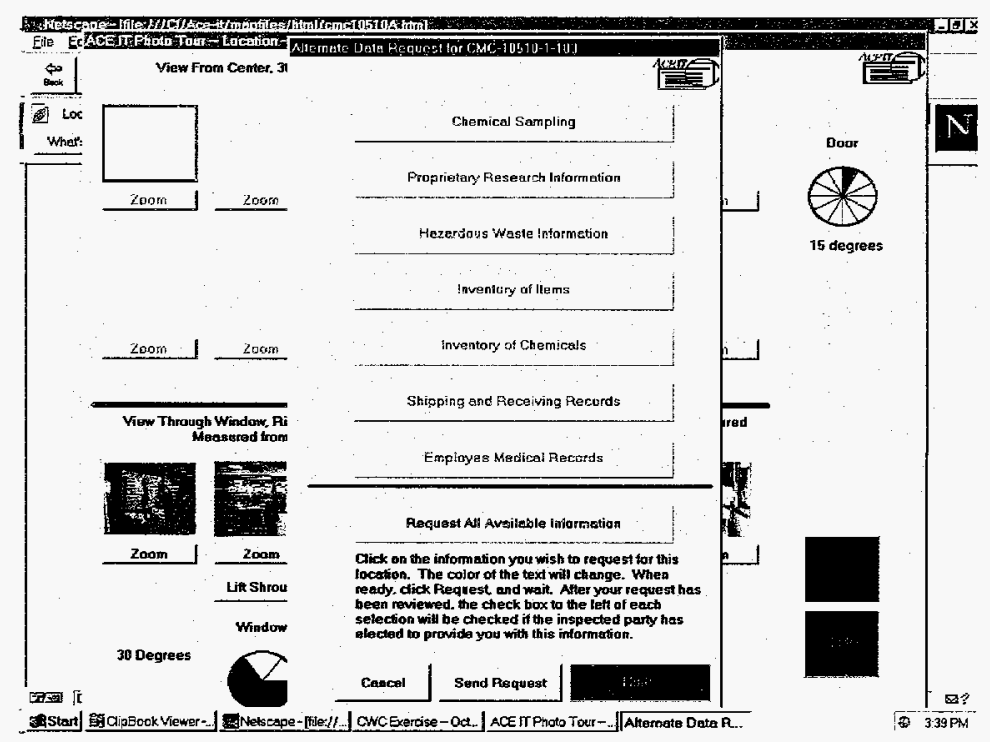

Figure 32. Inspection Team Requesting All Available Alternate Information 


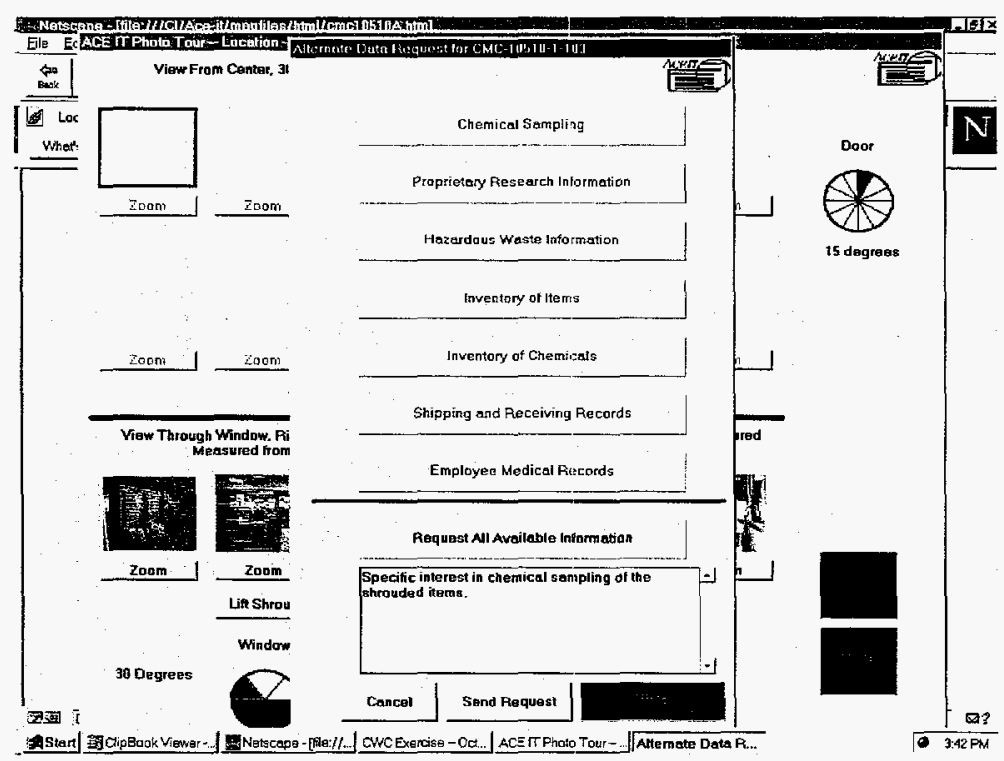

Figure 33. Inspection Team Adding Detail to Request for Alternate Information

A response is sent to the Inspection Team once the Inspected Party determines which types of alternate information will be provided. The topics of alternate information that the Inspected Party has agreed to provide are indicated by checks in the boxes on the left side of the window corresponding to each topic (See Figure 34.) Click the button next to the granted topic to view the available alternate information (See Figure 35.) If no data on the requested topic are available, the user is notified with a message box. stating which data are not available.

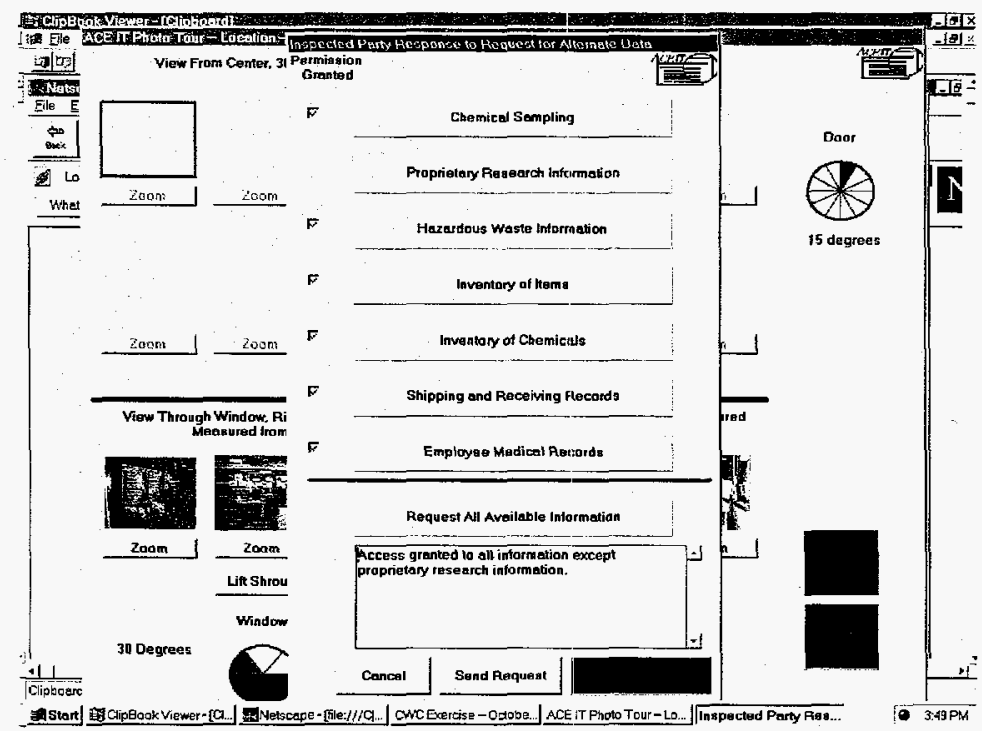

Figure 34. Granted Alternate Information 


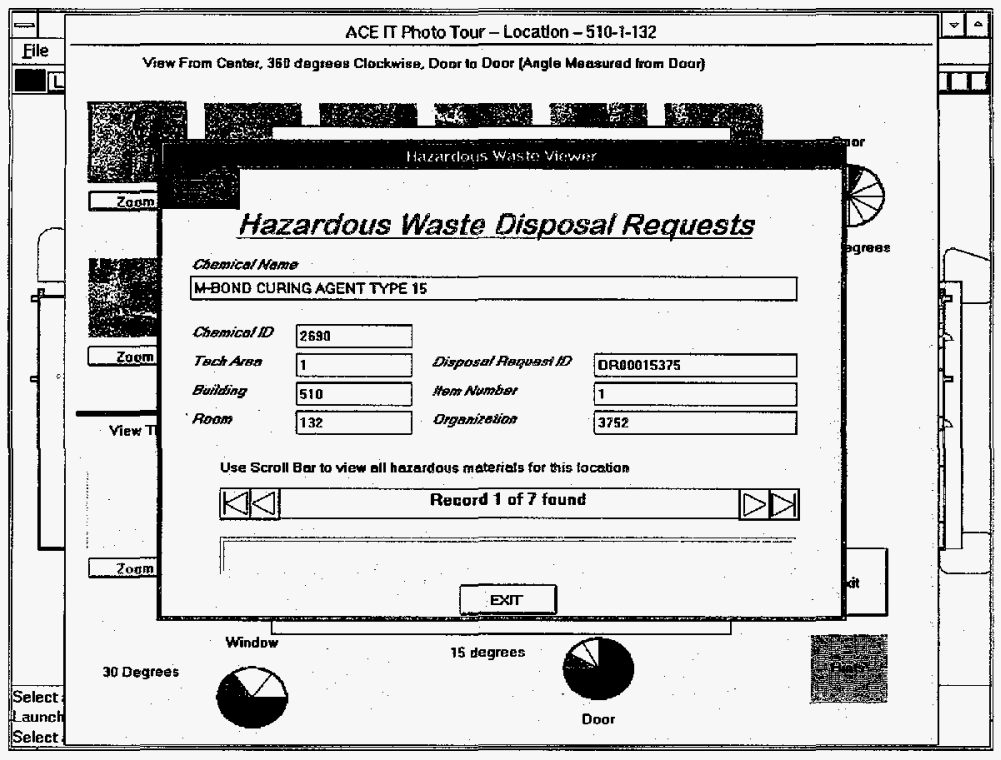

Figure 35. Viewing Alternate Information (Hazardous Waste Information)

If the Inspection Team requests chemical sampling and if the Hosts grant permission to perform chemical sampling, then the Inspection Team begins processing a chemical sample by clicking on the Chemical Sampling button. To provide a greater sense of realism, chemical sample results are not returned immediately. The user is notified of the amount of time required for sample processing, and decides whether or not to continue with the sampling process. (See Figure 36.) If the user elects to process a sample, the window shown in Figure 37 appears. The Inspection Team then assigns a "Sample ID" (identification), selects a "Sample Type," and adds any necessary detail in the box labeled "Location and Description of Sample." When the user clicks on the OK button, this window disappears.

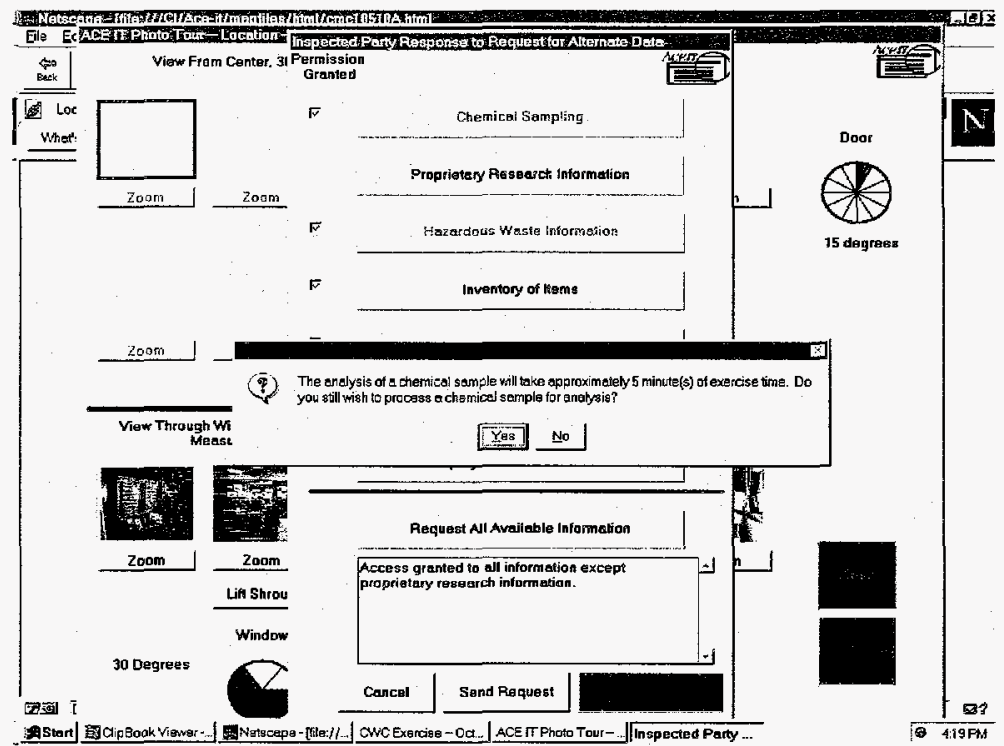

Figure 36. Inspection Team Receives Sample Analysis Time Delay Notification 


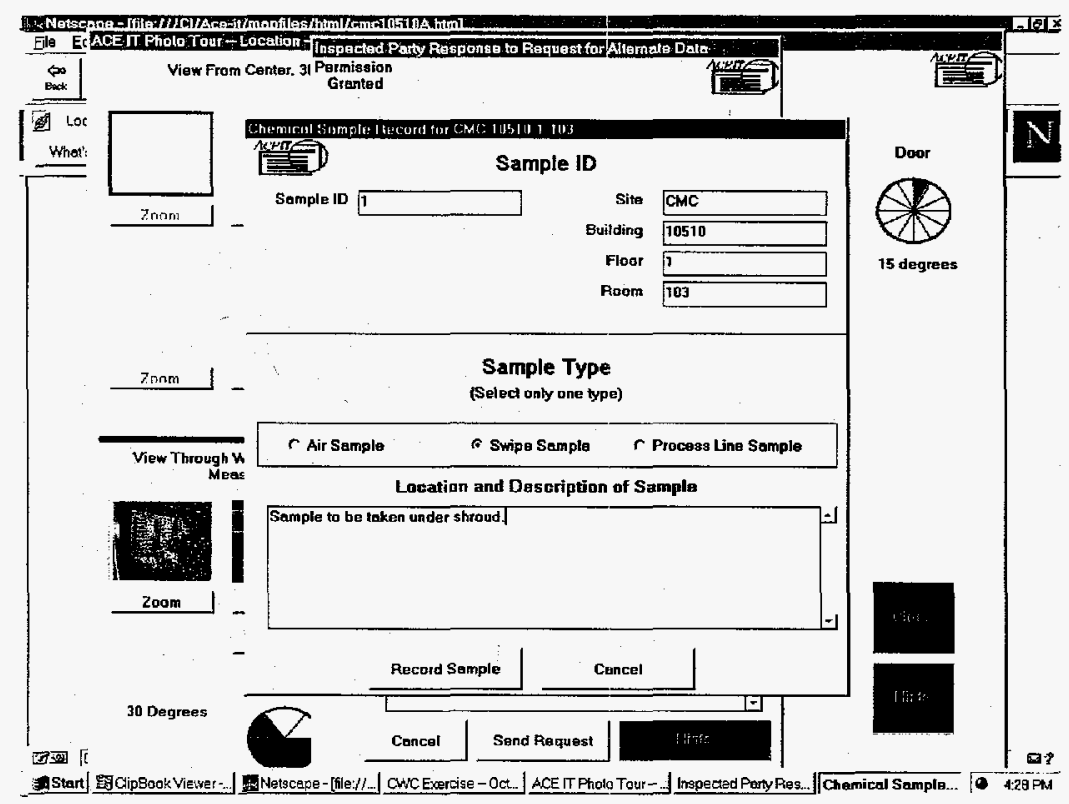

Figure 37. Inspection Team Records Sample Type and Analysis

When the amount of time required for sample processing has elapsed, the window shown in Figure 38 will. appear on the screen, regardless of any other actions in process.

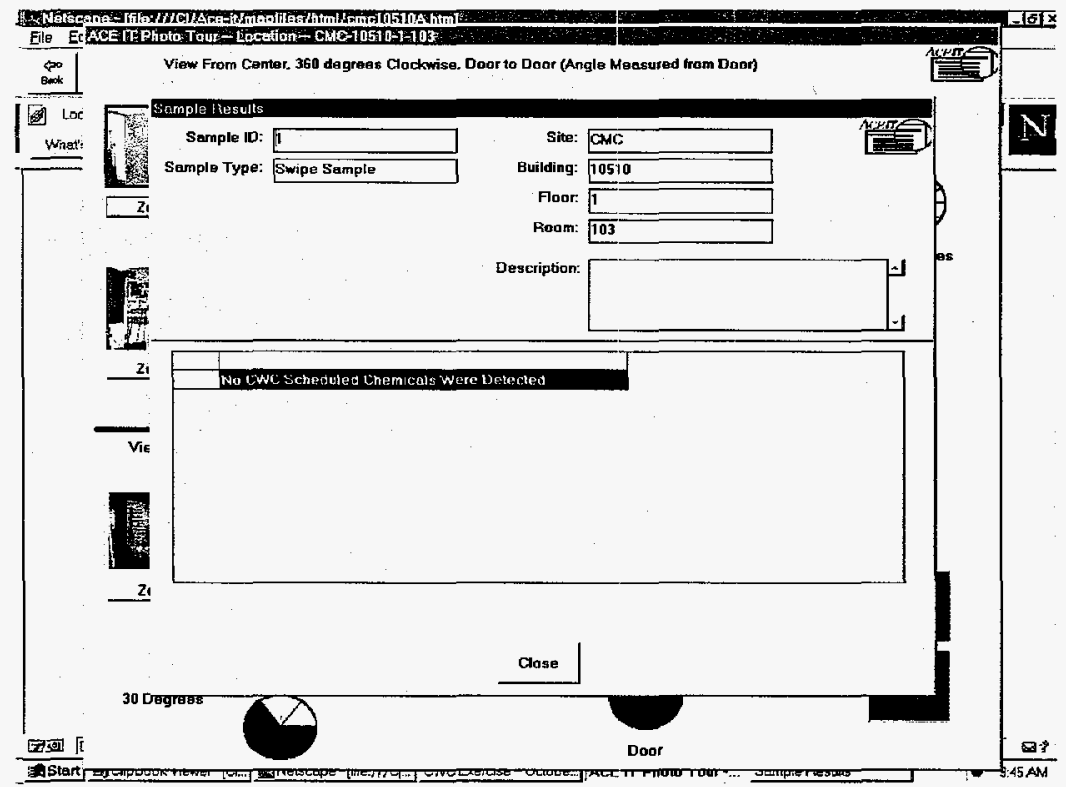

Figure 38. Inspection Team Receives Sample Results

\subsubsection{Inspected Party}

The Inspected Party receives a request for alternate information from the Inspection Team. The requested topics are indicated by checks in the corresponding boxes on the left side of the window. (See Figure 39.) The alternate information consists of seven topics: Chemical Sampling, Proprietary Research Information, Hazardous Waste Information, Inventory of Items, Inventory of Chemicals, Shipping and Receiving 
Records, and Employee Medical Records. Click any of the buttons to preview the alternate information. The Inspected Party responds to the Inspection Team by checking the boxes on the left side of the alternate information buttons. Any of the boxes may be checked if the Inspected Party wishes to provide the information to the Inspection Team.

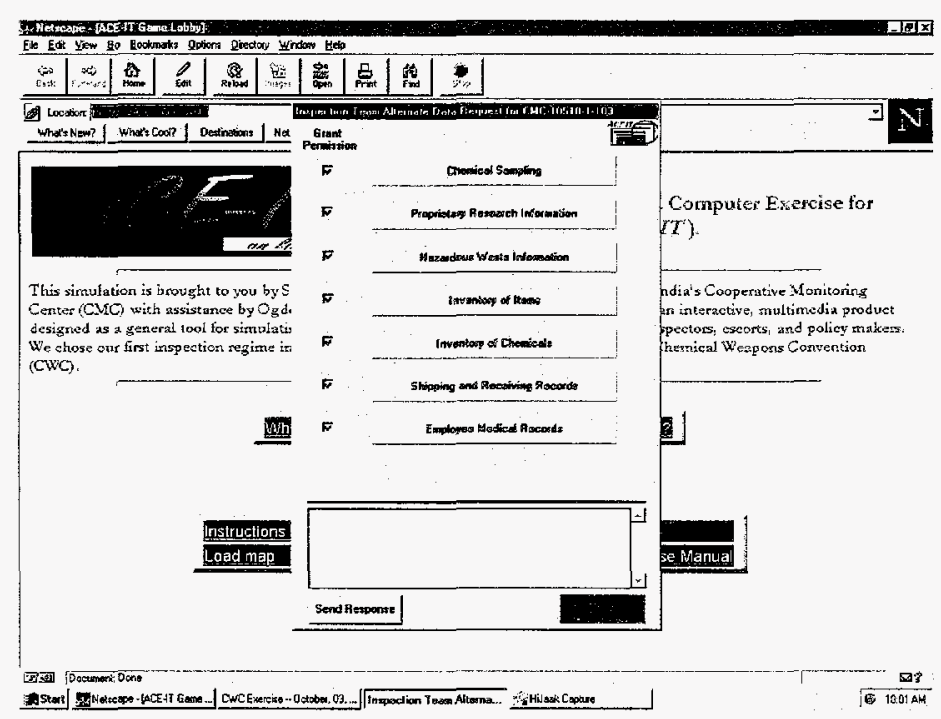

Figure 39. Receipt of Alternate Information Request

Chemical sampling can be initiated by clicking on the Chemical Sampling button. Once initiated, the Inspected Party can assign their own sample identification, sample type, and any desired details to the sample. They can then decide, based on the results of the sample, whether or not to allow the Inspection Team to process samples.

Proprietary research information can be previewed by clicking on the Proprietary Research Information button. (See Figure 40.) Since one of the core concepts of managed access is the legitimate protection of potentially sensitive information or items not related to the treaty, the Inspected Party must carefully consider the consequences of revealing information of this nature. If no information exists for the requested location, the user is notified with the appropriate message box. To close this window, click on the Close button. 


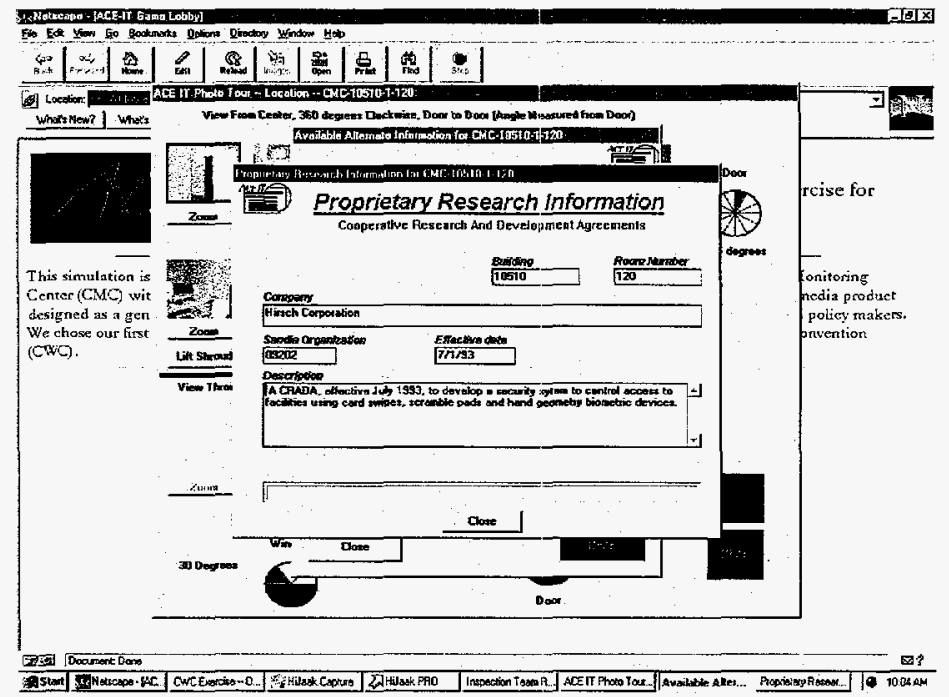

Figure 40. Inspected Party Views Proprietary Research Information

Hazardous Waste Information can be requested by clicking on the Hazardous Waste Information button. If no information exists for the requested location, the user is notified with the appropriate message box. Figure 41 shows the window displaying this information. To close this window, click on the Exit button.

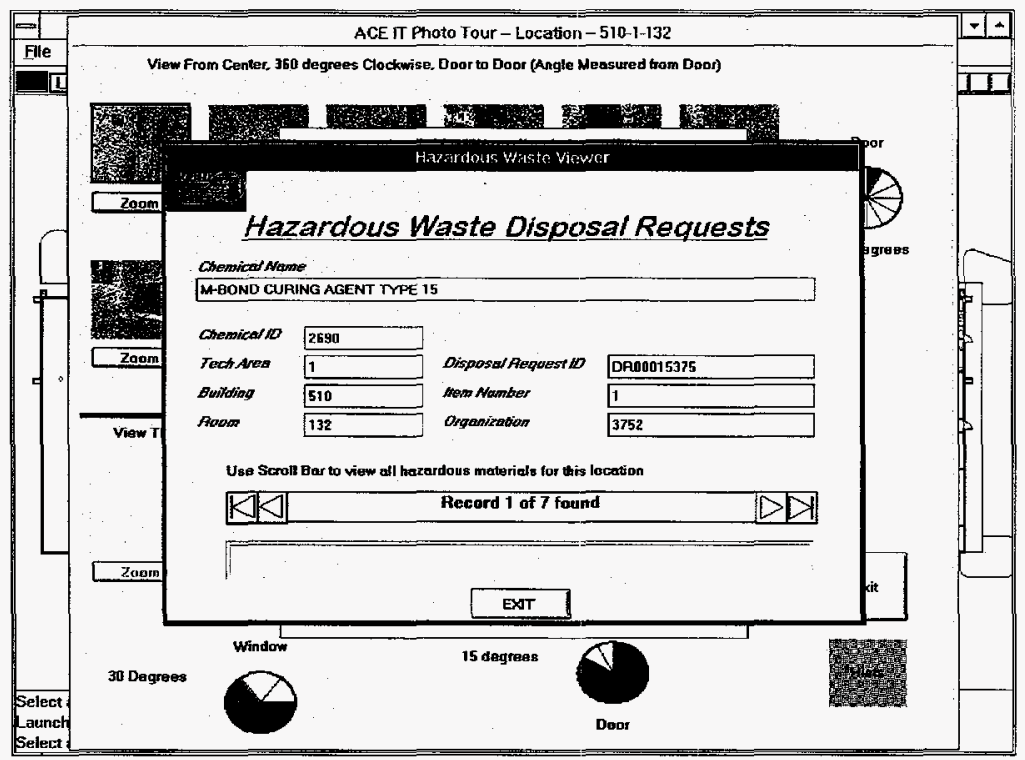

Figure 41. Inspected Party Views Hazardous Waste Information

The inventory of items can be requested by clicking on the Inventory Of Items button. If there is no inventory for the requested location, the user will be notified with the appropriate message box. Figure 42 shows the window displaying the inventory data. 


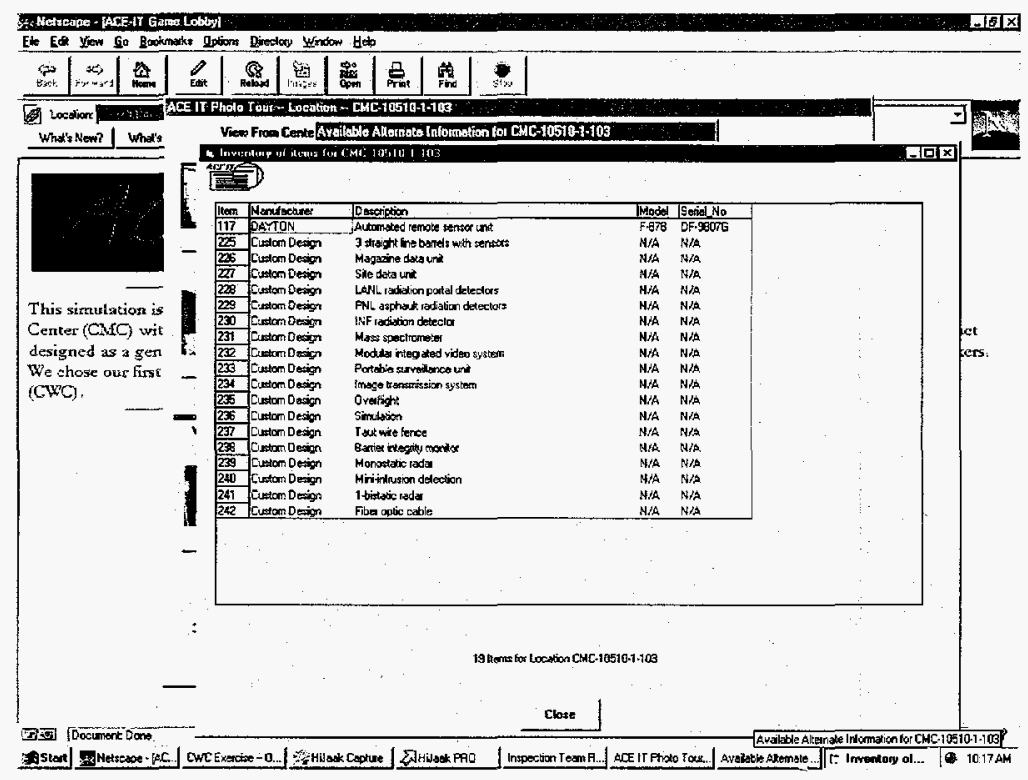

Figure 42. Inspected Party Views Inventory of Items

If access is granted to view the inventory, the Inspection Team receives all of the inventory data for the room. To close the window, click on the Close button.

\subsubsection{Ace-It Home Page}

At any time during the exercise, one may return to the ACE-IT Version 2.0 home page. Links to the Cooperative Monitoring Center (CMC) and the Organization for the Prohibition of Chemical Weapons (OPCW) home pages are also provided on the ACE-IT Version 2.0 home page. 


\subsection{EXERCISE EXAMPLE}

This section provides a series of sample inspection events that illustrate ACE-IT capabilities and provides a general program orientation to users. It does not provide detailed instructions on the use and application of individual modules. For more information on the individual negotiation modules for the inspection activity, see Section 3 .

The exercise begins at the ACE-IT Version 2.0 home page viewed with Netscape. The Inspected Party clicks on the Inspected Party (Host) button; the Inspection Team clicks on the Inspection Team button. Each team's start-up form must be filled in (See Section 2.0 and Appendix D), a Treaty selected, and an Inspection chosen. Each computer functions independently of the other, so it is not important which team starts first. Hosts will receive a message informing them that they are "waiting for a request" for access into an area. Inspectors may immediately click on the Load Maps button, click on a building, and select a room. They will then see a "waiting for response" message. (See Figure 43.)

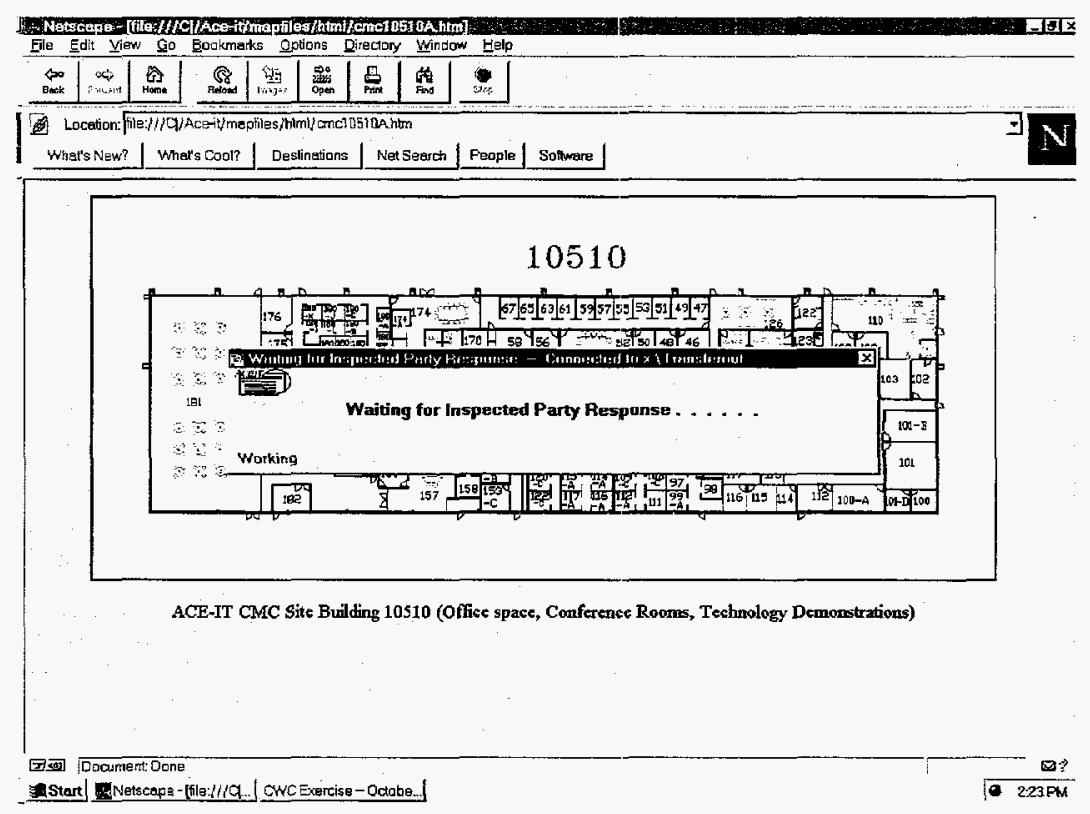

Figure 43. Inspection Team Initiates Request for Access

ACE-IT notifies the Inspected Party of the request. In this scenario, the initial response from the Inspected Party is to deny access to this location. (See Figure 44.) 


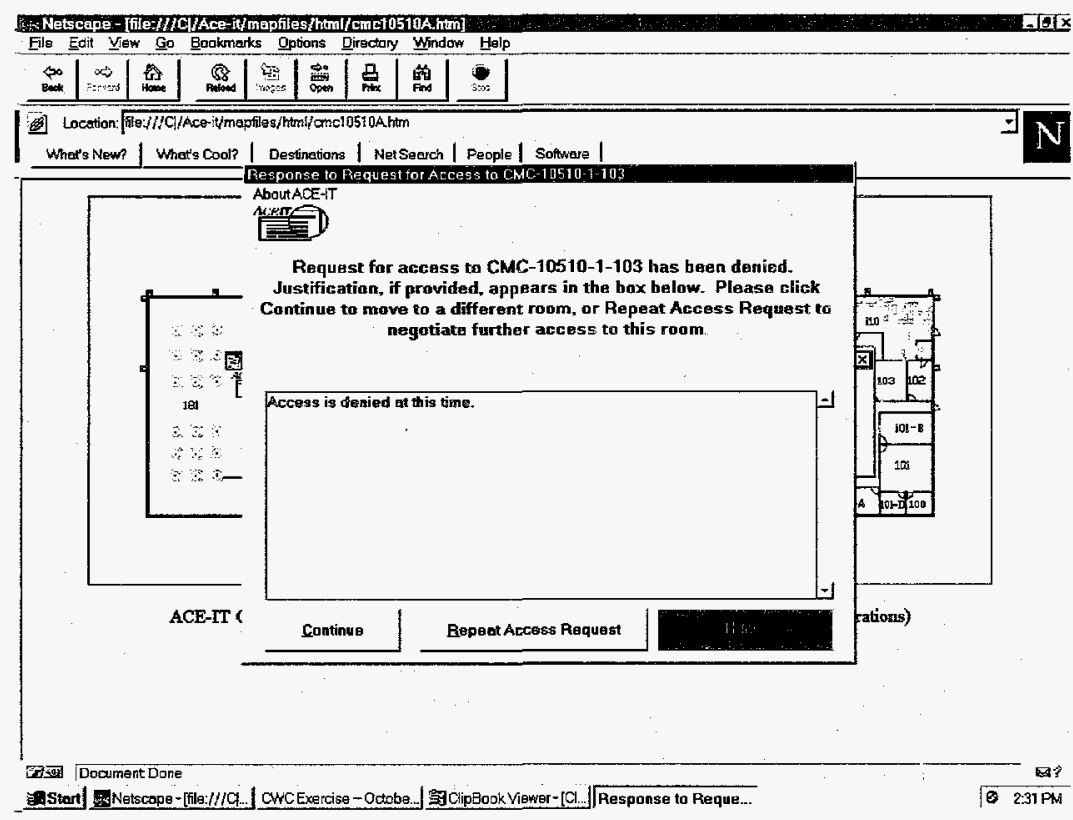

Figure 44. Inspected Party Denies Request for Access

The Inspection Team repeats the request for access to the room, justifying their request by stating that the door is large enough to admit a significant quantity of chemical weapons agent. (See Figure 45.)

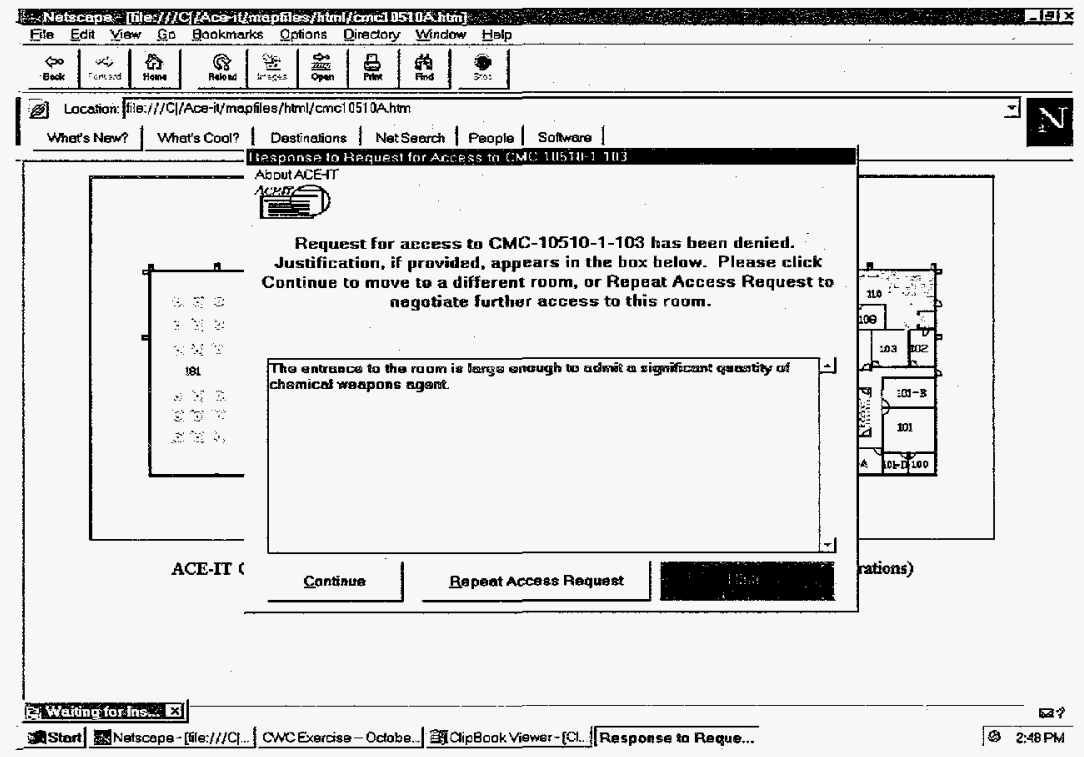

Figure 45. Inspection Team Repeats Request with Justification

The Inspected Party is notified of this second request, and decides to review the information available for this location before granting any level of access. The Inspected Party previews the room photo tour by clicking the Hints button on the request window, and then clicking the Preview Room button. (See Figure 46.) While previewing the photo tour for the requested location, the Inspected Party sees a number of large shrouded items in the room and decides to lift one of the shrouds to view what is underneath. (See Figure 47.) From the Photo Tour window, the Inspected Party clicks the Lift Shroud button located beneath a photo of the front right corner of the room, which contains a large, shrouded item. The window displays the digital photographic image of the shrouded item, along with a description of the item and its 
basic dimensions. The user moves the scroll bar at the bottom of the screen to $100 \%$ and clicks the Play button. The shroud is lifted to reveal a sensitive radar. (See Figure 48.) After previewing the room, the Inspected Party exits the lift-shroud and photo-tour windows and returns to the request window by clicking on Close.

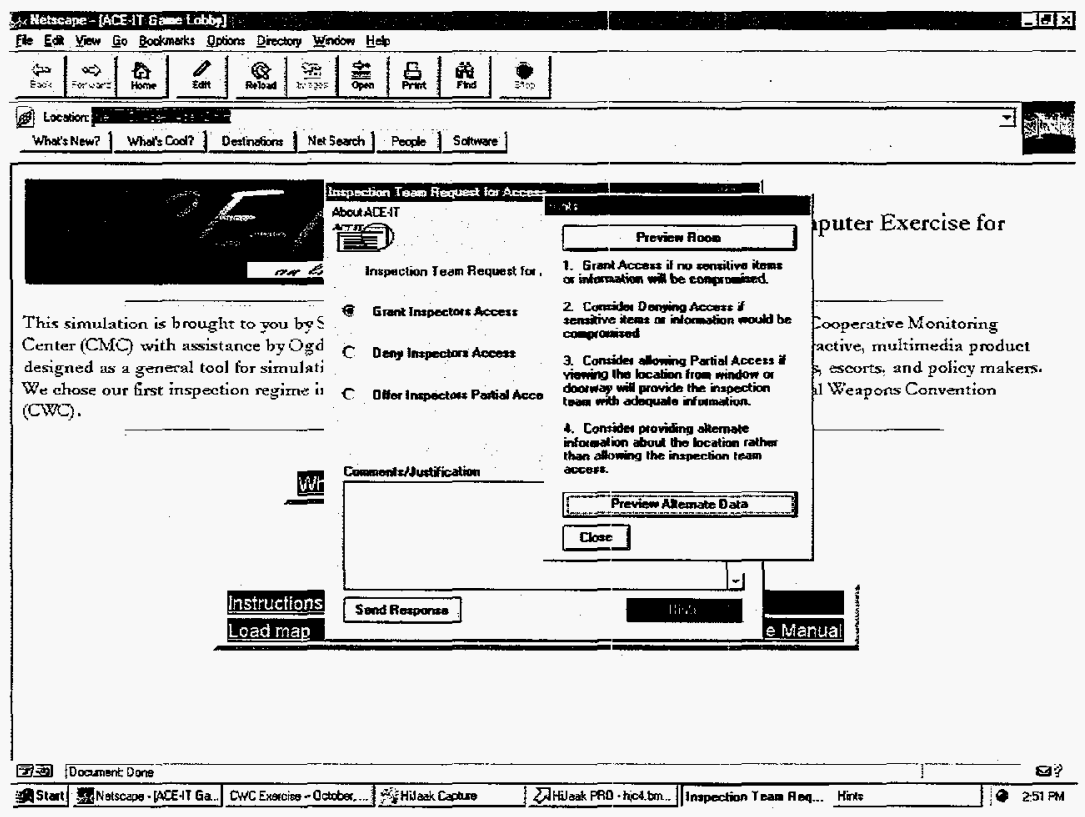

Figure 46. Inspected Party Previews Room

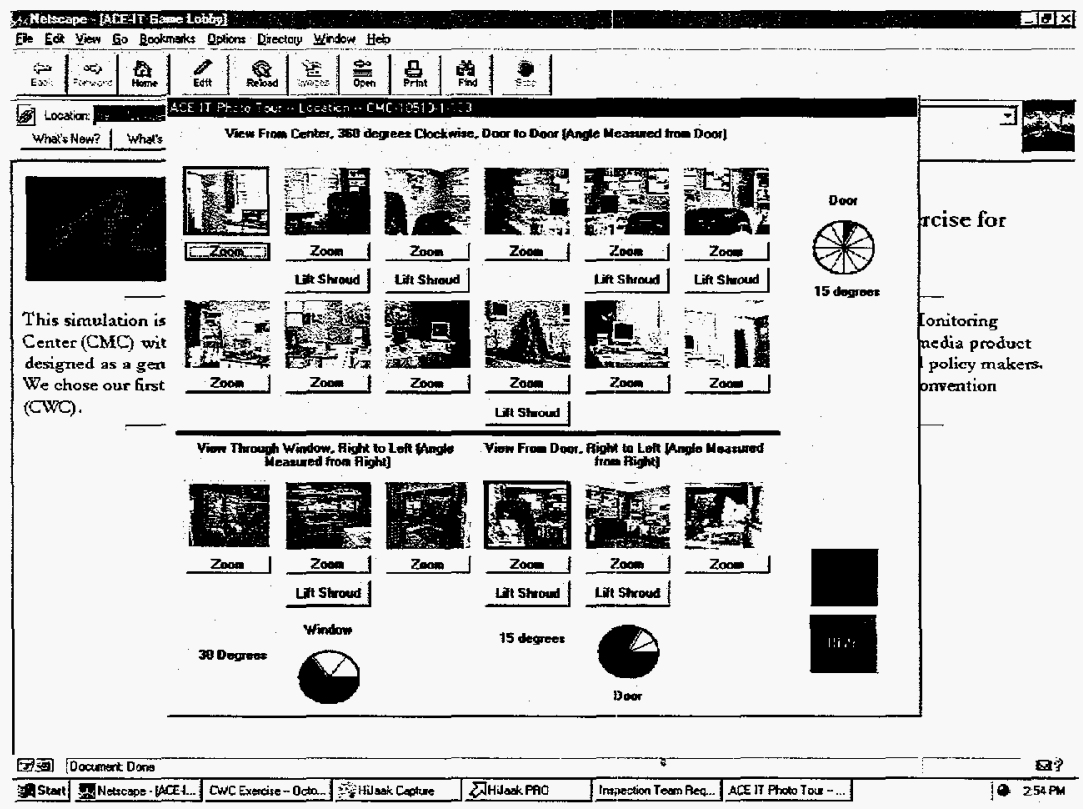

Figure 47. Inspected Party Previews Requested Location 


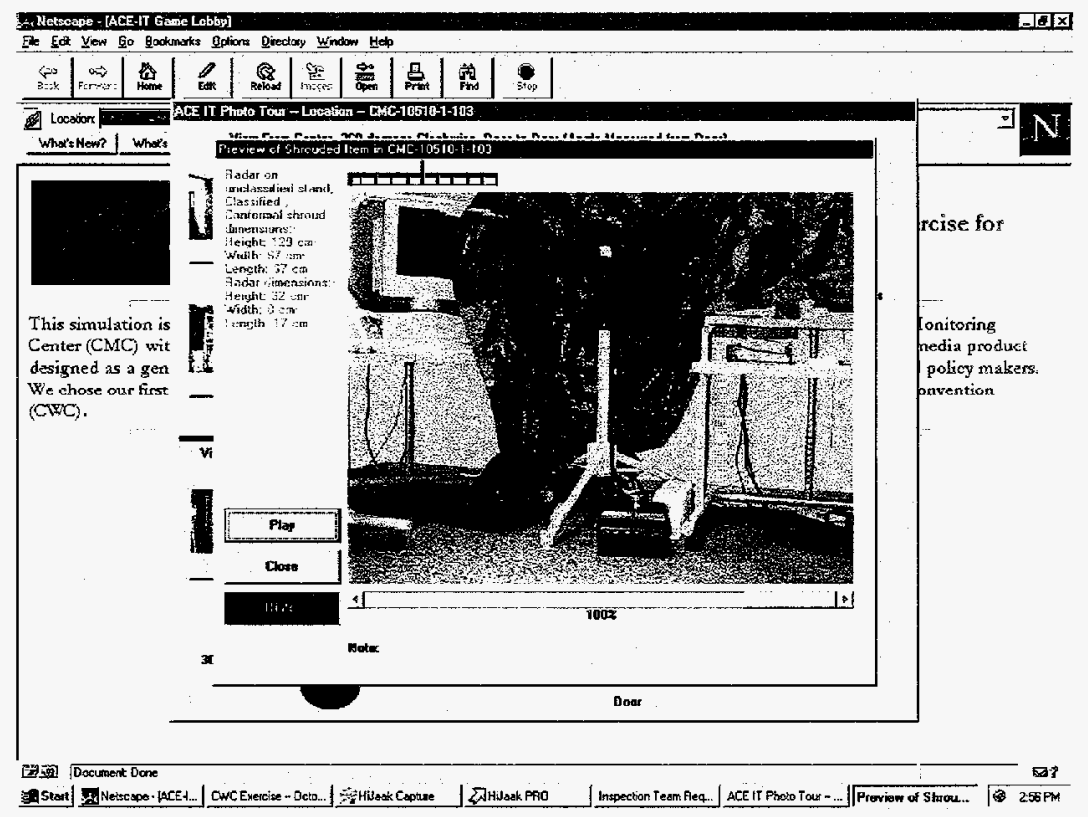

Figure 48. Inspected Party Previews 100\% Lift of Shroud from Item

Based on the preview of the room, the hosts decide to provide only partial access. Partial access is selected by clicking the request window line labeled "Offer the Inspectors Partial Access." (See Figure 46.) The level of partial access is selected by checking the appropriate boxes that correspond to the available views. The level of access is justified by typing, "The entire room can be seen from the window and door." (See Figure 49.)

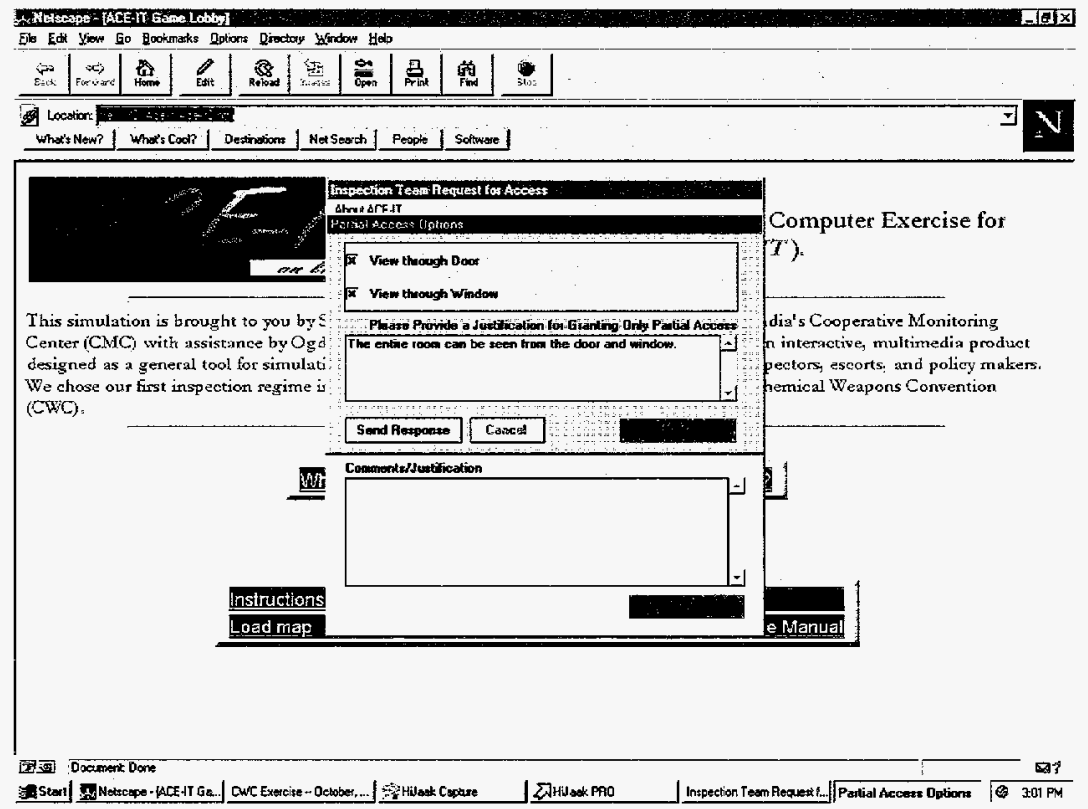

Figure 49. Inspected Party Grants Partial Access

The Inspection Team is notified that partial access has been granted. (See Figure 50.) The Inspection Team accepts the level of partial access based on the knowledge that further access can be requested if partial access is not sufficient. The Inspection Team clicks on the Continue button to view the Photo 
Tour of room 103. (See Figure 51.) The Inspection Team views the photos from both the door and window by clicking the Zoom button. (See Figure 52.) The Inspection Team then decides that the back left corner of the room is not adequately visible and that there are large shrouded objects of concern in the room. The Inspection Team exits the Photo Tour by clicking on the Exit button, returning to the map, and again requests full access to the room by clicking on the room.

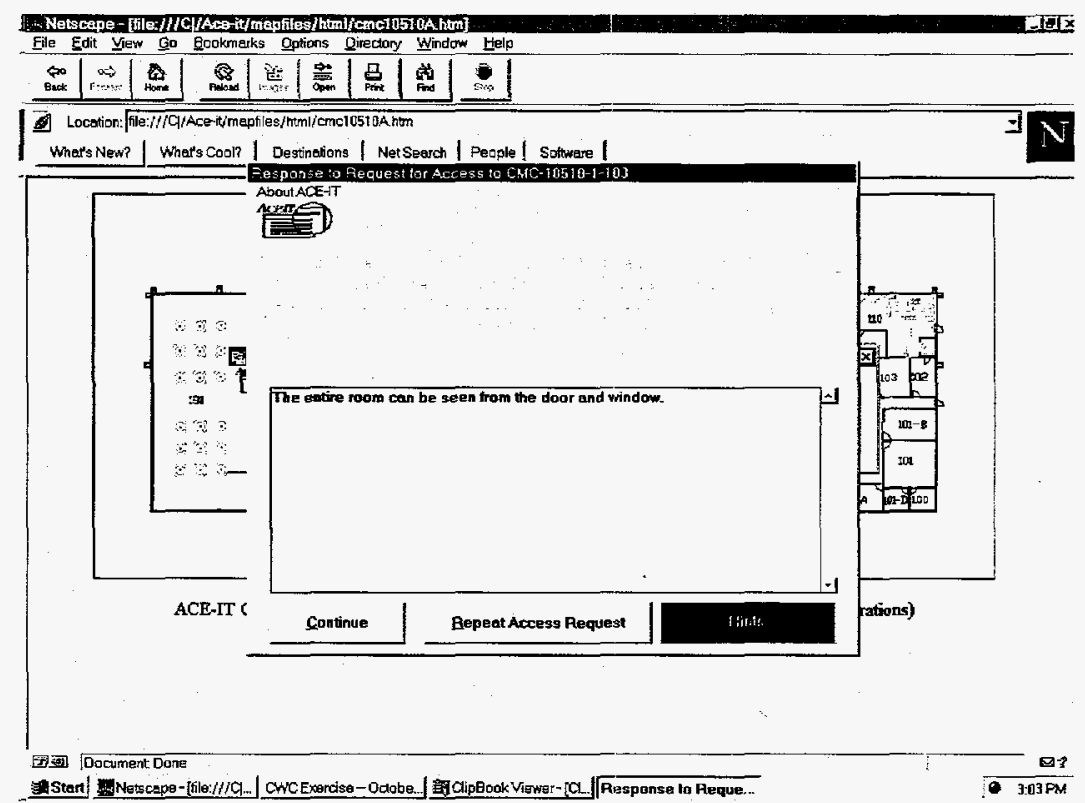

Figure 50. Inspection Team Receives Partial Access

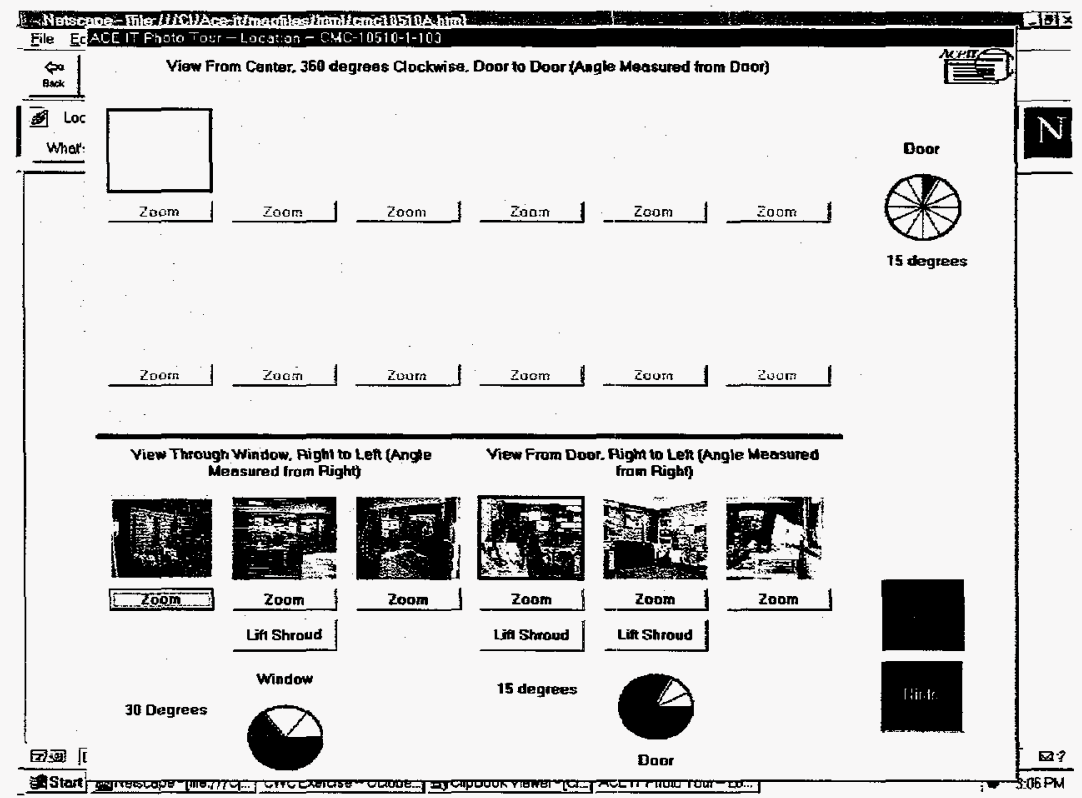

Figure 51. Inspection Team Views Partial Access 


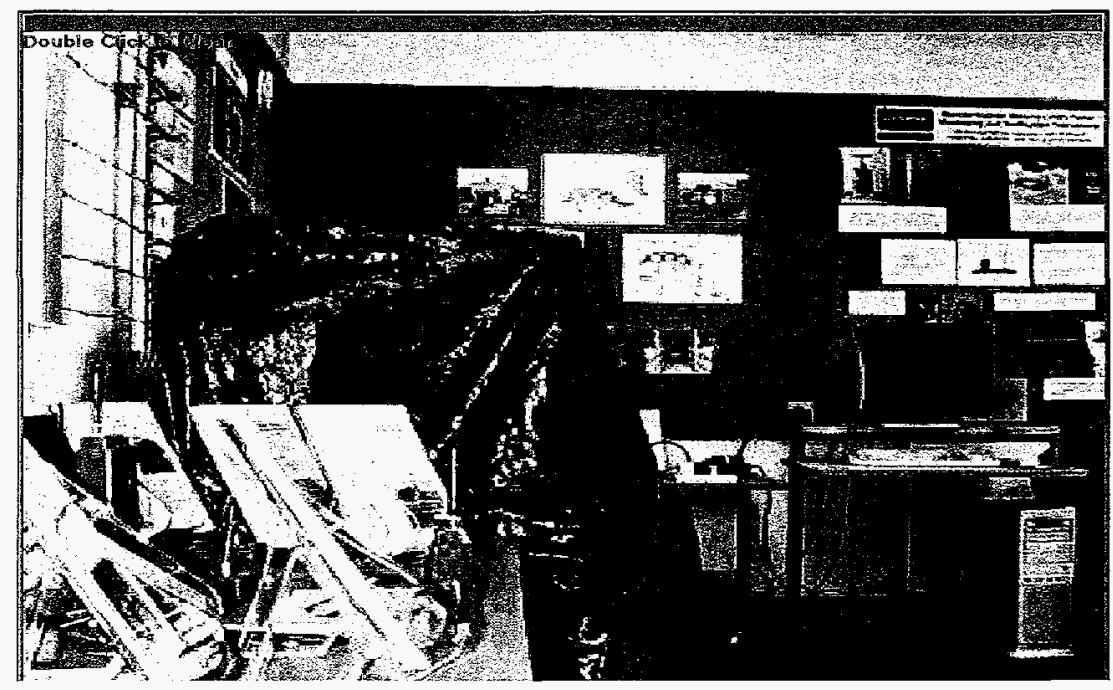

Figure 52. Inspected Party Views Zoomed Image

The Inspected Party receives the repeated request, and again provides partial access by clicking "Offer Inspectors Partial Access," and types, "I have already provided this level of access, why do you want to enter the room?" This can be done (1) verbally with the LAN version if the computers are near one another, (2) by telephone, (3) by using some form of network conferencing, (4) by using Netscape Communicator 4.0 for electronic messaging (see Appendix B), or (5) by using teleconferencing computers equipped with speakers and a microphone. The Inspection Team replies by clicking the Repeat Request button and typing "The back left corner of the room cannot be seen and there are large shrouded objects of concern in the room." (See Figure 53.)

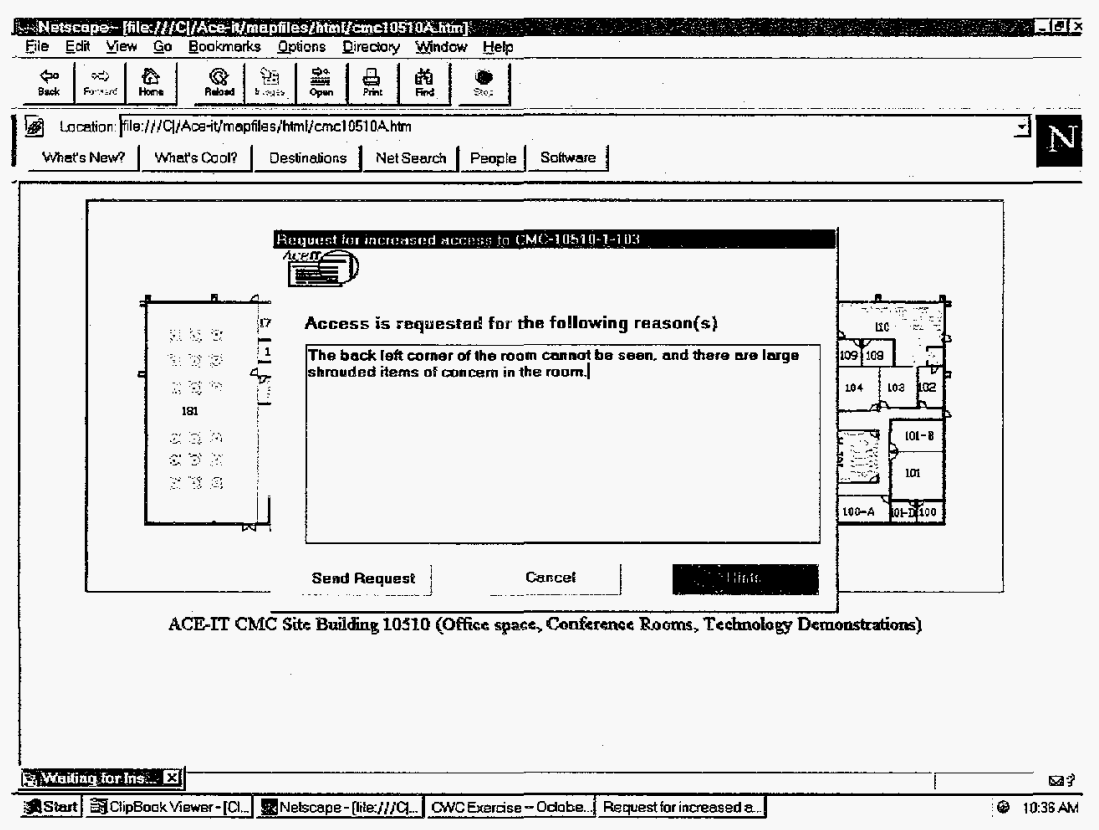

Figure 53. Inspection Team Requests Greater Access

The Inspected Party receives the Inspection Team's justification and decides that full access to the room may be granted. (See Figure 54.) 


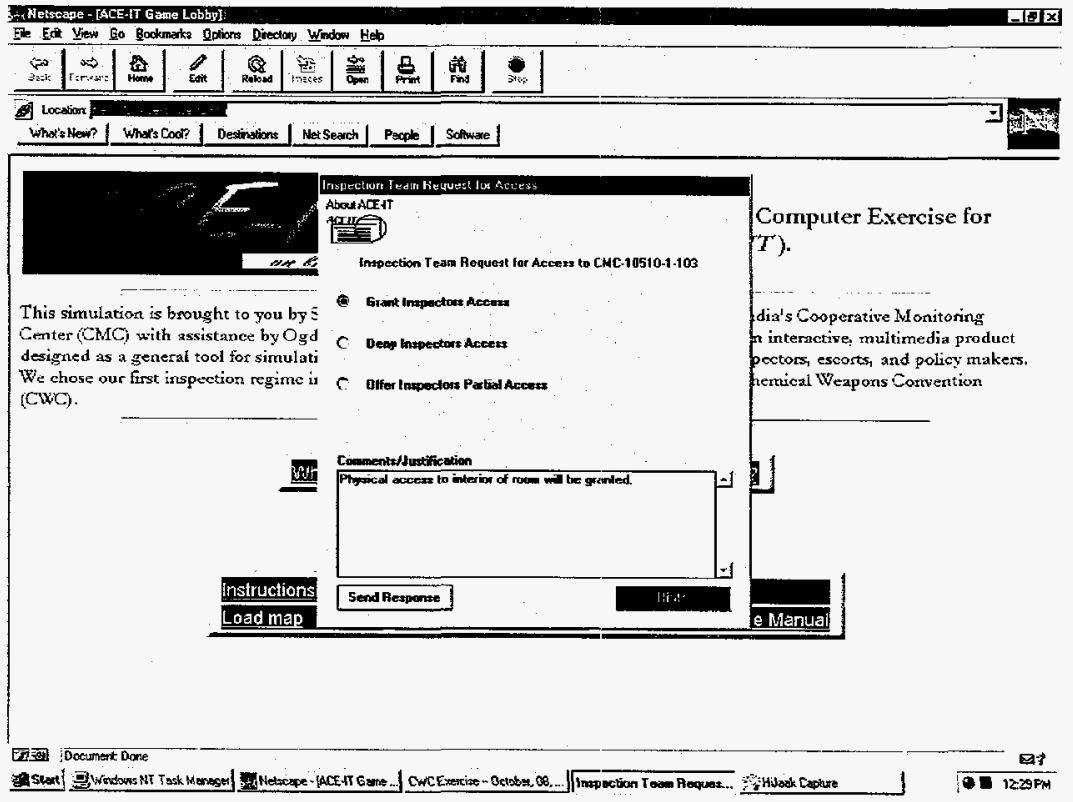

Figure 54. Inspected Party Grants Full Access

The Inspection Team is notified that full access has been granted, and clicks on Continue to fully view the room. (See Figures 55 and 56.)

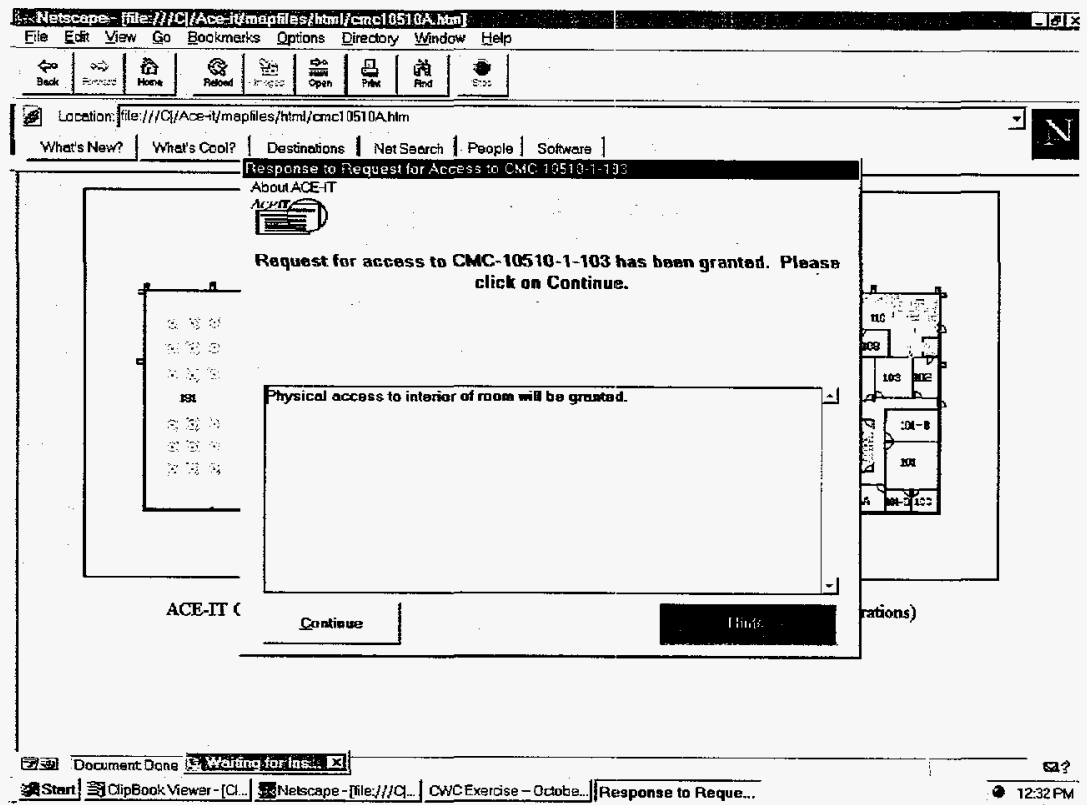

Figure 55. Inspection Team Receives Full Access 


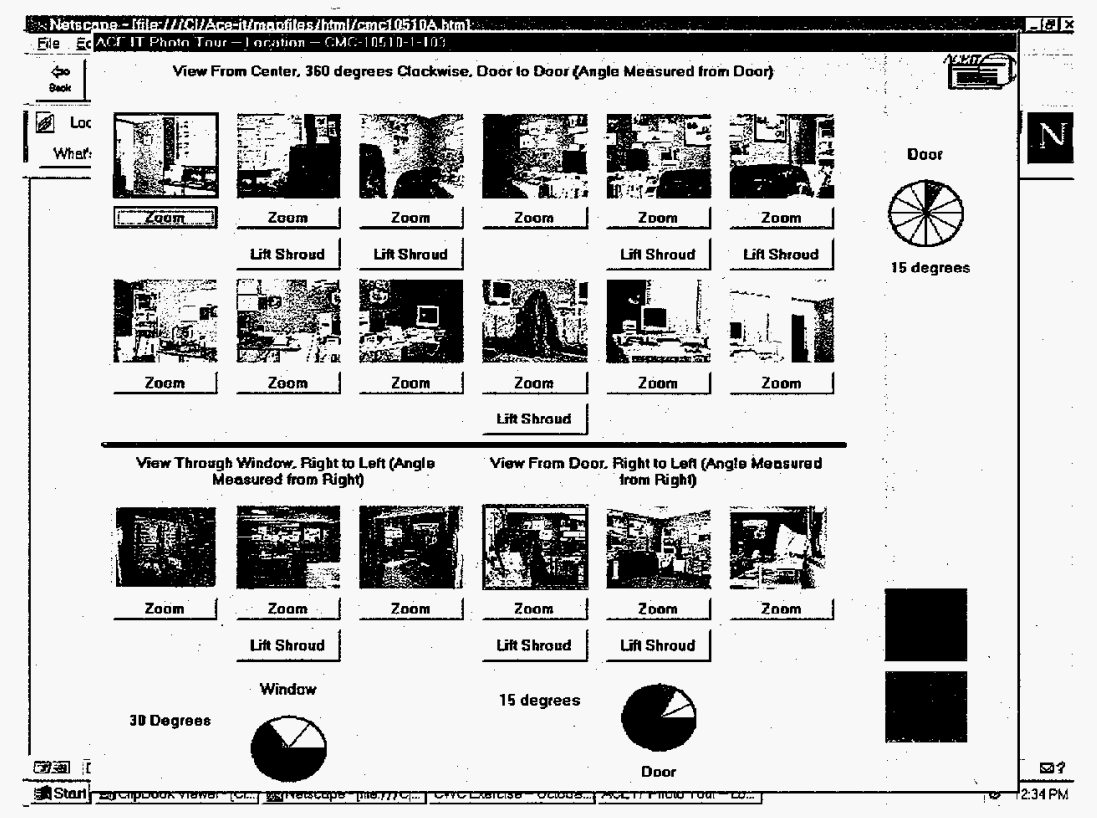

Figure 56. Inspection Team Views Full Access

The Inspection Team decides to request alternate information about the room. The Inspection Team first clicks the Hints button on the photo-tour window, then clicks the Request Alternate Information button on the Hints window. (See Figures 57 and 58.)

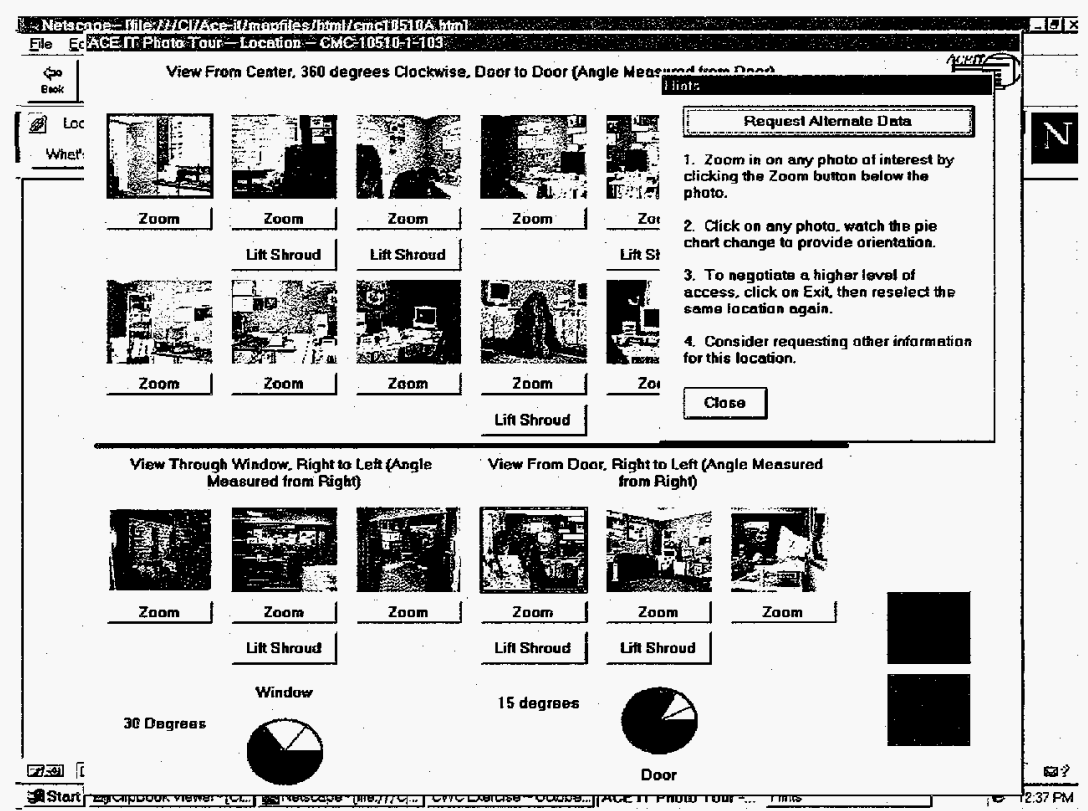

Figure 57. Inspection Team Views Hints Window from Photo Tour 


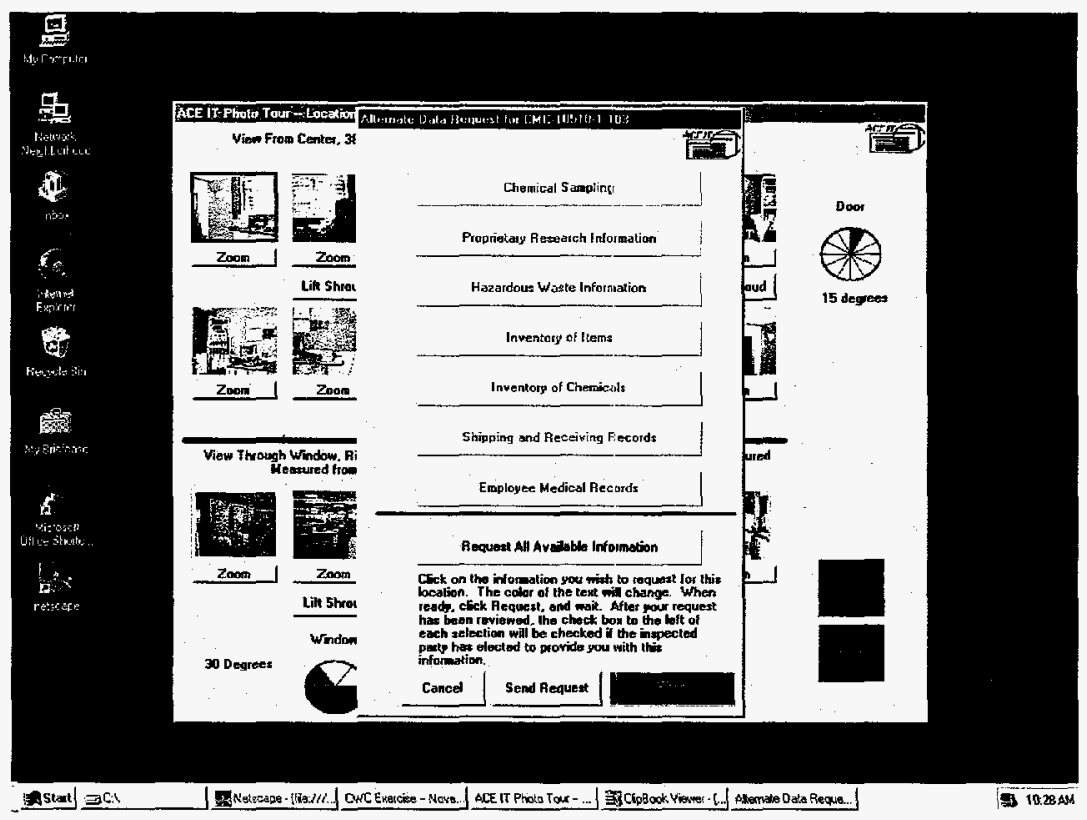

Figure 58. Inspection Team Requests Alternate Information

The Inspected Party receives the alternate information request (see Figure 59) and decides to allow only a chemical sample to be provided to the Inspection Team. The Inspected Party removes the checks from those boxes corresponding to the alternate information they are not willing to provide by clicking on the appropriate boxes.

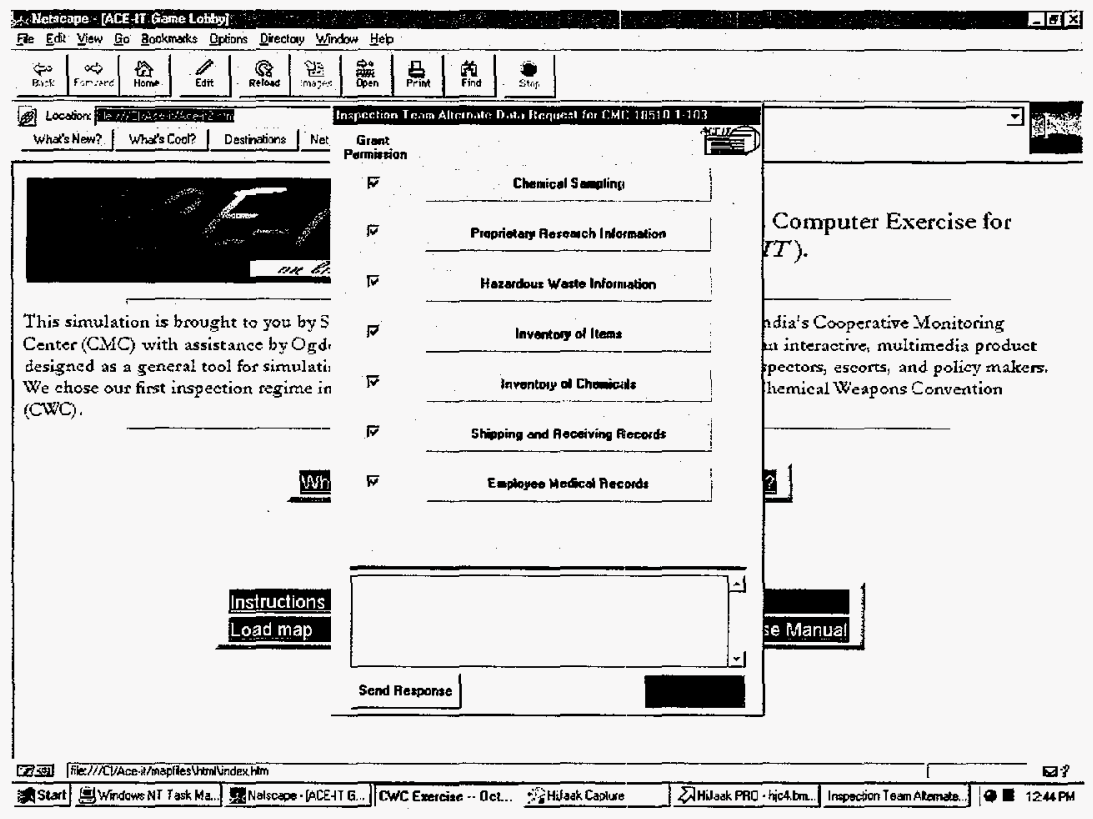

Figure 59. Inspected Party Receives Alternate Information Request

The Inspection Team is notified that chemical sampling will be allowed. (See Figure 60.) The Inspection Team decides that it would like the Inspected Party to take a chemical sample in the back left corner of the room, because the shrouded items are of concern. The Inspection Team clicks the Chemical Sampling button. The system notifies the team that there will be a delay before results are returned and asks if they 
would like to continue with the sample testing. The Inspection Team clicks on Yes to clear the message box, and enters the identifying information for the sample, including sample type. (See Figure 61.) It will be several minutes before the sample results are returned. The Inspection Team leaves the Alternate Information window by clicking on the Cancel button, and returns to the photo-tour window to continue the inspection. The Inspection Team requests that the shroud on the item in the front right corner of the room be lifted by clicking the Lift Shroud button below the front right corner picture. (See Figure 62.)

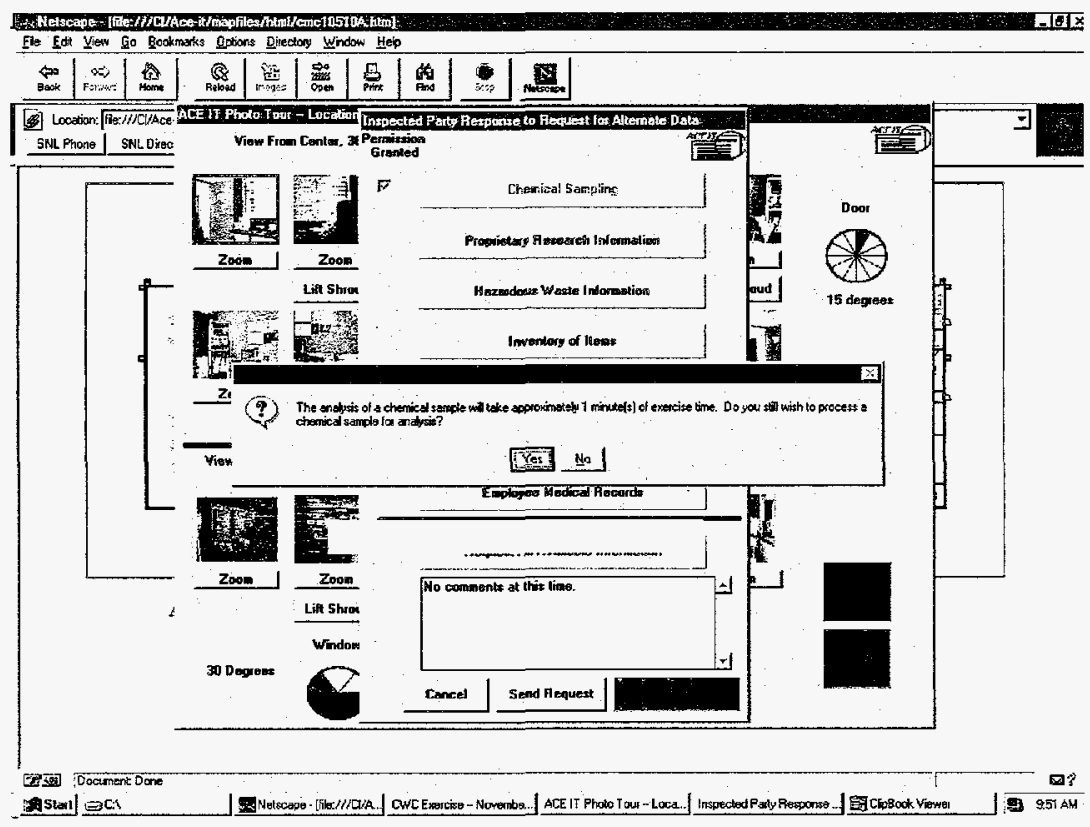

Figure 60. Inspection Team Requests Chemical Sample

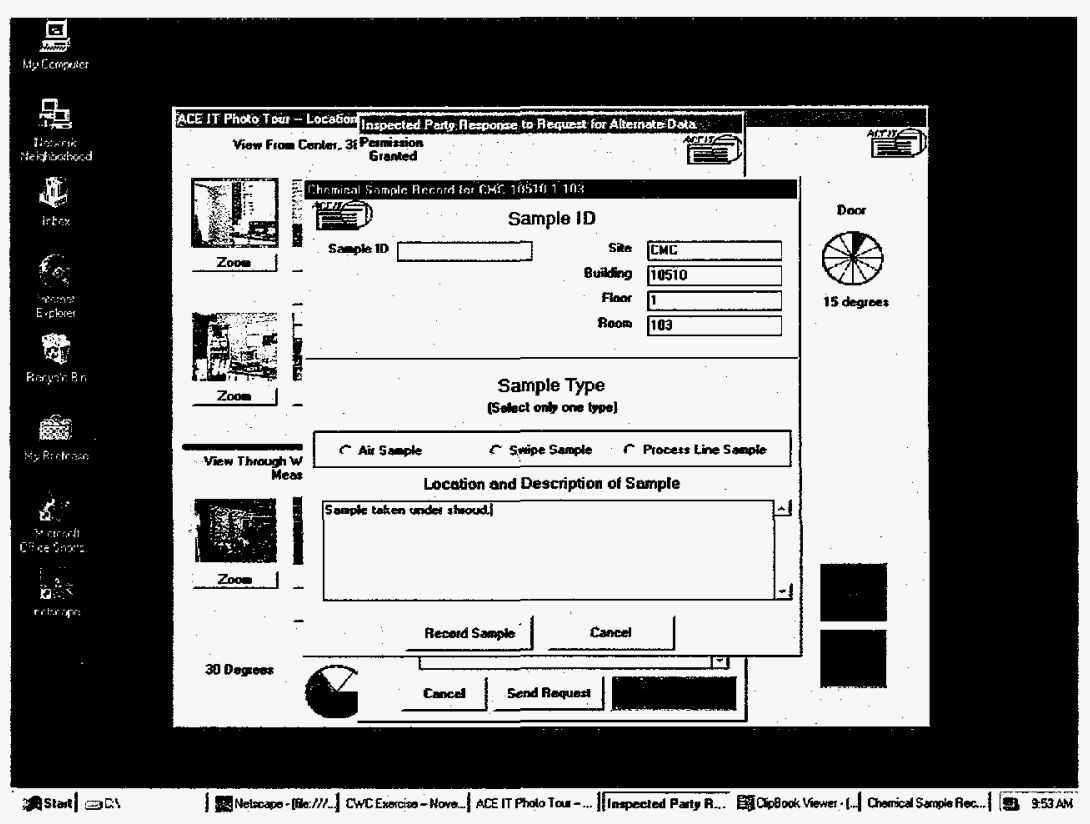

Figure 61. Recording of Chemical Sample 


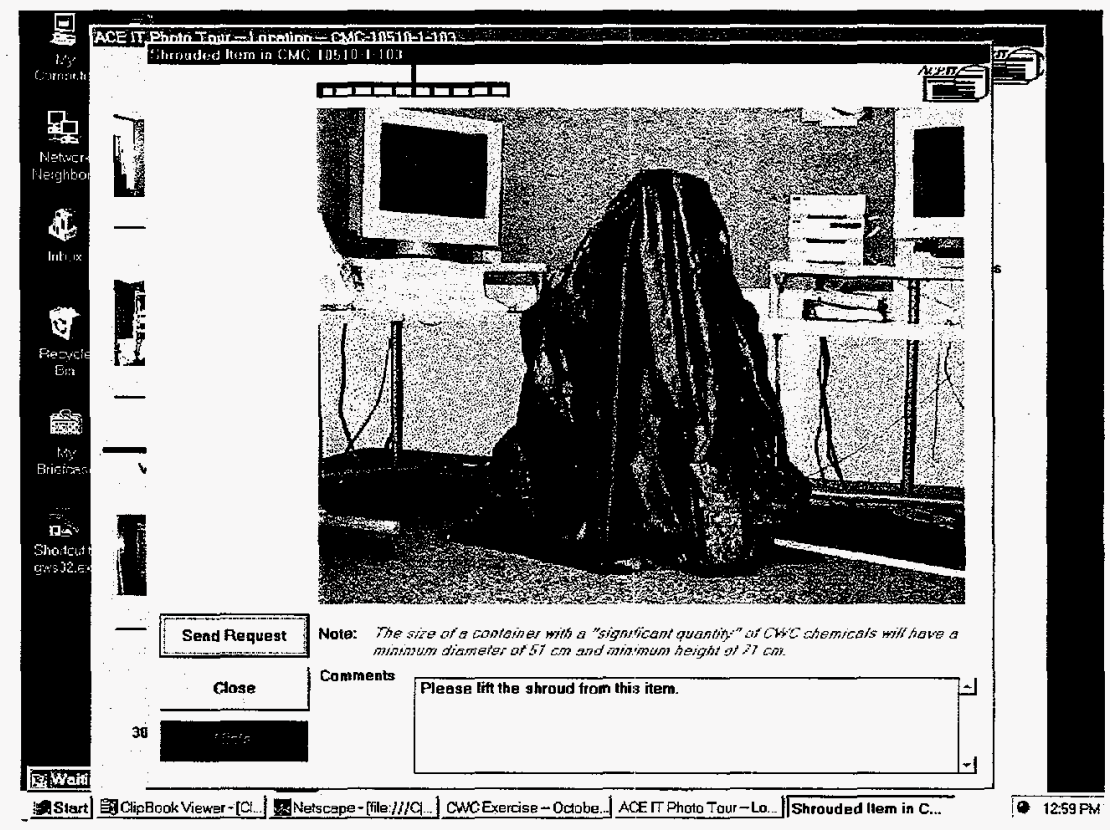

Figure 62. Inspection Team Views Shrouded Item

The Inspection Team receives the chemical sample results while negotiations are underway on lifting the shroud. The window presenting the sample results "pops" into place over the current window. In this scenario, the sample results are negative for any CWC-related chemicals. (See Figure 63.) The user closes the window by clicking on the Close button and returns to the lift-shroud request. The Inspection Team clicks on the Send Request button.

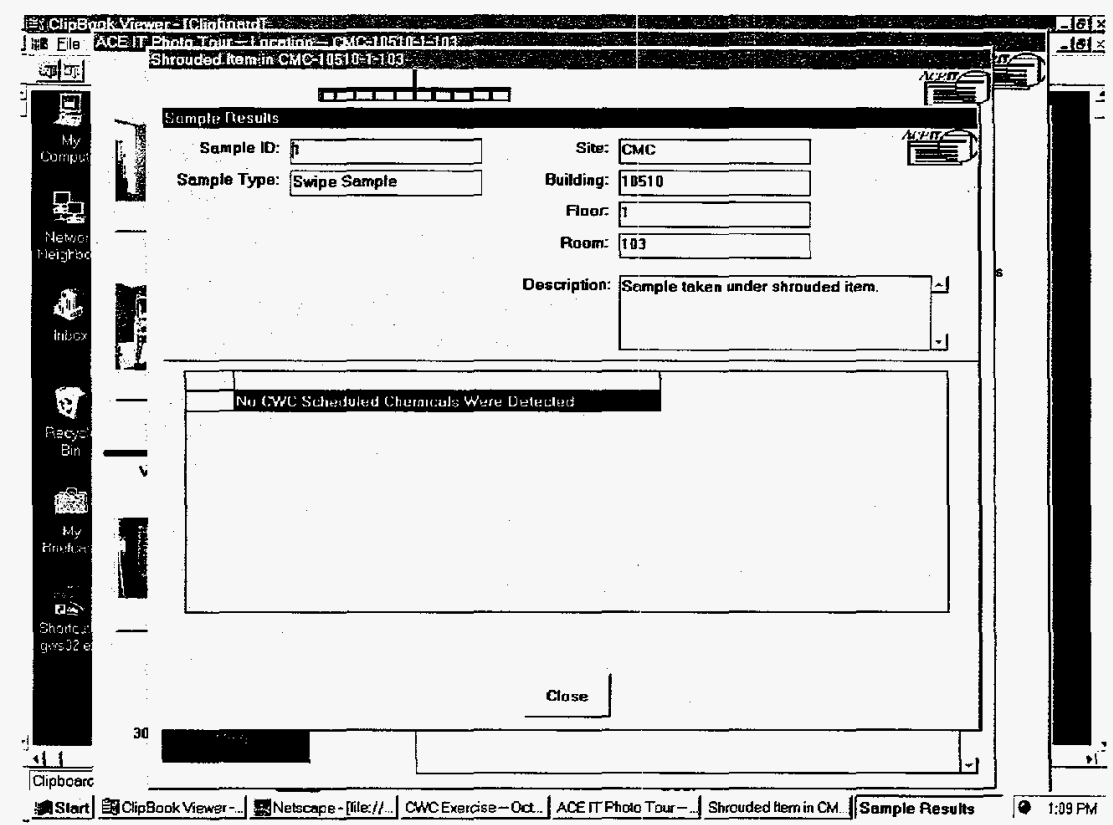

Figure 63. Chemical Sampling Results (Negative)

The Inspected Party receives the request to lift the shroud. The Inspected Party previews the shroud lift by sliding the scroll bar at the bottom of the screen to $100 \%$ and clicking Play. (See Figure 64.) The view, description, and dimensions of the object inform the Inspected Party that completely unshrouding this 
object would allow sensitive information - unrelated to the Chemical Weapons Convention - to be viewed by the Inspection Team. Therefore, the Inspected Party decides to allow the shroud to be lifted only halfway $(50 \%)$. This will allow the Inspected Party to show compliance, without revealing sensitive information that is unrelated to the Treaty. (See Figure 65.)

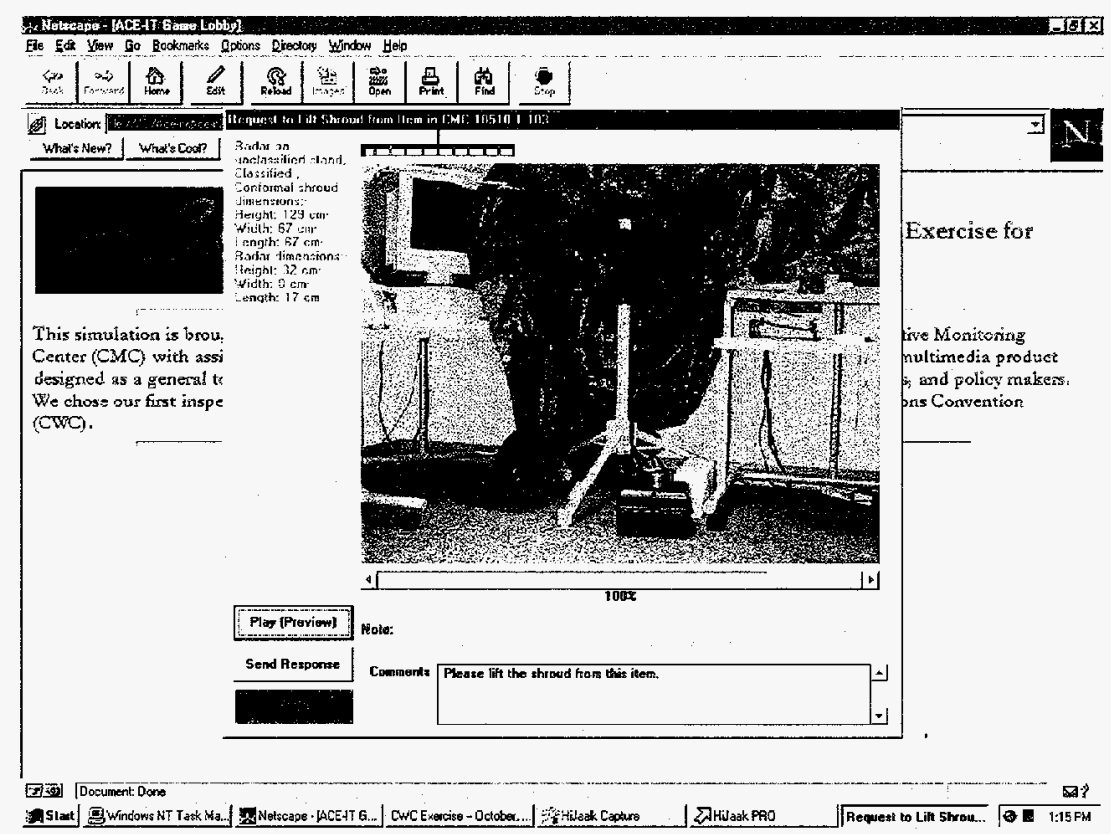

Figure 64. Inspected Party Previews Unshrouded Item

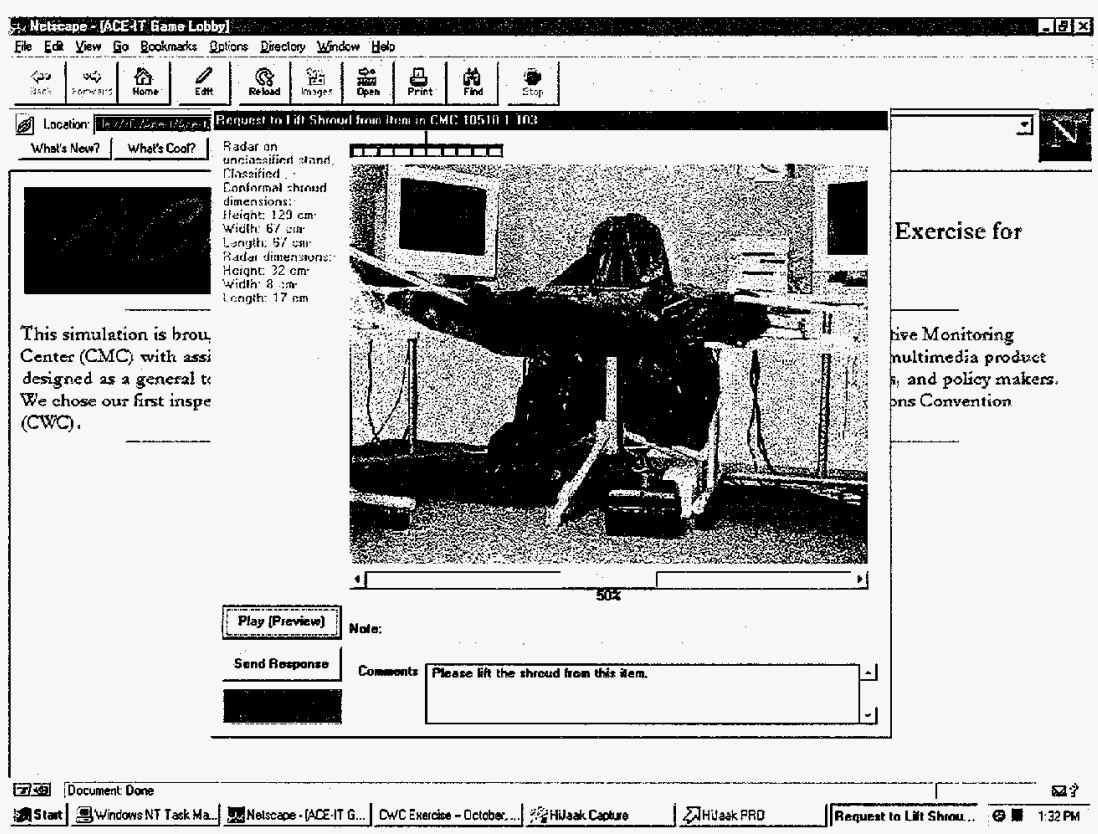

Figure 65. Inspected Party Previews 50\% Lift of Shroud from Item

The Inspection Team is notified by a chime that the shroud lift for the item requested is about to be displayed on the computer monitor. After several seconds, the shroud is lifted to expose $50 \%$ of the item. (See Figure 66.) Once the Inspection Team has seen that there are no objects of concern hidden under the shroud, they are satisfied with the inspection of this room and move on to another room. 


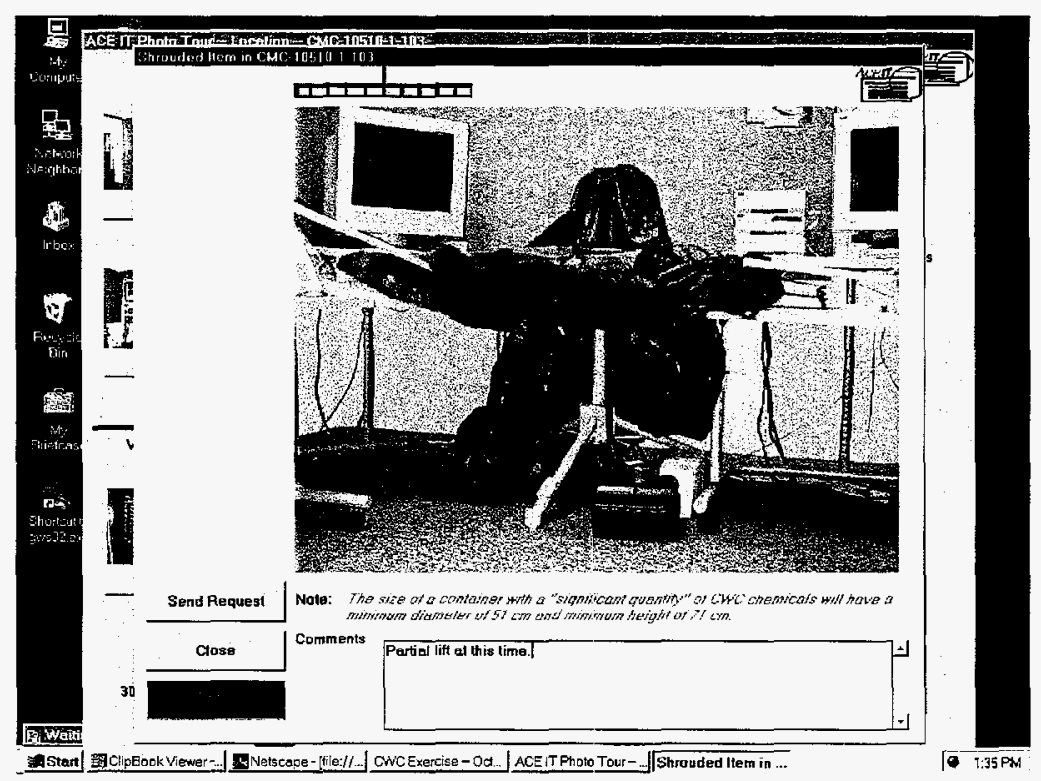

Figure 66. Inspection Team Views 50\% Lift of Shroud from Item

The Inspection Team leaves the lift-shroud window and the photo-tour window of the requested location, and moves on to the next location by clicking on the map. This concludes the basic negotiation sequence, which is similar for all locations. 


\section{PREPARING THE EXERCISE REPORT AND ENDING THE EXERCISE}

\subsection{Preparing the Exercise Report}

Before ending the training exercise, participants should print out the Exercise Report by clicking on the Prepare Exercise Report button located on the Control Center. (See Figure 67.) However, if the exercise has ended, you may click on the Exercise Report icon on your desktop to view and save the report.

The Exercise Report summarizes all of the areas entered during the exercise, the actions taken in each, comments made, samples taken, etc. An examination of this report will remind participants of the exact process followed during the exercise and will provide an outline that can be used in further discussions of lessons learned.

Each team should review the entire exercise report, taking into account their inspection goals. As Hosts, did they facilitate the inspection, yet protect sensitive information? As Inspectors, did they collect enough information to allow a compliance decision to be made?

\subsection{Ending the Exercise}

To end the exercise, activate the Control Center by clicking on that item in the Windows Taskbar. Select the End This Ace-It Exercise button. (If your counterpart has already chosen this option, you will be notified on-screen.)

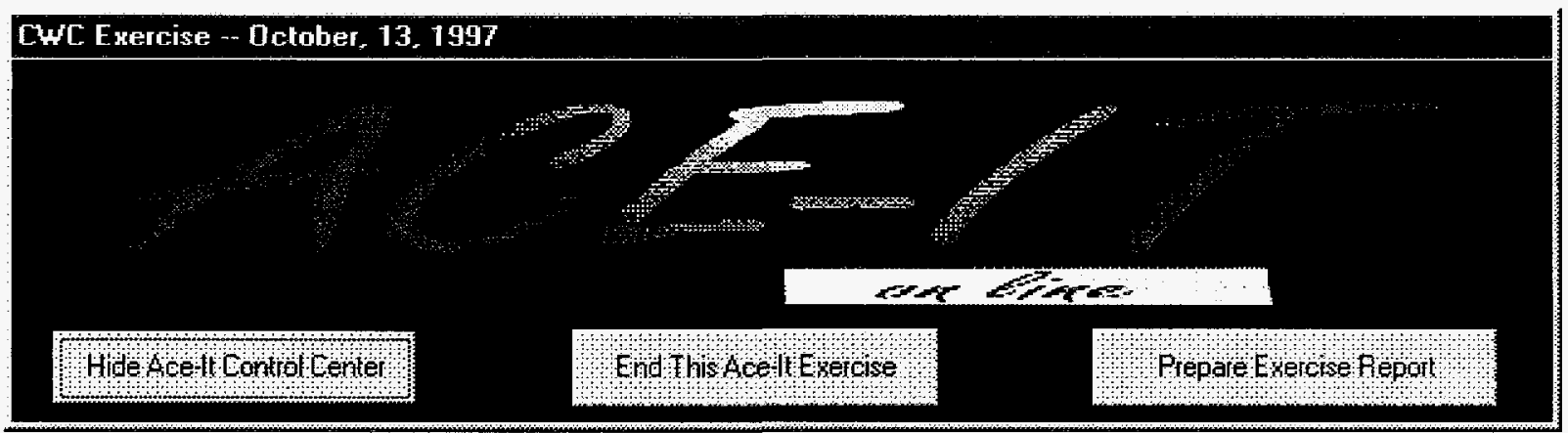

Figure 67. Control Center 


\section{INITIALIZATION FILES, SYSTEM REINITIATION, AND SYSTEM RECOVERY}

ACE-IT Version 2.0 uses two initialization files (INI files) that provide the system with crucial information about network drive connections, database filles, and installation parameters. Once these files have been configured properly, they should not require user manipulation. Section 6.1 shows an example, of the INI files, which can be modified using any ASCII text editor. Section 6.2 provides instructions for: system recovery following failures resulting from network errors and power surges.

\subsection{Initialization Files}

There are two INI files associated with ACE-IT Version 2.0. They reside in the LACE-ITVINI directory. The first file, GO.INI, has the following contents:

\section{NetScape Temp Directory=C:ITemp}

This INI file tells the system in which directory Netscape stores its temporary files. Using this directory. GO.EXE acts as a Netscape helper application.

The second INI file, ACEIT.INI, is found in the \ACE-ITVINI subdirectory and contains all of the relevant: database and network configuration information. Although this file will be edited for the users' computers, the contents of this file will be similar to the following sample data:

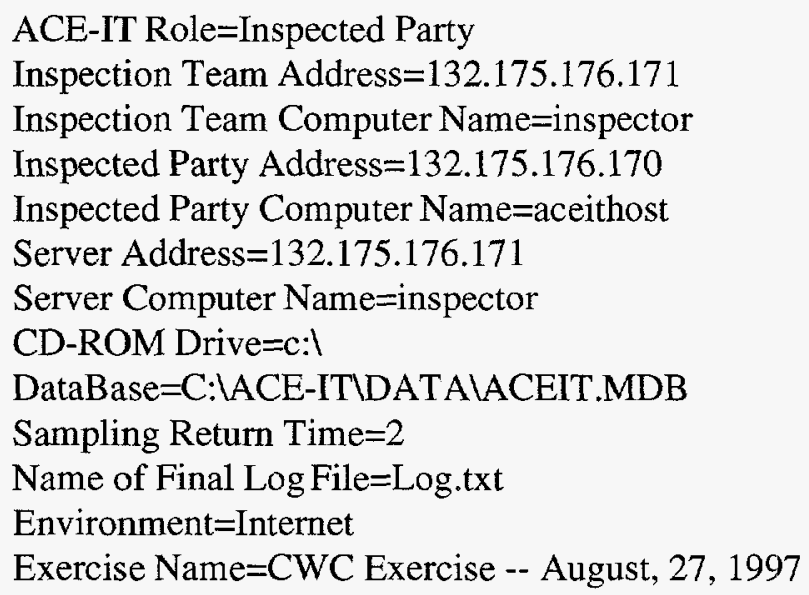

These files can be edited using any ASCII text editor.

\subsection{System Recovery}

If a network connection is lost during an exercise, re-establish the connection (this may require rebooting the computer) and start Netscape again. Navigate to the ACE-IT Version 2.0 home page and begin the session again. 


\section{SUMMARY}

The Augmented Computer Exercise for Inspection Training (ACE-IT) is a tool for training both the Inspection Team (inspectors) and the Inspected Party (host) to conduct a hypothetical challenge inspection under the CWC. ACE-IT Version 2.0 provides exercise participants with the capabilities to use the Internet or a local area network for remote training, to access relevant documents and information with an Internet browser, and to interactively view areas with QTVR technology or digital images. Specifically, ACE-IT Version 2.0 can be used to teach (1) how to collect information to determine compliance, and (2) how to balance the obligation to demonstrate compliance with the need to protect sensitive information that is unrelated to the Treaty.

The focus of the training is on the actual on-site inspection. Three buildings can be inspected: one for the production of chemical weapons agents and two for its storage. Under the challenge inspection regime, the Inspected Party can control the movement of the inspectors using the concept of managed access. One way to manage access is to control physical access to the room by only allowing the inspectors to view the room through the window and the door. Another way to manage access is to control access to a shrouded (or covered) item, by partially removing the shroud, or by providing alternate information (such as chemical sampling) to assure the inspectors that the site is in compliance with the treaty.

In addition, ACE-IT Version 2.0 can be used by policymakers to understand the implications of a challenge inspection regime by showing how on-site inspection provisions impact the ability to determine compliance and protect unrelated sensitive information. 
Section 7.-Summary

This page intentionally left blank. 


\section{Appendix A}

\section{ACE-IT Hardware/Software Requirements}

\section{and Installation, Setup, and Startup Instructions}

\section{A.1 Hardware Requirements}

Two computers are required: one for the Inspection Team and one for the Inspected Party. The minimum requirements for each computer are: a Pentium with $32 \mathrm{MB}$ of RAM, a CD-ROM drive, and $15 \mathrm{MB}$ of hard disk space. An additional $275 \mathrm{MB}$ of hard drive space may be used for a complete installation from the CD of all photos (.bmp), video (.avi), and QTVR (.mov) files to provide faster image access. Because the application is graphics-intensive, enhanced video cards with 4 to $8 \mathrm{MB}$ of video RAM will improve performance.

\section{A.2 Software Requirements}

ACE-IT Version 2.0 requires the 32-bit operating system Windows NT 4.0. A Windows-compatible FTP server (Microsoft Internet Information Services, Peer Web Services, or Personal Web Server) is also required. Netscape 3.0 or higher is required; however, Netscape Communicator 4.0 is recommended.

\section{A.3 Installation and Setup}

Preparing a computer for ACE-IT Version 2.0 involves seven steps for a minimal installation, eight for a full installation. The steps include:

1. Install Read-Write subdirectories.

2. Set up Crescent FTP tools.

3. Set up "GetAddress".

4. Set up FTP server.

5. Set up QTVR player.

6. Configure Netscape helper applications.

7. Obtain participant information.

8. Install bitmaps, video, and QTVR (optional).

\section{Install Read-Write Subdirectories}

Copy the LAce-it subdirectory of the IReadWriteFiles directory of the distribution CD to your hard drive, preferably to drive $C_{:}$. This process will create C:Ace-it and its constellation of subdirectories. These files are write-protected. If you must edit any of them, be sure to right-click on the file name, select Properties, and uncheck the "read-only" box.

\section{Set Up Crescent FTP Tools}

On your CD drive, open the Crescent directory. Double-click on the Setup.exe file and follow the onscreen instructions. 


\section{Set Up "GetAddress"}

Get Address is part of the Crescent Tool Pack and is installed during the Crescent setup. This useful utility provides Internet protocol (IP) addresses and names for your computer as well as for other ACE-IT participant computers. It can be used prior to starting an exercise to obtain IP addresses that will be requested during ACE-IT startup.

\section{Set Up FTP Server}

NT Internet Information Services (IIS) are installed and started automatically with a normal NT Server 4.0 setup. NT Peer Web Services for NT Workstation 4.0 must be installed from the Internet icon in the Control Panel. Personal Web Server for Windows 95 is installed from the Microsoft FrontPage CD. During installation, be sure to allow anonymous FTP access when prompted.

FTP services must be set up to include C:LAce-itlTransferout as the FTP home directory. With Windows NT, this is accomplished using the Web Services Manager, which is accessible from the Start menu by selecting Programs and then selecting either Internet Information Services or Peer Web Services. Once the Web Services Manager is started, double-click the FTP choice to bring up a submenu. Click on the Properties choice. Select the Directories tab and enter C:LAce-itlTransferout as the home directory (a. warning will appear regarding changing the FTP home directory). Under the General tab of Properties, change the type of FTP file naming. Click on "MS-DOS file naming" (instead of the default "UNIX").

\section{Set Up QTVR Player}

On the distribution CD, open the QTVR subdirectory and run the Setup.exe file. Follow the on-screen instructions. Install files in the C:\Ace-itlBin directory.

\section{Configure Netscape Helper Applications}

Netscape can be installed from the distribution CD. Change to the Netscape subdirectory and run Setup.exe. Follow the on-screen instructions. When installing Netscape, note the location of temporary files, usually C:ITemp. This location will be requested by ACE-IT during startup.

With Netscape running, select the Options menu, General submenu, and click on the Helpers tab. Three helper applications are needed for proper operation of ACE-IT. For each helper, click on Create New, type "application" for MIME type, type the appropriate MIME subtype listed in the table below, and click on OK. Type the appropriate file extension given in the table below, click on Launch the application, and type the appropriate program path and filename listed in the table below:

\begin{tabular}{|c|c|c|l||}
\hline Helper & $\begin{array}{c}\text { MIME } \\
\text { Subtype }\end{array}$ & $\begin{array}{c}\text { File } \\
\text { Extension }\end{array}$ & \multicolumn{1}{|c|}{$\begin{array}{c}\text { Program Path and } \\
\text { Name }\end{array}$} \\
\hline Go & go & $\mathrm{cmc}$ & C:IAce-itlBinlgo.exe \\
\hline Host & hs & hs & C:IAce-itlBinlhost.exe \\
\hline Inspector & in & in & $\begin{array}{l}\text { C:Mce-itlBin } \\
\text { inspector.exe }\end{array}$ \\
\hline
\end{tabular}




\section{A.4 Starting ACE-IT}

This start-up information is also available online by accessing the ACE-IT home page and selecting the Instructions to Start button.

\section{A.4.1 Conventions}

The quotation marks indicate the data you need to type. The boldfaced items indicate buttons you need to click on. Items in Courier type indicate pull-down list choices that need to be selected.

\section{A.4.2 LAN Configuration}

The following instructions are meant to be used with a Local Area Network (LAN) configuration.

\section{If you are playing the role of Host (Inspected Party):}

1. Start Netscape.

2. Load the ACE-IT home page ("file:///Cl/Ace-it/Ace-it2.htm").

3. Click on "Inspected Party (Host)".

The System Startup screen will appear. Computer names, if any, will be grayed out. (If you have run the exercise before, the screen will show previously saved values.)

4. In the field for ACE-IT Role, select Inspected Party.

5. Click on the LAN button.

6. For the Inspection Team Drive field, type a valid drive letter based on your LAN connection. Do not include a path beyond $\backslash$. Use the drive letter where an $\backslash$ Ace-it directory tree is installed for your counterpart. If necessary, you may toggle to "My Network Neighborhood" or use "NT Explorer" to set up this LAN connection before preceding.

7. Next, type your (Inspected Party Team) drive, usually "C:I".

8. For the ACE-IT Server, type your local drive, usually "C:I".

9. If your image and video files are stored on CD-ROM, type your CD-ROM drive letter (often "D:l"). The image and video files may be installed on your hard drive in \Aceitlvideo and $\backslash$ Aceitlimages subdirectories. If this is the case, enter "C:l" as your CD-ROM drive.

10. For the ACE-IT Database Name, type "C:LAce-itldatalaceit.mdb".

11. For the exercise log name, accept the default (recommended), or type a name of your choice.

12. For the name of this particular exercise session, accept the default (recommended), or type a name of your choice.

13. Click on the Select regime pull-down menu. Select Chemical Weapons Convention.

14. Click on the Select scenario pull-down menu. Select Chemical weapons Convention Challenge Inspection.

15. Click on Continue.

16. Wait for a request to come from the Inspection Team.

Photographs are always displayed when available to you, but only after an inspector has requested access to an area. Use the Hints button to get access to other data about an area. Respond to inspector requests as prompted by the screen messages.

17. At any time, you may return to the ACE-IT Welcome page and selectHost's Exercise Manual. This on-line reference set has more instructions, summaries, maps, images, text data, and accessory data that you should be familiar with in your role as the Inspected Party.

18. To end the simulation, click on CWC Exercise--<date> in your taskbar (usually at the bottom of the screen) and choose End This ACE-IT Exercise. Your counterpart will be notified. 


\section{If you are playing the role of Inspector (Inspection Team):}

1. Start Netscape.

2. Load the ACE-IT home page ("file:///Cl/Ace-it/Ace-it2.htm").

3. Click on "Inspection Team".

The System Startup screen will appear. Computer names, if any, will be grayed out. (If you have run the exercise before, it will display those previously saved values.)

4. In the field for ACE-IT Role, select Inspection Team.

5. Click on the LAN button.

6. For the Inspection Team Drive field, type your drive, usually "C:l".

7. Next, for the Inspected Party, type a valid drive letter based on your LAN connection.

Do not include a path after the "Y". Use the drive letter where an \Ace-it directory tree is installed for your counterpart. If necessary, you may toggle to "My Network Neighborhood" or use "NT Explorer" to set up this LAN connection before proceeding. Your counterpart will have had to share the \Ace-it subdirectory.

8. For ACE-IT Server, type your local drive, usually drive "C:l".

9. If your image and video files are stored on CD-ROM, type your CD-ROM drive letter (often "D:l"). The image and video files may be installed on your hard drive in $\backslash$ Aceitlvideo and $L A c e-$ itlimages subdirectories. If this is the case, type "C:l" as your "CD-ROM" drive.

10. For the ACE-IT Database Name, type "C:IAce-itldatalaceit.mdb".

11. For the exercise log name, accept the default (recommended), or type a name of your choice.

12. For the name of this particular exercise session, accept the default (recommended), or type a name of your choice.

13. Click on the Select regime pull-down menu. Select Chemical Weapons Convention.

14. Click on the Select scenario pull-down menu. Select Chemical weapons Convention Challenge Inspection.

15. Click on Continue.

16. At the Welcome page, select Load Maps. The CMC site map will appear.

17. Click on a building. The detailed building map will appear.

18. Click on a room. This will signal the host that you wish to inspect that particular room.

19. Wait for permission to enter the room (or another level of access) from the host.

20. Use the Hints button to request other, nonphotographic information.

21. At any time, you may return to the ACE-IT Welcome page and selectInspector's Exercise Manual.

This on-line reference set has more instructions, summaries, maps, images, text data, and accessory data that you should be familiar with in your role as an "inspector." Some of this information would come from perimeter negotiations, perimeter monitoring, and preinspection briefings.

22. To end the simulation, click on CWC Exercise--<date> in your taskbar (usually at the bottom of the screen) and choose End This ACE-IT Exercise. Your counterpart will be notified. 


\section{A.4.3 Internet Configuration}

The following instructions are meant to be used with the Internet configuration.

\section{If you are playing the role of Host (Inspected Party):}

1. Start Netscape.

2. Load the ACE-IT home page ("file:///Cl/Ace-it/Ace-it2.htm").

3. Click on "Inspected Party (Host)".

The System Startup screen will appear. Computer names, if any, will be grayed out. (If you have run the exercise before, it will display previously saved values.)

4. In the field for ACE-IT Role, select Inspected Party.

5. Click on the Internet button.

6. For the Inspection Team address, enter an Internet protocol (IP) address, for example, 134.176.74.192. Your counterpart must provide you with this information before beginning the exercise.

7. Type the computer name for the other team, also provided before you begin the exercise.

8. Next, type your Inspected Party Address. If necessary, you may run the programGetAddress.exe located in C: $\backslash$ Aceitlbin. Click on the Display Host Information button to view your computer name and your IP Address. Provide this information to your counterpart as discussed above.

9. For the Inspected Party Computer Name, type your computer name, for example, "Host", or the name of your choice.

10. For ACE-IT Server, type yourIP Address.

11. For Server Computer Name, type your computer name, for example, "Inspector," or the name of your choice.

12. If you are accessing image files from the CD-ROM, type your CD-ROM drive letter (often $D: I$ ). The image and video files may be installed on your hard drive in \Aceitlvideo and Ace-itlimages subdirectories. If this is the case, enter "C:l" as your "CD-ROM" drive.

13. For the ACE-IT Database Name, type "C:IAce-itldatalaceit.mdb".

14. For the exercise log name, accept the default (recommended), or type a name of your choice.

15. For the name of this particular exercise session, accept the default (recommended), or type a name of your choice.

16. Click on the Select regime pull-down menu. Select Chemical weapons Convention.

17. Click on the Select scenario pull-down menu. Select Chemical Weapons Convention Challenge Inspection.

18. Click on Continue.

19. Wait for a request to come from the Inspection Team. Photographs are always displayed when available to you, but only after an inspector has requested access to an area. Use the Hints button to get access to other data about an area. Respond to inspector requests as prompted by the screen messages. You may at any time return to the Ace-It Welcome page and selectHost's Exercise Manual. This on-line reference set has more instructions, summaries, maps, images, text data, and accessory data that you should be familiar with in your role as the Inspected Party.

20. To end the simulation, click on CWC Exercise--<date> in your taskbar (usually at the bottom of the screen) and choose End This Ace-It Exercise. Your counterpart will be notified. 


\section{Appendix A-ACE-IT Hardware/Software Requirements and \\ Installation, Setup, and Startup Instructions}

\section{If you are playing the role of Inspector (Inspection Team):}

1. Start Netscape.

2. Load the ACE-IT home page ("file:///Cl/Ace-it/Ace-it2.htm").

3. Click on "Inspection Team".

The System Startup screen will appear. Computer names, if any, will be grayed out.

(If you have run the exercise before, it will display previously saved values.)

4. In the field for ACE-IT Role, select Inspection Team.

5. Click on the Internet button.

6. For the Inspection Team Address, enter your Internet Protocol (IP) Address.

If necessary, you may run the programGetAddress.exe located in C: $\backslash$ Aceitlbin. Click on the Display Host Information button to view your computer name and yourIP Address. Provide this information to your counterpart.

7. For the Inspected Party Computer Name, enter your computer name, for example, "Host".

8. Next, for the Inspected Party Address, enter the IP Address provided by the other team before beginning the exercise.

9. For ACE-IT Server, type yourIP Address.

10. For Server Computer Name, type your computer name, for example, "Inspector," or a name of your choice.

11. If your image and video files are stored on CD-ROM, type your CD-type drive letter (often "D:I"). The image and video files may be installed on your hard drive in \Ace-itlvideo and $\backslash$ Ace-itlimages subdirectories. If this is the case, enter "C:l" as your "CD-ROM" drive.

12. For the ACE-IT Database Name, enter "C:\Ace-itldatalaceit.mdb".

13. For the exercise log name, accept the default (recommended), or type a name of your choice.

14. For the name of this particular exercise session, accept the default (recommended), or type a name of your choice.

15. Click on the Select regime pull-down menu. Select Chemical Weapons Convention.

16. Click on the Select scenario pull-down menu. Select Chemical weapons Convention Challenge Inspection.

17. Click on Continue.

18. At the Welcome page, select Load Maps. The CMC site map will appear.

19. Click on a building. The detailed building map will appear.

20. Click on a room. This will signal the host that you wish to inspect that particular room.

21. Wait for permission to enter (or other level of access) from the host. Use the Hints button to request other nonphotographic information.

22. At any time, you may return to the Ace-It Welcome page and selectInspector's Exercise Manual. This on-line reference set has more instructions, summaries, maps, images, text data, and accessory data that you should be familiar with in your role as "inspector." Some of this information would come from perimeter negotiations, perimeter monitoring, and pre-inspection briefings.

23. To end the simulation, click on CWC Exercise--<date> in your taskbar (usually at the bottom of the screen) and choose End This Ace-It Exercise. Your counterpart will be notified. 


\section{Appendix B}

\section{Using Netscape Conference}

\section{B.1 About Netscape Conference}

Netscape Conference provides you with the following real-time audio and data collaboration capabilities:

- In a chat session, you can post text messages back and forth (Chat tool).

- You can sketch on a collaborative whiteboard (Whiteboard tool).

- You can exchange or transfer data files (File Exchange tool).

\section{B.1.1 Starting Netscape Conference}

To launch Conference, click the Conference icon in your Communicator program folder, or choose Conference from the Communicator menu.

Note: In order to receive calls, Conference must be active. Likewise, in order for another party to receive a call from you, Conference must be running on their system.

\section{B.1.2 Making a Call}

1. In the Netscape Conference window, type the email address or the direct address/numerical IP address (in parentheses) of the person you want to call.

2. Click Dial.

3. When you are finished with the call, click Hang Up.

Tip: You can also choose Direct Dial from the Call menu and enter the direct address in the dialog box that appears.

The Pending Invitation dialog appears and displays the other party's name while it informs you of the status of the pending call. You can click Cancel to terminate the call at this point.

Note: If the other party declines your invitation or is not available, you will be prompted as to whether you wish to send a voicemail message. Once the call connects, Conference displays the other party's business card photo or logo (or the Netscape Conference logo, if no photo is available) on the right side of the Netscape Conference window. Select one or more tools to use for your Conference session: Chat, Whiteboard, File Exchange, or Collaborative Browsing.

\section{B.1.3 Calling from the Address Book}

1. Click the Address Book button or choose Address Book from the Communicator menu.

2. Select the person's address.

3. Click the Call button. 
Clicking the Address Book button in the Netscape Conference window takes you directly to the Address Book in Netscape Communicator. If you don't have a Communicator session already in progress, it launches automatically.

To call from the Address Book window:

1. Select the person you want to call. Make sure the person is set up in your address book as a Conference call recipient by clicking the Netscape Conference tab in the Address Card dialog and entering the DLS server or IP address.

2. Click the Call button.

\section{B.2 About the Chat Tool}

Once you re in a call, you can use the Chat tool to send messages or other textual content to a conference participant. The Chat Tool provides an alternative way to conduct a conversation in real time. You can conduct meetings while dynamically generating transcripts that you can then save and print for later use.

\section{B.2.1 Posting a Message}

1. Click the Chat Tool button in the toolbar of the Netscape Conference window.

2. Type your message in the Personal Note Pad field.

3. Choose Post Note Pad from the File menu, or click the Send button.

To post a message with the Chat tool:

1. Click the Chat tool button in the toolbar of the Netscape Conference window.

You see the Chat tool window. The top portion of the window, the Log, is where you view posted messages. The bottom portion of the window, the Personal Note Pad, is where you compose your messages.

2. Type your message (or paste some text from the clipboard) in the Personal Note Pad field. If you wish to include the contents of a text file, choose Include from the File menu.

3. When you've completed your message, choosePost Note Pad from the File menu or click the Send button.

You see your message in the Log window. Messages appear in the order in which they are posted.

Note: By selecting the Chat Tool Option "Pop Up on Receive" the Chat Tool window will automatically open as soon as you receive a message.

\section{B.3 About the Whiteboard Tool}

You can use the Whiteboard tool to open and share image files, as well as interactively edit the whiteboard canvas and mark up any images you import. Even if you're not in a Conference session, you can use the whiteboard to create and edit image files. On Windows and Unix, the whiteboard supports a variety of graphics formats, and is capable of capturing images from the Windows desktop. 
1. To launch the whiteboard, click the Whiteboard button in the toolbar of the Netscape Conference window.

The whiteboard provides simultaneous painting or marking up of images with the other party during a call. You can also synchronize the whiteboard screen during the session to assure both parties are viewing the same information. The graphics toolbox contains several drawing tools you can use to create and edit images and text.

The whiteboard canvas has two distinct layers, the markup layer and the image layer:

Markup layer: Consists of drawings made using tools from the toolbox, including circles, squares, and lines.

Image layer: Contains images captured from the desktop using the tools on the Capture menu, and images loaded from disk.

Important: If your call option is set to Auto Answer, and you are in the middle of a Whiteboard or Chat session, you may notice performance problems caused by incoming calls, that is, your files may be corrupted or lost. It is a good idea to choose Auto Answer only when you are not using the Whiteboard or Chat tools.

\section{B.4 About the File Exchange Tool}

The File Exchange tool lets you easily exchange files such as application files, images, and data with another party during a call.

To send files with the File Exchange tool:

1. Once you're in a call, click theFile Exchange button on the toolbar in the Netscape Conference window. You see the File Exchange window. The top half of the window is the Send window, where you list the files to be sent. The bottom half of the window is the Receive window, where the files sent to you are listed.

2. Choose Add to Send List from the File menu and then select the files you want to send.

3. Click the Send button or choose Send from the File menu. 
Appendix B-Using Netscape Conference

This page intentionally left blank. 


\section{Appendix C}

\section{ACE-IT Version 2.0 \\ Example Exercise Report}

\section{Example Number 1}

INSPECTION TEAM

Request for Physical Access

Site Code: CMC

Current Location: CMC-10510-1-104

\section{INSPECTED PARTY}

Response to Request for Physical Access

Site Code: CMC

Current Location: CMC-10510-1-104

Physical Access is Granted

\section{Example Number 2}

\section{INSPECTION TEAM}

Request for Physical Access

Site Code: CMC

Current Location: CMC-10510-1-103

\section{INSPECTED PARTY}

Response to Request for Physical Access

Site Code: CMC

Current Location: CMC-10510-1-103

Partial Access to this location is granted; you may view the room through the door and window only.

We offer partial access because the entire room can be seen from the door and window. 


\section{Example Number 3}

\section{INSPECTION TEAM}

Request for Physical Access

Site Code: CMC

Current Location: CMC-10510-1-103

\section{INSPECTED PARTY}

Response to Request for Physical Access

Site Code: CMC

Current Location: CMC-10510-1-103

Physical Access is Denied

You have already seen through the door and window.

\section{INSPECTION TEAM}

Request for Physical Access

Site Code: CMC

Current Location: CMC-10510-1-103

Our Chief Inspector wishes to go in the room because the view is blocked behind the shrouded item on the left.

\section{INSPECTED PARTY}

Response to Request for Physical Access

Site Code: CMC

Current Location: CMC-10510-1-103

Physical Access is Granted

\section{Example Number 4}

\section{INSPECTION TEAM}

Request for Physical Access

Site Code: CMC

Current Location: CMC-10510-1-103

\section{INSPECTED PARTY}

Response to Request for Physical Access

Site Code: CMC

Current Location: CMC-10510-1-103

Physical Access is Granted 


\section{INSPECTION TEAM}

Request to Lift Shroud from an Item

Site Code: CMC

Current Location: CMC-10510-1-103

Please lift the shroud because it is large enough to contain a significant quantity of chemical weapons agent.

\section{INSPECTED PARTY}

Response to Request to Lift Shroud from an Item

Site Code: CMC

Current Location: CMC-10510-1-103

The shroud will be lifted $50 \%$

Information on Shrouded Item:

We will partially lift the shrouded item to show that there are no items of concern.

\section{Example Number 5}

\section{INSPECTION TEAM}

Request for Physical Access

Site Code: CMC

Current Location: CMC-10510-1-102

\section{INSPECTED PARTY}

Response to Request for Physical Access

Site Code: CMC

Current Location: CMC-10510-1-102

Physical Access is Denied

\section{Example Number 6}

\section{INSPECTION TEAM}

Request for Physical Access

Site Code: CMC

Current Location: CMC-10510-1-103 
INSPECTED PARTY

Response to Request for Physical Access

Site Code: CMC

Current Location: CMC-10510-1-103

Physical Access is Denied

You have seen this room.

\section{INSPECTION TEAM}

Request for Physical Access

Site Code: CMC

Current Location: CMC-10510-1-103

We are not satisfied and require access.

\section{INSPECTED PARTY}

Response to Request for Physical Access

Site Code: CMC

Current Location: CMC-10510-1-103

Physical Access is Granted

\section{INSPECTION TEAM}

Request for Alternate Information

Site Code: CMC

Current Location: CMC-10510-1-103

Alternate Information Items Requested

\section{Chemical Sampling}

We would like a chemical sample taken from the surface of the item under the shroud.

\section{INSPECTED PARTY}

Response to Request for Alternate Information

Site Code: CMC

Current Location: CMC-10510-1-103

Permission Granted for Access to the Following Alternate Information Items

Granted.

$$
\text { Chemical Sampling }
$$




\title{
Example Number 7
}

\author{
INSPECTION TEAM
}

Request for Physical Access

Site Code: CMC

Current Location: CMC-10510-1-121

\section{INSPECTED PARTY}

Response to Request for Physical Access

Site Code: CMC

Current Location: CMC-10510-1-121

Partial Access to this location is granted, you may view the room through the door only.

\section{INSPECTION TEAM}

Request for Alternate Information

Site Code: CMC

Current Location: CMC-10510-1-121

Alternate Information Items Requested

\section{Relevant Medical Records}

May we view medical records for this facility?

\section{INSPECTED PARTY}

Response to Request for Alternate Information

Site Code: CMC

Current Location: CMC-10510-1-121

Permission Granted for Access to the Following Alternate Information Items

\section{Relevant Medical Records}

Yes, there is only one recent medical event in our records. Please view the URL file:///Cl/Aciit/HTML/medical,htm for more information about the case. 
This page intentionally left blank. 


\section{Appendix D}

\section{ACE-IT Version 2.0 - Home Page}

After installation, your Netscape browser will have a bookmark allowing quick access to the ACE-IT home page, shown below in Figure D-1.

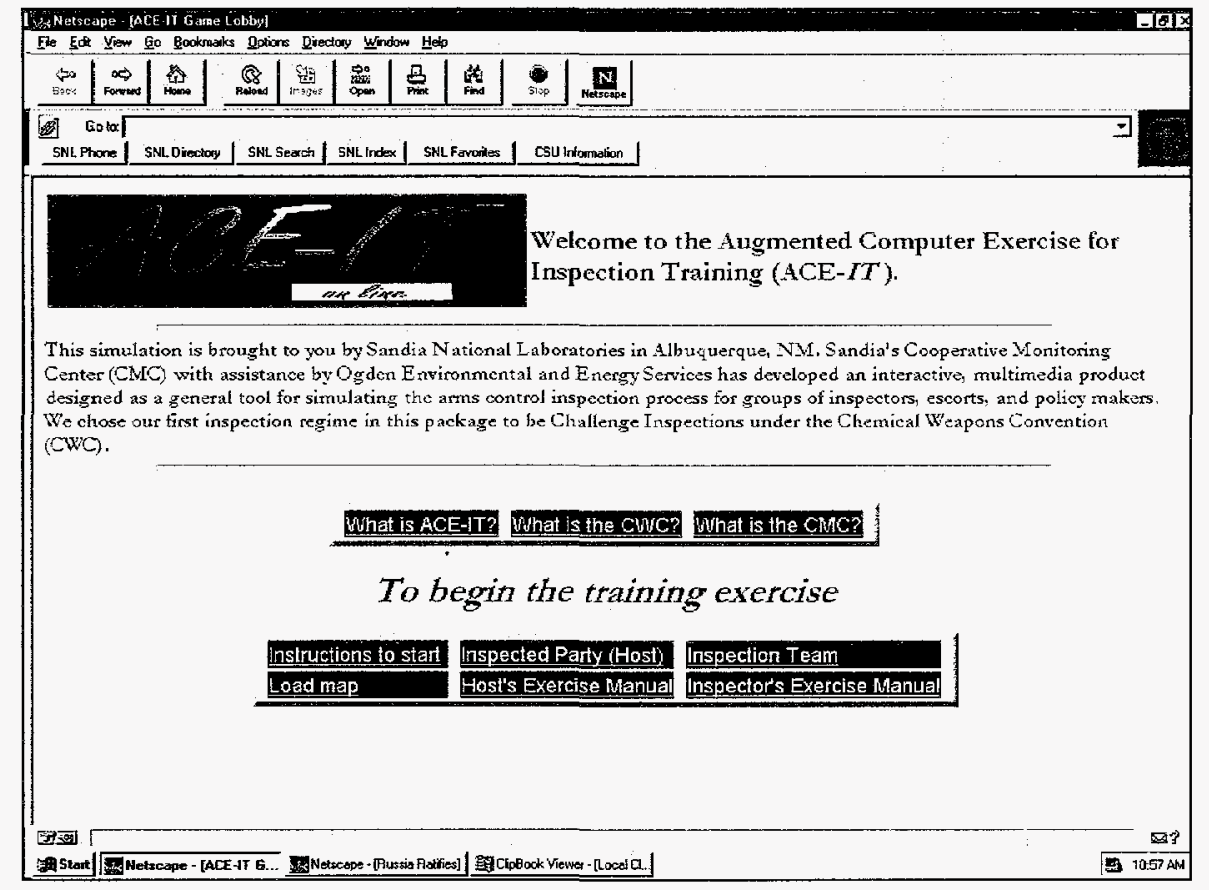

Figure D-1 ACE-IT Home Page

The ACE-IT Home Page provides background information for review prior to starting the exercise in the top three buttons. This information consists of the following:

1. "What is ACE-IT?" - A summary of the computer program,

2. "What is the CWC?" - The Chemical Weapons Convention text via the Organization for the Prohibition of Chemical Weapons (OPCW) Web site, and

3. "What is the CMC?" - Information on the Cooperative Monitoring Center

The bottom section allows the user to begin the training. These functions include

(1) detailed start-up instructions,

(2) team selections,

(3) access to the site map, and

(4) exercise manuals.

All of these items are available at any time during an exercise and the CWC text may be particularly useful as a reference. The OPCW Web site also has on-line training materials that complement the ACEIT system. 
Appendix D-ACE-IT Version 2.0-Home Page

This page intentionally left blank. 


\section{Appendix E}

\section{ACE-IT \\ Online Exercise Manual}

Figure E-1 shows the index that allows users easy access to the Online Exercise Manual.

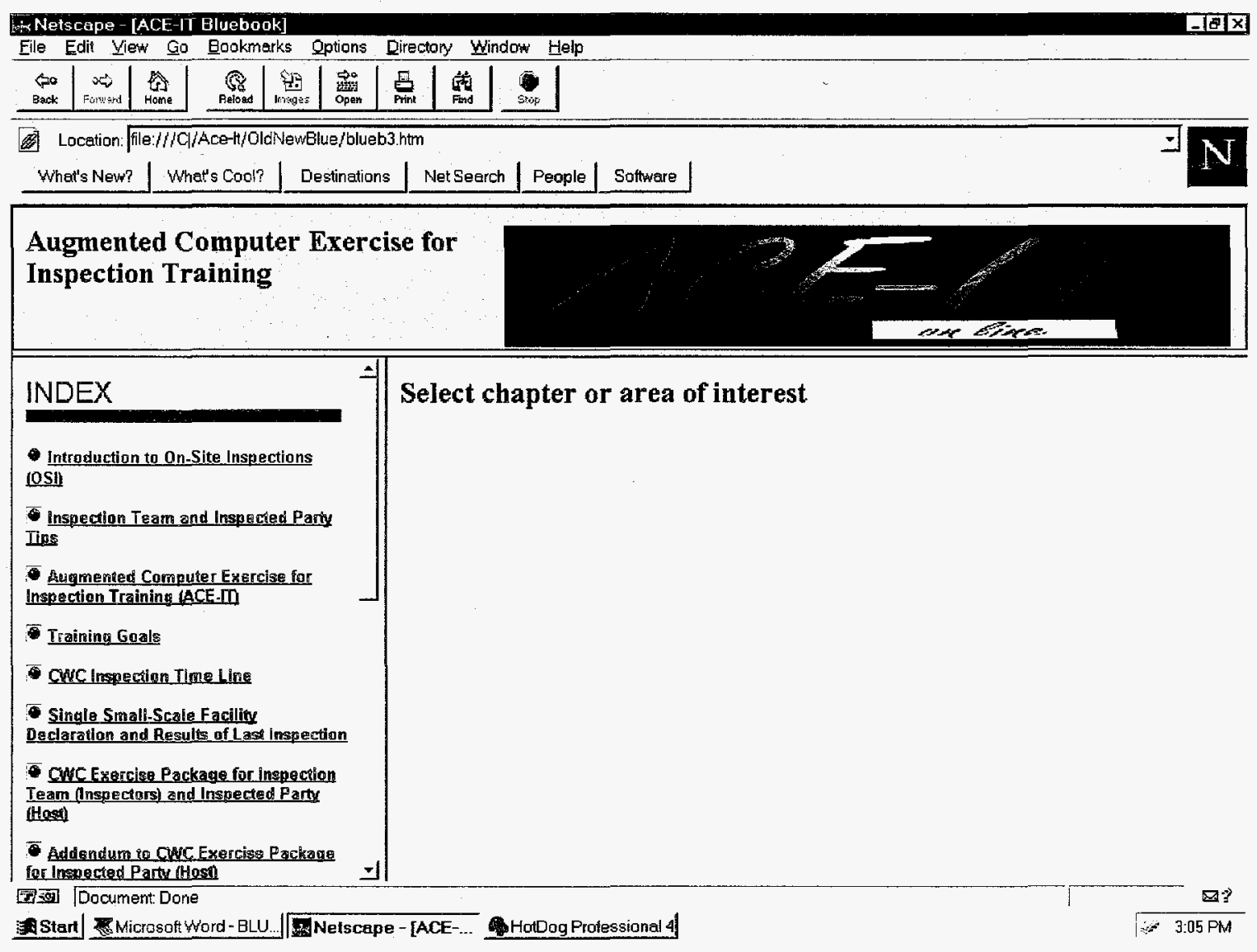

Figure E-1. ACE-IT Index in the ACE-IT Online Exercise Manual

The index shown on the left side of the screen contains all entries in the Online Exercise Manual. The following page shows the complete index. 


\section{INDEX}

- Imtroduction to On-Site Inspections (0S)

- Inspection Team and Inspected Partu Tins

- Augumented Computer Exercise for Inspection Training (ACE-IT)

- Iraining Goals

- cucc Inspection Time Line

- Single Small-Scale Facility Declaration and Results of Last Inspection

- CNC Exercise Package for Inspection Team inspectors) and Inspected Party (Host)

- Addendum to CwC Exercise Package for Inspected Partv (Host)

- "Requested" Perimeter: Satellite (KMR-1000) View of the Cooperative Monitoring Center (CMC)

- "Remuested" and "Alternative" Perimeter Maps

Vehicle Logs

Pre-Inspection Briefing

Sensitive ltems in the CHC Complex

- Mans of the cuc Complex

Evacuation Plans for the CMC Complex

Medical Records

- Material and Safetv Data Sheets

- Shipping and Receiving Records

List of Findings

- Glossany

- RETURA TO WELCOME PAGE 


\section{DISTRIBUTION}

$1 \quad$ U.S. Department of Energy

Attn: Josh Segal

International Policy and Analysis Division (NN-42)

1000 Independence Ave., SW

Washington, DC 20585

1 Tactical Staffing Resources, Inc.

1700 Louisiana Blvd. NE

Suite 210

Albuquerque, NM 87110

1 Ogden Environmental and Energy Services

7301 Indian School Rd., NE

Albuquerque, NM 87110

$1 \quad$ MS 1373

2 MS 0415

28 MS 1373

$1 \quad$ MS 9018

2 MS 0899

$2 \quad$ MS 0619

$1 \quad$ MS 0161
Arian Pregenzer, 5341

Pauline Dobranich, 5411

Deborah Evanko, 5341

Central Tech Files, 8940-2

Technical Library, 4916

Review \& Approval Desk, 12690

for DOE/OSTI

Patent and Licensing Office, 11500 
This page intentionally left blank. 